\title{
Aplicação de Algoritmos Bio-Inspirados ao Problema de Geração Automática de Grades Horárias
}

Dissertação de Mestrado apresentada à Escola de Engenharia de São Carlos da Universidade de São Paulo, como parte dos requisitos para obtenção do título de Mestre em Ciências, Programa de Engenharia Elétrica.

Área de Concentração em Sistemas Dinâmicos.

Orientador: Prof. Dr. Ivan Nunes da Silva

\section{São Carlos}

2013

Trata-se da versão corrigida da dissertação. A versão original se encontra disponível na EESC/USP que aloja o Programa de Pós-Graduação de Engenharia Elétrica. 
AUTORIZO A REPRODUÇÃO TOTAL OU PARCIAL DESTE TRABALHO, POR QUALQUER MEIO CONVENCIONAL OU ELETRÔNICO, PARA FINS DE ESTUDO E PESQUISA, DESDE QUE CITADA A FONTE.

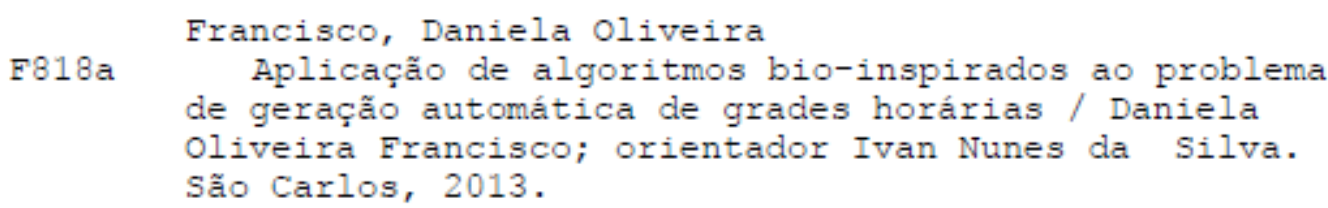

Dissertação (Mestrado) - Programa de Pós-Graduação em Engenharia Elétrica e Área de Concentração em Sistemas Dinâmicos -- Escola de Engenharia de São Carlos da Universidade de São Paulo, 2013.

1. Algoritmos genéticos. 2. Sistemas imunológicos artificiais. 3. Problema de geração de grades horárias. 4. Otimizaçã̃o de sistemas. I. Título. 


\section{FOLHA DE JULGAMENTO}

Candidata: Bacharel DANIELA OLIVEIRA FRANCISCO.

Título da dissertação: "Aplicação de algoritmos bio-inspirados ao problema de geração automática de grades horárias".

Data da defesa: $25 / 06 / 2013$

\section{Comissão Julgadora:}

Prof. Associado Ivan Nunes da Silva (Orientador)

(Escola de Engenharia de São Carlos/EESC)

Prof". Associada Roseli Aparecida Francelin Romero

(Instituto de Ciências Matemáticas e de Computação/ICMC)
Resultado:

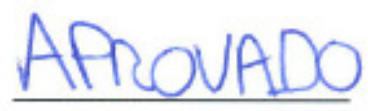

APROVADO

Prof. Dr. Antonio Fernando Crepaldi

APROVHDO

(Universidade Estadual Paulista "Júlio de Mesquita Filho"/UNESP-Bauru)

Coordenador do Programa de Pós-Graduação em Engenharia Elétrica e Presidente da Comissão de Pós-Graduação:

Prof. Titular Denis Vinicius Coury 
"Escolhe um trabalho de que gostes, e não terás que trabalhar nem um dia na tua vida." 


\section{Agradecimentos}

À Deus, por me ter orientado em qual caminho eu deveria seguir na minha vida, por me permitir realizar meus sonhos e não permitir que eu desistisse diante de todos os obstáculos.

Ao meu orientador, Prof. Dr. Ivan Nunes da Silva, pela oportunidade, por ter acompanhado com interesse minha pesquisa, por toda paciência, sugestões e por toda contribuição para meu crescimento e aprendizado dentro da área, tanto como professor em sala de aula, quanto durante a orientação.

Aos meus pais, Vera e Luiz, pelo apoio em todas as minhas decisões e compreensão na minha ausência para dedicação ao meu trabalho.

Aos meus irmãos, Fábio e Pedro Henrique, pela existência e presença em minha vida.

Ao meu noivo, João Mario, pela força nos momentos de fadiga e desânimo e por perder tantos finais de semana somente para estar do meu lado enquanto eu me dedicava aos meus estudos.

Ao Laboratório de Automação Inteligente de Processos e Sistemas (LAIPS) pela infraestrutura fornecida, e aos seus integrantes, por todos os momentos de descontração e cooperação. 


\section{Sumário}

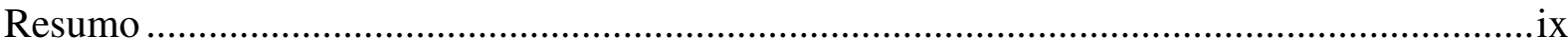

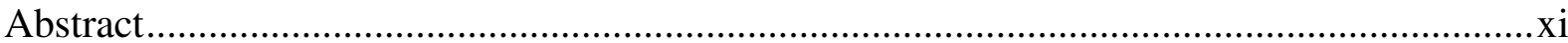

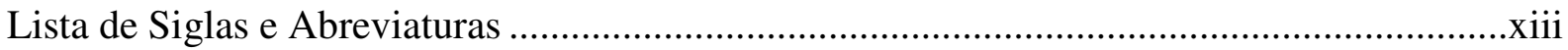

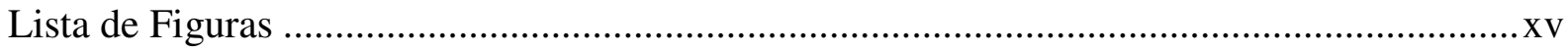

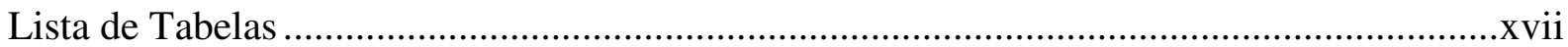

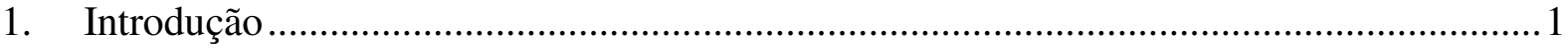

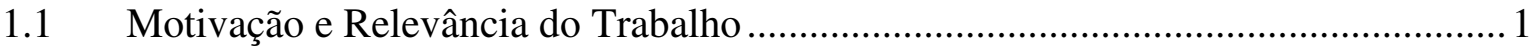

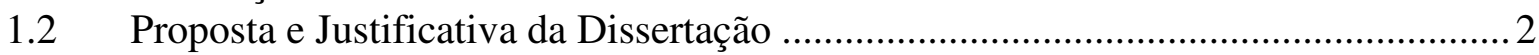

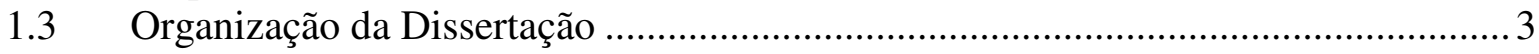

2. O Problema de Geração Automática de Grades Horárias .................................................5

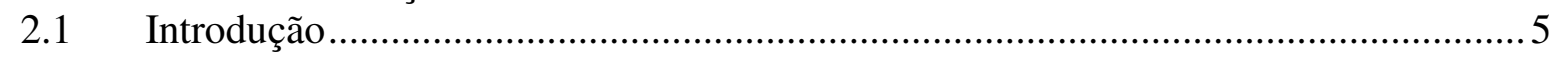

2.2 Gerador de Grades Horárias ............................................................................ 6

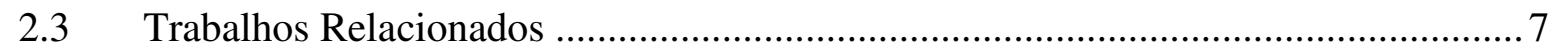

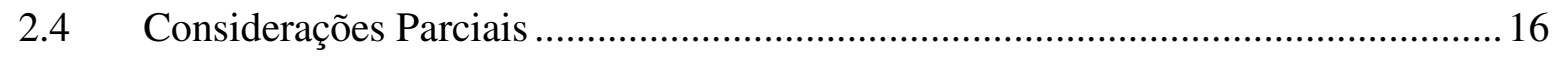

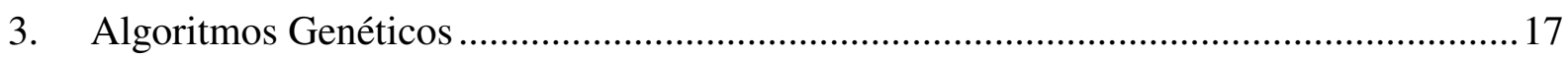

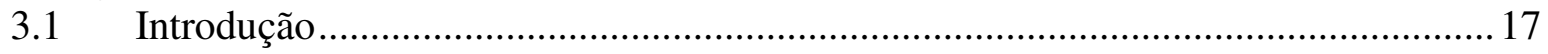

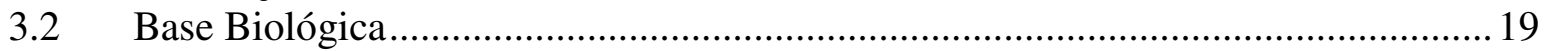

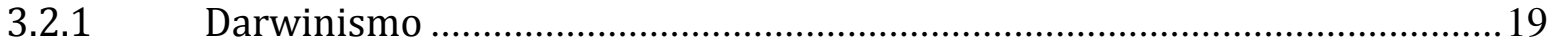

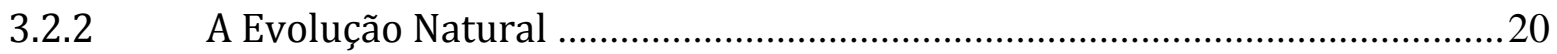

3.2.3 Terminologias Básicas dos Sistemas Naturais ............................................20

3.3 Conceitos Relacionados aos Algoritmos Genéticos ............................................. 21

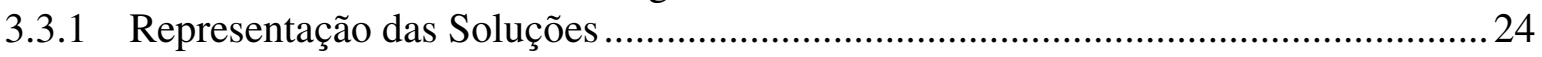

3.3.2 Definição da População e seu Tamanho............................................................... 25

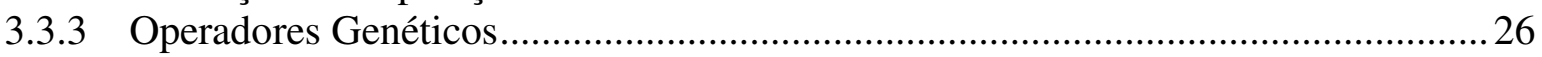

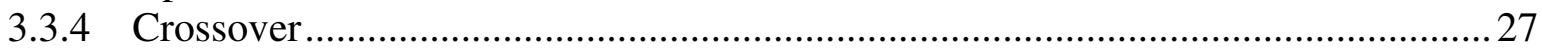

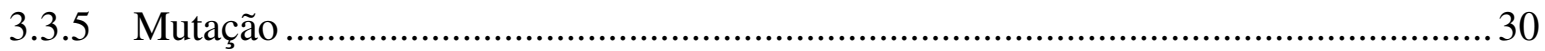

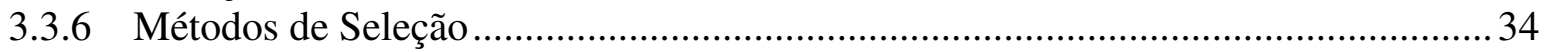

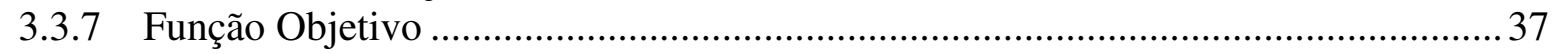

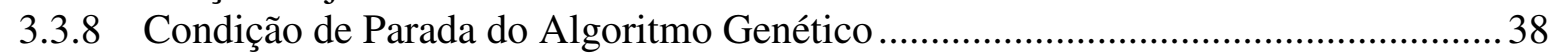

3.4 Considerações Parciais ....................................................................................... 39

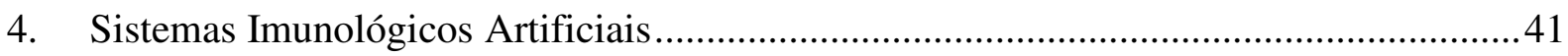

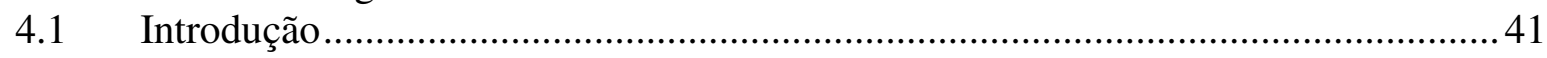

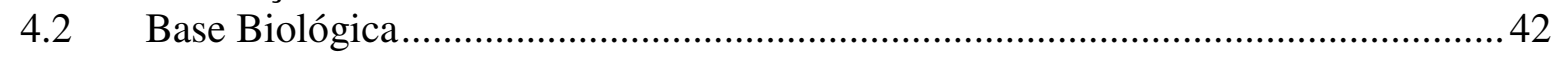

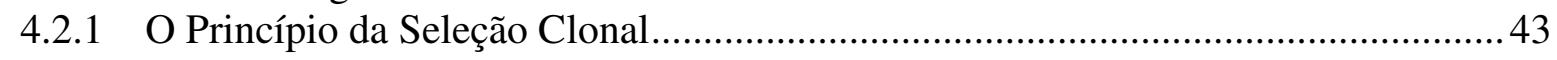

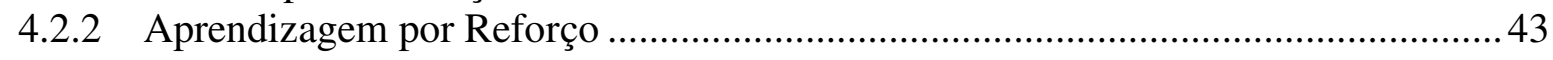

4.3 Conceitos Relacionados aos Sistemas Imunológicos Artificiais............................... 44

4.3.1 Analogia entre os Sistemas Imunológicos Biológicos e os Sistemas Computacionais

4.3.2 Escopo de Aplicação dos Sistemas Imunológicos Artificiais ................................... 48

4.3.3 Vantagens Encontradas nos Sistemas Imunológicos Artificiais .............................. 48

4.3.4 Descrição do Algoritmo dos Sistemas Imunológicos Artificiais ............................ 49

4.3.5 Algoritmo de Seleção Clonal - CLONALG .....................................................52

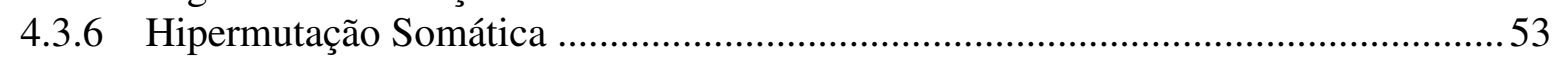




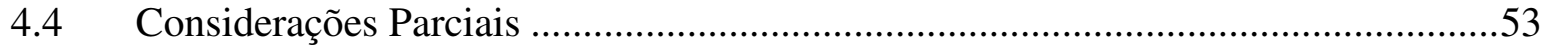

5. Otimização de Grades Horárias Baseada em Sistemas Inteligentes ................................ 55

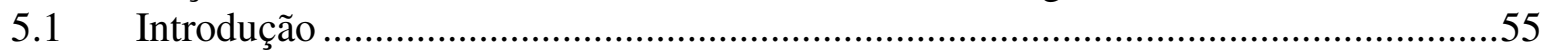

5.2 Representação das Soluções Candidatas do Algoritmo Genético .............................55

5.3 Inicialização da População no Algoritmo Genético .................................................58

5.4 Função de Avaliação e Condição de Parada do Algoritmo Genético........................59

5.5 Método de Seleção Aplicado no Algoritmo Genético Desenvolvido.........................60

5.6 Operadores Genéticos Aplicados no AG: Mutação e Crossover ...............................61

5.7 Representação das Soluções Candidatas no CLONALG ……...................................64

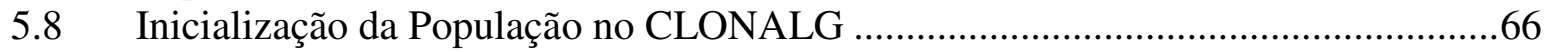

5.9 Função de Avaliação e Condição de Parada do CLONALG .....................................67

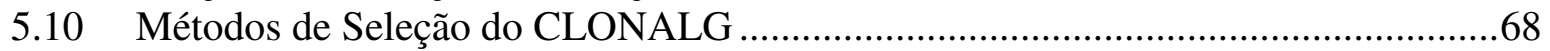

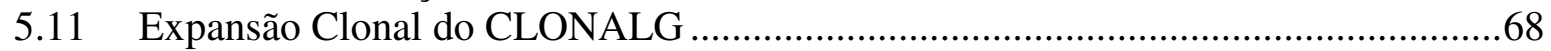

5.12 Inserção de Diversidade na População do CLONALG ............................................69

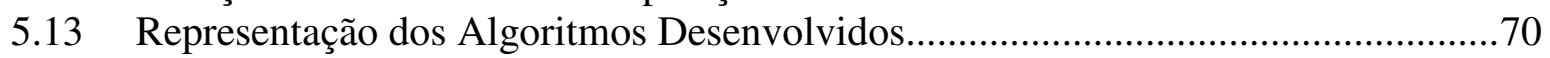

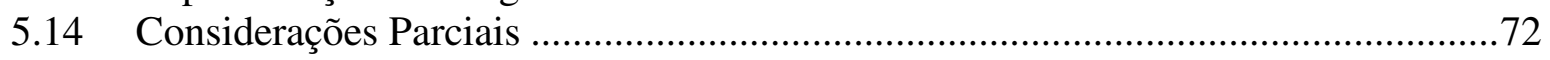

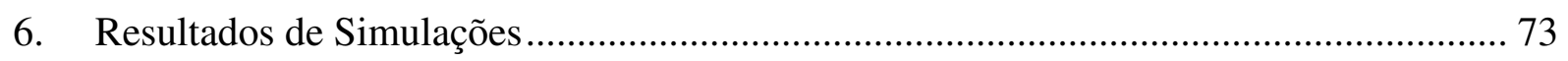

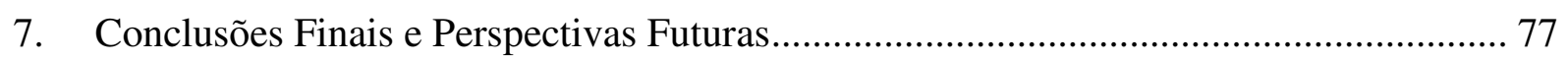

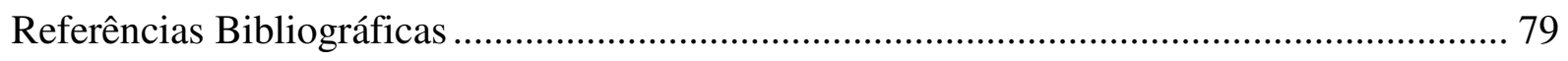

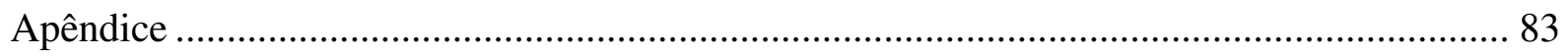

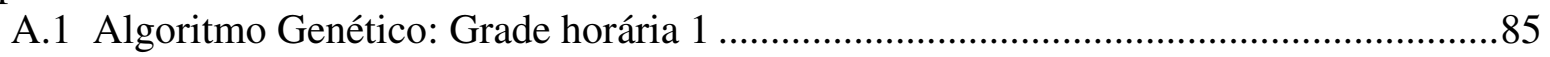

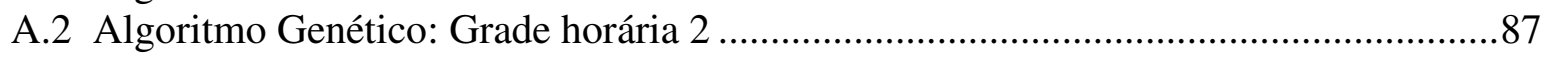

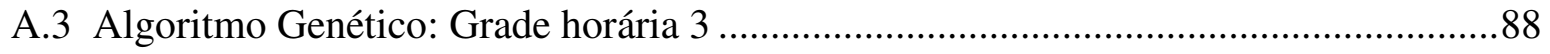

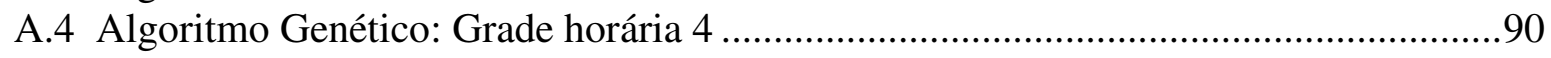

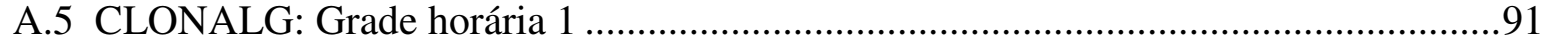

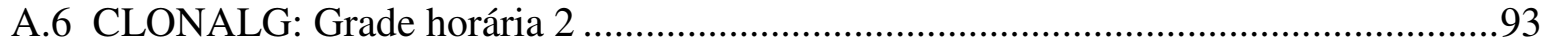

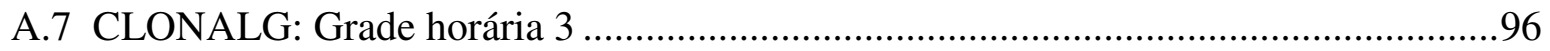

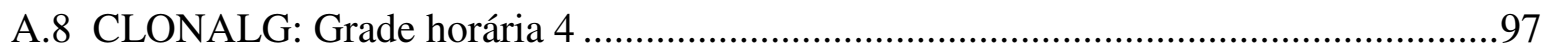




\section{Resumo}

Francisco, D.O. (2013). Aplicação de Algoritmos Bio-Inspirados ao Problema de Geração Automática de Grades Horárias. Dissertação (Mestrado) - Escola de Engenharia de São Carlos, Universidade de São Paulo, 2013.

A geração de grades horárias de qualidade é um fator crítico em qualquer instituição de ensino, tanto em escolas de ensino fundamental/médio como em universidades. Este problema é considerado complexo, pois devem ser relacionados e otimizados diversos recursos, tais como horários, disciplinas, professores e alunos. Em grande parte das instituições de ensino, a geração de grades horárias é realizada manualmente, o que vem a tornar este processo custoso e sujeito a falhas. Diversas abordagens são também encontradas na literatura para resolução deste problema, nas quais foram aplicados métodos de busca estocástica, devido à sua inerente complexidade. As estratégias de busca formuladas e comparadas no presente trabalho foram baseadas no uso de algoritmos genéticos e de sistemas imunológicos artificiais. Tais técnicas foram capazes de fornecer soluções de qualidade para o problema de geração automática de grades horárias. Neste trabalho foram desenvolvidos dois sistemas de apoio à decisão, nos quais foram combinadas técnicas heurísticas aos algoritmos genéticos e ao algoritmo de seleção clonal. O propósito desta investigação é realizar uma análise comparativa entre as duas técnicas a fim de verificar qual delas apresenta resultados mais promissores para a resolução do problema de geração automática de grades horárias.

Palavras Chave: Algoritmos Genéticos, Sistemas Imunológicos Artificiais, Problema de Geração de Grades Horárias, Otimização de Sistemas. 


\begin{abstract}
Francisco, D. O. (2013). Bio-Inspired Algorithms's Application to the Timetabling Problem. Dissertation (Master's Degree) - Escola de Engenharia de São Carlos, Universidade de São Paulo, 2013.
\end{abstract}

The generation of timetables with good quality is a critical factor in any educational institution. This is considered a complex problem because it involves several types of information, such as schedules, course subjects, teachers and students. Several search strategies have been applied to solve timetabling problems, whose constraints may vary from one educational institution to another. Most educational institutions still prepare their timetables manually, which is a highly time-consuming process and subjected to errors. Several approaches to solve this problem are also found in technical studies, which use stochastic search methods due to the problem's complexity. The search optimization methods used in this work to solve the timetabling problem are genetic algorithms and the clonal selection algorithm, whose satisfactory results when applied to optimization problems are reported in the literature. Two decision support systems were developed in this work, combining heuristic techniques with the genetic algorithms and the clonal selection algorithm. The purpose of this research is to make a comparative analysis of these two techniques in order to determine which one offers the most promising results for solving the timetabling problem.

Keywords: Genetic Algorithms, Artificial Immune Systems, Timetabling Problem, Systems Optimization. 


\section{Lista de Siglas e Abreviaturas}
AG
Algoritmos Genéticos
SAI
Sistemas Imunológicos Artificiais
CLONALG Clonal Selection Algorithm
ICMA Interleaved Constructive Memetic Algorithm
PSO
Otimização por Enxame de Partículas
GCCHH Hiper-heurística construtiva de coloração de grafos
LD
Largest Degree First
$\mathrm{SD}$
Saturation Degree First
LCD
Largest Colored Degree First
LE
Largest Enrolment First
DNA
Ácido desoxirribonucleico 


\section{Lista de Figuras}

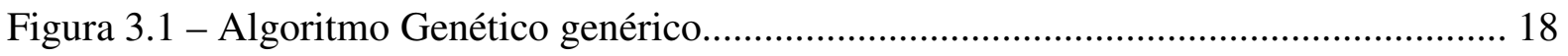

Figura 3.2 - Cromossomo codificado em arranjos binários................................................... 24

Figura 3.3 - Cromossomo codificado em números reais...................................................25

Figura 3.4 - Inicialização da População Inicial no AG.......................................................... 26

Figura 3.5 - Inicialização da População Inicial no AG.......................................................... 27

Figura 3.6 - Funcionamento do Crossover um ponto..............................................................29

Figura 3.7 - Funcionamento do Crossover de $N$ Pontos........................................................ 30

Figura 3.8 - Exemplo de mutação aleatória, em um indivíduo de codificação binária............. 32

Figura 3.9 - Exemplo de mutação indutiva, em um indivíduo de codificação em ponto

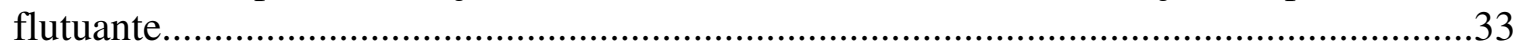

Figura 3.10 - Roleta representando a população apresentada na tabela 3.1 ............................ 36

Figura 3.11 - Avaliação da População no AG........................................................................ 38

Figura 3.12 - Condição de Parada no AG............................................................................ 39

Figura 4.1 - Fluxograma do algoritmo imuno-inspirado....................................................... 50

Figura 4.2 - Taxonomia dos algoritmos imune-inspirados................................................. 51

Figura 5.1 - Modelo relacional do banco de dados do algoritmo desenvolvido utilizando-se

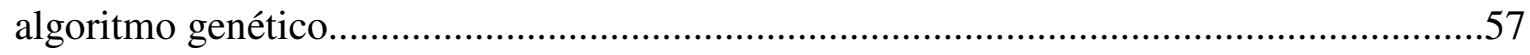

Figura 5.2 - Modelo relacional do banco de dados do algoritmo desenvolvido utilizando-se o

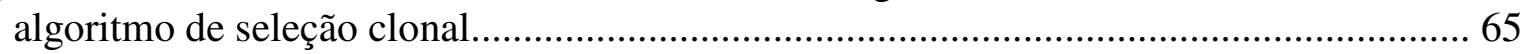

Figura 5.7 - Representação gráfica do algoritmo genético adotado na otimização de grades horárias.

Figura 5.8 - Representação gráfica do algoritmo de seleção clonal adotado na otimização de grades horárias. 


\section{Lista de Tabelas}

Tabela 3.1 - Exemplo de população de indivíduos previamente avaliados e nos quais a porcentagem correspondente à sua representatividade na população também calculada

Tabela 5.1 - Representação tabular de uma grade horária

Tabela 5.2 - Representação tabular de uma grade horária na qual será aplicada a mutação...662

Tabela 5.3 - Representação tabular de uma grade horária após a realização da mutação. .63

Tabela 5.4 - Representação tabular de uma grade horária. .67

Tabela 6.1 - Resultados de Simulações do CLONALG desenvolvido....... .74

Tabela 6.2 - Resultados de Simulações do AG desenvolvido.. 74

Tabela A.1 - Principais parâmetros de entrada para os sistemas desenvolvidos. 83 
xviii 


\section{Introdução}

\subsection{Motivação e Relevância do Trabalho}

A geração automática de grades horárias é um problema clássico encontrado na literatura (Ozcan et al., (2012); Naseem e Yang, (2011); Nothegger et al., (2012); Burke et al., (2012); Turabieh e Abdullah, (2011); Sabar et al., (2012); Pais e Amaral, (2012); Tassopoulos e Beligiannis, (2012); Sabar et al., (2012)). As estratégias de busca formuladas e comparadas no presente trabalho foram baseadas no uso de algoritmos genéticos e de sistemas imunológicos artificiais. Tais técnicas foram capazes de fornecer soluções de qualidade para o problema em questão.

$\mathrm{Na}$ literatura relacionada, podem ser encontradas diversas abordagens para o problema de geração de grades horárias, nas quais se pode deparar com variações, que ocorrem devido às particularidades da instituição de ensino investigada (Ozcan et al., (2012); Naseem e Yang, (2011); Nothegger et al., (2012); Burke et al., (2012); Turabieh e Abdullah, (2011); Sabar et al., (2012); Pais e Amaral, (2012); Tassopoulos e Beligiannis, (2012); Sabar et al., (2012)). As particularidades de cada universidade são relacionadas às restrições e recursos que devem ser atendidos, tais como combinações de horários da grade horária, os professores, os alunos, entre outros.

As restrições impostas ao problema de geração de grades horárias podem ser divididas entre grau de relevância alto ou baixo, sendo, respectivamente, restrições que invalidam uma solução ou restrições que não invalidam uma solução, porém, afetam a sua qualidade. Uma solução factível para o problema de geração de grades horárias é encontrada quando todas as restrições de alto grau são satisfeitas. Já as restrições de baixo grau podem ser adotadas com o objetivo de mensurar o desempenho das soluções geradas. 
O sistema de otimização de grades horárias proposto neste trabalho é um procedimento sistemático e automático, no qual serão geradas tabelas contendo todas as disciplinas de um determinado curso, organizadas de acordo com o semestre correspondente, satisfazendo-se também às disponibilidades de recursos impostas.

No presente estudo são então aplicados e confrontados os resultados de simulações de dois métodos de busca e otimização, i.e., algoritmos genéticos e sistemas imunológicos artificiais. Os algoritmos genéticos (AG) e os sistemas imunológicos artificiais (SIA) são caracterizados como algoritmos evolucionários, inspirados em metáforas biológicas. Neste caso, os AG são inspirados na teoria da evolução de Darwin, enquanto os SIA são baseados no sistema imunológico natural (He et al., 2005). Como principal contribuição, sistemas de apoio à decisão, responsáveis pela geração automática de grades horárias, serão então desenvolvidos, baseados em AG e SIA, levando-se em consideração as restrições mais comuns encontradas na literatura, tais como:

- Disciplinas de um mesmo semestre somente podem ser alocadas em diferentes horários na grade;

- Disciplinas ministradas por um mesmo professor não podem ser alocadas no mesmo horário;

- Deve ser verificada a disponibilidade de cada um dos professores, sendo que não pode ser alocada disciplina no horário de sua indisponibilidade.

\subsection{Proposta e Justificativa da Dissertação}

Neste trabalho serão desenvolvidos dois sistemas de apoio à decisão, nos quais são combinadas técnicas heurísticas aos algoritmos genéticos e ao algoritmo de seleção clonal. 
O propósito desta investigação é realizar uma análise comparativa entre as duas técnicas a fim de verificar qual delas apresenta resultados mais promissores para a resolução do problema de geração automática de grades horárias.

Tal problema possui características e restrições que podem variar de acordo com a instituição de ensino, cuja implementação é destinada.

Segundo Yue et al. (2009), o problema de otimização de grades horárias é considerado um problema do tipo NP-Completo, devido à complexidade matemática aqui encontrada. Os problemas são classificados, segundo a teoria da complexidade computacional, entre àqueles com complexidade P (polinomial) ou complexidade NP (não-polinominal). A classe de complexidade P é descrita como uma abstração matemática de tarefas computacionais, as quais podem ser resolvidas por meio de um algoritmo eficiente. Já a classe de complexidade NP é composta por problemas em que não podem ser solucionados por meio de algoritmos eficientes conhecidos. Desta forma, foram aqui aplicados métodos de busca estocástica e não determinísticos.

\subsection{Organização da Dissertação}

Todo o escopo deste trabalho é dividido em seis seções, conforme descrito a seguir. $\mathrm{Na}$ Seção 2 são apresentados o problema de geração de grades horárias, e também trabalhos encontrados na literatura relacionada. Já a Seção 3 descreve o funcionamento dos algoritmos genéticos, os quais foram aplicados na presente pesquisa. A Seção 4 apresenta os sistemas imunológicos artificiais, destacando-se o funcionamento do algoritmo de seleção clonal, o qual foi também aplicado. A Seção 5 descreve os algoritmos desenvolvidos e os parâmetros que foram adotados em suas configurações. A Seção 6 apresenta os resultados das aplicações desenvolvidas. Finalmente, na Seção 7 são descritas as conclusões e propostas para trabalhos futuros. 


\section{O Problema de Geração Automática de Grades Horárias}

\subsection{Introdução}

A geração de grades horárias em instituições de ensino é um fator crítico, devido à inerente complexidade em se realizar manualmente tal tarefa. No presente problema, são necessárias as combinações de diversos recursos, tais como horários, disciplinas, professores e alunos, conforme relacionado em Pillay e Banzhaf (2010).

Atualmente, em diversas instituições de ensino a geração de grades horárias ainda é realizada manualmente, o que vem a tornar este procedimento sujeito a falhas. Diversas abordagens para o problema de geração de grades horárias podem ser encontradas na literatura relacionada, conforme encontrado em Ozcan et al. (2012); Naseem e Yang (2011); Nothegger et al. (2012); Burke et al. (2012); Turabieh e Abdullah (2011); Sabar et al. (2012); Pais e Amaral (2012); Tassopoulos e Beligiannis (2012) e Sabar et al. (2012).

Existem diversas abordagens para o problema de geração de grades horárias, nas quais as restrições podem variar de acordo com as particularidades da instituição de ensino investigada (Suyanto, 2010).

Em Wang et al. (2009), os autores afirmam que a geração de grades horárias deve satisfazer as restrições impostas pelas instituições de ensino na qual o problema foi baseado. Quanto mais restrições forem atendidas pelas soluções geradas, mais adaptadas se encontram tais soluções.

As restrições possuem diferentes graus de relevância, sendo que restrições de alto grau podem invalidar uma solução, enquanto aquelas restrições de baixo grau não invalidam uma solução; porém, afetam o seu desempenho, conforme descrito em Wang et al. (2009). É 
importante ressaltar que a complexidade deste problema está diretamente relacionada à adição de restrições de recursos.

Como principal contribuição, sistemas de apoio à decisão, responsáveis pela geração automática de grades horárias, foram então desenvolvidos, baseados em AG e SIA, levando-se em consideração as restrições mais comuns encontradas na literatura, tais como:

- Disciplinas de um mesmo semestre devem ser alocadas em diferentes horários na grade horária;

- Disciplinas ministradas por um professor não devem ser alocadas no mesmo horário na grade;

- Em horário de indisponibilidade do professor, não deve ser alocada disciplina.

\subsection{Gerador de Grades Horárias}

Segundo Yue et al. (2009), o problema de otimização de grades horárias é considerado um problema do tipo NP-Completo, devido à complexidade matemática encontrada. Desta forma, devem ser aplicados métodos de busca estocástica e não determinísticos.

Os métodos de busca aplicados neste trabalho, com propósito de solucionar o problema de geração de grades horárias, são os algoritmos genéticos e o algoritmo de seleção clonal, devido aos resultados satisfatórios já encontrados na literatura relacionada, conforme visto em Ozcan et al. (2012); Naseem e Yang (2011); Nothegger et al. (2012); Burke et al. (2012); Turabieh e Abdullah (2011); Sabar et al. (2012); Pais e Amaral (2012); Tassopoulos e Beligiannis (2012) e Sabar et al. (2012), quando aplicados em problemas de otimização.

Neste trabalho foram desenvolvidos dois sistemas de apoio à decisão, no qual foram combinadas técnicas heurísticas aos algoritmos genéticos e ao algoritmo de seleção clonal, com o propósito de realizar uma análise comparativa entre as duas técnicas aqui adotadas e verificar 
em qual caso são apresentados resultados mais promissores, quando aplicados na resolução do problema de geração automática de grades horárias.

Foram adotadas aqui, as restrições de alto grau, ou seja, se alguma destas restrições for violada, o resultado gerado será inválido.

O gerador de grades horárias, aqui desenvolvido, é um procedimento sistemático e automático, no qual são geradas grades horárias contendo todas as disciplinas de um determinado curso, organizadas de acordo com o semestre correspondente, satisfazendo-se ainda todas as restrições impostas, as quais serão discutidas nos próximos capítulos.

\subsection{Trabalhos Relacionados}

Na presente seção, serão brevemente apresentadas algumas abordagens encontradas na literatura relacionada e que apresentaram resultados satisfatórios na resolução do problema tratado.

No trabalho apresentado por Ozcan et al. (2012), foi proposto um algoritmo híbrido nomeado pelos autores de "Interleaved Constructive Memetic Algorithm" (ICMA). Tal algoritmo intercala algoritmos meméticos e métodos construtivos, trabalhando com um subconjunto ativo de eventos. O processo inicia-se com alguns eventos e, posteriormente, em múltiplos estágios construtivos, o ICMA aumenta o conjunto ativo, até que todos os eventos sejam incluídos. Em cada estágio, o algoritmo memético é aplicado, com objetivo de inserir melhorias na solução parcial, antes do próximo passo construtivo do algoritmo. O algoritmo descrito foi aplicado na geração automática de grades horárias.

Os resultados empíricos apresentaram superioridade do algoritmo ICMA sobre os algoritmos meméticos convencionais, frente à resolução do problema de geração de grades horárias. 
O trabalho desenvolvido por Naseem e Yang (2011) apresenta um algoritmo híbrido para a resolução do problema de pós-inscrição na geração de grades horárias. Este problema é uma variação do problema de geração automática de grades horárias, no qual os conjuntos de eventos devem ser arranjados em grades horárias e deve ser gerada a organização das salas de aula, de acordo com a matrícula dos estudantes.

O algoritmo proposto é composto por duas fases:

- Fase 1: A fase inicial do algoritmo é composta pela busca dirigida por meio de algoritmos genéticos. O algoritmo desenvolvido pelos autores trabalha com a estratégia de busca dirigida combinada às técnicas de busca local. A estratégia de busca dirigida utiliza estruturas de dados contendo informações úteis, extraídas previamente dos melhores indivíduos, com objetivo de gerar descendentes melhores adaptados. Já a busca local foi adotada com objetivo de melhorar a qualidade dos indivíduos.

- Fase 2: Nesta fase, foi aplicada a heurística Tabu Search na melhor solução obtida a partir da primeira fase do algoritmo, na qual foram adotados os algoritmos genéticos, com objetivo de melhorar a otimalidade da solução, se for possível.

Como resultado deste trabalho, foram apresentados os testes realizados em conjuntos de benchmarks utilizados em competições internacionais de geradores de grades horárias, e a comparação com outros métodos encontrados na literatura.

Os resultados experimentais demonstraram a capacidade das técnicas adotadas em se gerar resultados factíveis para o problema em questão.

O trabalho de Nothegger et al. (2012) tem como proposta a utilização da heurística baseada na colônia de formigas, com objetivo de se obter a otimização do problema de pósinscrição na geração de grades horárias.

O algoritmo de colônia de formigas pertence ao conjunto de técnicas heurísticas baseadas em modelos probabilísticos, com objetivo de solucionar problemas de otimização. O 
algoritmo de colônia de formigas foi inspirado no comportamento das formigas quando estão procurando por alimento.

As formigas iniciam a busca por alimento aleatoriamente, até que encontram seu objetivo e retornam à colônia, deixando um rastro de feromônios. O rastro de feromônios é seguido pelas próximas formigas, que também enfatizam o rastro.

A técnica proposta pelos autores foi desenvolvida utilizando-se os conceitos de algoritmos de colônia de formigas executado em paralelo, frente à busca da solução ótima para o problema em questão.

A paralelização do algoritmo foi obtida facilmente, devido a cada formiga construir uma solução para o problema, de forma independente. A sincronização do algoritmo ocorre somente no momento de avaliação das soluções e atualização dos feromônios.

A partir dos resultados apresentados pelos autores, conclui-se que o algoritmo desenvolvido foi capaz de encontrar soluções de alta qualidade, especialmente quando adotados métodos de melhoria local.

O trabalho de Burke et al. (2012) apresenta a abordagem de uma hiper-heurística híbrida como solução para o problema de geração de grades horárias em instituições de ensino.

A hiper-heurística pode ser vista como uma técnica heurística adotada para definir qual a heurística será utilizada para a solução do problema, elevando-se desta forma, o nível de generalidade das metodologias de pesquisa para se obter algoritmos que operaram de forma eficaz, para uma série de problemas de otimização. Já as técnicas heurísticas de baixo nível representam o espaço de busca do problema em questão.

No problema de geração automática de grades horárias, híper-heurísticas de baixo nível são categorizadas como técnicas heurísticas adotadas na construção de grades horárias, ou ainda, na melhoria das grades horárias geradas. 
O objetivo desta pesquisa foi realizar uma análise comparativa sobre o desempenho de diferentes técnicas heurísticas de baixo nível, adotadas na minimização da penalidade encontrada na construção de soluções para o problema de geração automática de grades horárias. Os resultados apresentados possibilitaram concluir que, a técnica heurística adotada na troca de horários disponíveis na grade é viável em combinações com cadeias de Kempe (Burke et al.,2012).

Adicionalmente, foi ainda possível concluir que as melhores soluções para o problema são geradas ao se obter soluções que violem as restrições de baixo grau, ou seja, aquelas que não invalidam a solução, utilizando-se graus de saturação e também se quebrando o vínculo com graus de maior ponderação.

Com base na saída do processo de aprendizagem, uma abordagem adaptativa, responsável pela análise e ajuste de algumas sequências de soluções geradas aleatoriamente, pôde ser obtida e aplicada aos demais casos.

Finalmente, uma abordagem de híper-heurística foi aplicada em um conjunto de dados mais restritos, os quais possibilitaram a geração de resultados satisfatórios e mais competitivos, se comparados às outras abordagens encontradas na literatura.

No trabalho de Turabieh e Abdullah (2011) foi desenvolvido um algoritmo híbrido no qual foram combinados operadores heurísticos e o algoritmo Great Deluge.

O algoritmo great deluge é um procedimento de busca local, aplicado em problemas de otimização. O algoritmo great deluge foi adotado devido aos bons resultados encontrados na literatura relacionada, quando aplicados ao problema de geração automática de grades horárias.

Com objetivo de melhorar o algoritmo, foram adicionados procedimentos heurísticos. Tais procedimentos podem ser encontrados na literatura sob o termo electromagnetic-likemechanism. 
O objetivo do algoritmo proposto pelos autores é mover os pontos para uma solução de alta qualidade, evitando-se ótimos locais, por intermédio da adoção de um valor, chamado de taxa de decaimento de força, o qual será calculado dinamicamente, determinando-se então o nível da solução no algoritmo great deluge.

No algoritmo desenvolvido, dois parâmetros são requeridos, os quais são representados pelos requisitos do usuário:

- O tempo computacional disponibilizado.

- E a qualidade estimada da solução requisitada.

O valor de nível inicial do algoritmo representa o valor da função objetivo da população inicial. Durante a execução do algoritmo, o valor de nível será reduzido a partir do valor da taxa de decaimento de força dinâmica, calculado pelo algoritmo electromagnetic-like-mechanism. A construção da população inicial foi realizada utilizando-se a heurística de coloração de grafos.

O desempenho do trabalho foi demonstrado pelos autores a partir de testes comparativos com trabalhos encontrados na literatura relacionada. Os resultados obtidos possibilitaram concluir que o trabalho proposto foi capaz de gerar soluções factíveis para o problema de geração automática de grades horárias.

No trabalho de Sabar et al. (2012), foi proposto um algoritmo variante do algoritmo de otimização de colônias artificiais de abelhas. Este algoritmo possui o objetivo de solucionar o problema de geração automática de grades horárias em instituições de ensino.

O desempenho do algoritmo proposto foi testado em dois diferentes, porém relacionados, domínios de dados de teste, dentro do problema de geração de grades horárias: exames e cursos.

O algoritmo proposto é composto por:

- Uma abelha rainha, representado a solução ótima para o problema;

- Zangões, representando soluções incumbentes para o problema tratado; 
- Trabalhadores, representadas pelas heurísticas adotadas;

- Ninhadas, as quais representam as soluções utilizadas em testes.

O presente algoritmo simula o comportamento natural da abelha rainha, quando sai da colméia, para acasalar com zangões.

Antes de o vôo ser iniciado, a abelha rainha recebe o valor de energia, o qual é inicializado com um valor positivo, gerado aleatoriamente. $\mathrm{O}$ valor de energia da abelha rainha é decrementado durante o vôo de acasalamento, até que o valor de energia atinja um valor abaixo do limiar pré-definido.

Os resultados demonstram que, o desempenho do algoritmo desenvolvido pode ser comparado aos resultados obtidos em outras abordagens encontradas na literatura relacionada. Em alguns casos foram, inclusive, obtidos melhores resultados, se comparados às outras técnicas, o que vêm a indicar que tal algoritmo é uma abordagem promissora na resolução do problema de geração de grades horárias.

O trabalho de Pais e Amaral (2012) tem como proposta o uso de Tabu Search aplicado ao problema de geração automática de grades horárias.

Tabu search é uma meta-heurística que vem sendo aplicada com sucesso, na busca de soluções factíveis, para problemas complexos de otimização. Em geral, tabu search pode ser descrito como uma técnica de busca por vizinhança combinada à técnica de escape de ótimos locais.

Os autores adotaram Sistemas Baseados em Regras Fuzzy (Zadeh, 1965) para obter o cálculo de valores de tabu, em cada elemento da lista tabu, no algoritmo tabu search aplicado ao problema de geração automática de grades horárias. Dois conceitos de entrada foram adotados para os sistemas fuzzy, são eles: frequência e inatividade do tabu. 
O algoritmo proposto neste trabalho gerou resultados, os quais tiveram seu desempenho comparado a outros eficientes métodos encontrados na literatura relacionada. Foi possível concluir, a partir dos resultados obtidos, que o algoritmo desenvolvido é simples e limitado.

$\mathrm{Na}$ investigação desenvolvida por Bai et al. (2012) foi adotada a hiper-heurística Simulated Annealing na resolução de dois diferentes problemas de otimização: a geração automática de grades horárias e o problema de empacotamento de objetos em caixas. Ambos os problemas possuem alta complexidade, e são considerados problemas do tipo NP-Completo.

A hiper-heurística simulated annealing proposta pelos autores possui uma barreira de domínio localizada entre o domínio da hiper-heurística e o domínio do problema.

O objetivo deste trabalho foi desenvolver um framework genérico, o qual é composto por três características:

- Critério de aceitação do simulated annealing: foi adotado com objetivo de melhorar as decisões de aceitação de movimentos heurísticos, além de prover, no futuro, a informação relacionada às melhores heurísticas utilizadas.

- Estratégia heurística de seleção estocástica: foi empregada na hiper-heurística, em especial nos métodos de seleção heurística determinística, devido aos resultados encontrados na literatura relacionada.

- Memória de curto prazo: foi adotada com objetivo de sustentar o mecanismo de heurística.

Resultados experimentais demonstraram que o algoritmo proposto produziu melhores resultados que diversas aplicações similares encontradas na literatura relacionada. Uma significante vantagem deste trabalho encontra-se no alto nível de generalidade do algoritmo.

Tassopoulos e Beligiannis (2012) têm como proposta o desenvolvimento de um algoritmo híbrido baseado na técnica de Otimização por Enxame de Partículas (PSO) modificada, adotados na resolução do problema de geração automática de grades horárias. 
A idéia básica encontrada no algoritmo PSO é simular o comportamento social dos animais, de forma simplificada, tais como peixes, pássaros, entre outros. A noção dominante do PSO são as partículas e seus movimentos no espaço de busca.

A partícula corresponde à uma entidade, a qual representa uma potencial solução para o problema tratado, que não possui massa ou volume. As partículas sobrevoam o espaço de busca e suas trajetórias são ajustadas dinamicamente, tendo sua velocidade alterada de acordo com a sua experiência de vôo e a experiência de vôo das partículas do enxame.

O fitness de cada partícula corresponde à função objetivo, calculada a partir das coordenadas correspondentes à localização da partícula e que deve ser otimizada, até que seja encontrada a solução para o problema em questão.

As principais diferenças entre o algoritmo proposto pelos autores e o algoritmo PSO padrão são as seguintes:

- A quantidade de partículas não é fixa. O algoritmo inicia-se com uma alta quantidade de partículas e esta quantidade é reduzida durante a execução do algoritmo.

- O vetor de velocidade não é utilizado. A posição das partículas é perturbada e então atualizada, por meio da inserção aleatória de horários da grade, advindos do ótimo local e ótimo global.

Os resultados experimentais demonstraram a eficiência do algoritmo desenvolvido, quando aplicado na resolução do problema de geração de grades horárias. O método apresentado foi comparado à outros algoritmos encontrados na literatura relacionada, e apresentou melhores resultados que os demais métodos.

Sabar et al. (2012) apresenta uma abordagem para resolução do problema de grades horárias por meio da hiper-heurística construtiva de coloração de grafos (GCCHH).

No algoritmo proposto pelos autores, o nível de dificuldade da organização da disciplina na grade horária é determinado pela hibridização simultânea de heurísticas de coloração de 
grafos. As aulas com maiores graus de dificuldade a serem alocadas serão alocadas primeiramente na grade horária frente ao mecanismo de seleção Roulette Wheel. Caso existam aulas com mesmo grau de dificuldade, a seleção será realizada aleatoriamente.

O presente trabalho adotou o uso de quatro heurísticas de coloração de grafos:

- Largest Degree First (LD): As aulas são ordenadas, em ordem decrescente, de acordo com o número de conflitos que apresentam com as demais aulas.

- Saturation Degree First (SD): As aulas são ordenadas dinamicamente, em ordem ascendente, de acordo com a quantidade de horários remanescentes na grade horária.

- Largest Colored Degree First (LCD): As aulas são ordenadas, baseando-se a quantidade de conflitos existentes com as aulas que já foram alocadas na grade horária.

- Largest Enrolment First (LE): As aulas são ordenadas, em ordem decrescente, de acordo com a quantidade de alunos matriculados.

Tais heurísticas foram adotadas com objetivo de gerar quatro listas ordenadas. O algoritmo é finalizado quando todas as listas formadas estiverem vazias, sem que nenhuma das restrições de alto grau tenha sido violada e, desta forma, uma solução viável para o problema tenha sido encontrada.

Os experimentos computacionais realizados demonstraram os bons resultados obtidos nesta abordagem, quando comparada aos dois conjuntos de dados adotados: Carter e International Timetabling Competition 2007. A partir dos resultados obtidos, foi possível concluir que o algoritmo desenvolvido é simples e eficaz, sendo capaz de produzir resultados competitivos, ou ainda, melhores que os resultados encontrados na literatura relacionada e aqui comparada.

Paechter et al. (1994) desenvolveram um sistema computacional, adotado na Universidade de Napier, o qual utilizou-se de algoritmos genéticos, aplicados como uma 
seqüência de eventos em grades horárias. Os operadores genéticos, por eles aplicados, representaram uma seqüência de cromossomos combinados e que produziram novas sequencias de eventos, até que a grade horária necessária for obtida.

\subsection{Considerações Parciais}

Neste capítulo, foram brevemente explanados alguns dos trabalhos recentes encontrados na literatura relacionada, nos quais abordaram o problema de geração de grades horárias em instituições de ensino. A partir dos trabalhos investigados, foi possível verificar a eficiência de métodos heurísticos, quando combinados com algoritmos de busca estocástica, objetivando-se encontrar soluções factíveis para o problema tratado no presente trabalho. 


\section{Algoritmos Genéticos}

\subsection{Introdução}

Métodos baseados em Computação Evolutiva constituem uma classe de algoritmos de busca e otimização estocástica, inspiradas na teoria da evolução natural, segundo Darwin (1859).

Diferentes abordagens de algoritmos baseados na teoria evolutiva são encontradas na literatura relacionada. Entre elas, destacam-se os Algoritmos Genéticos, os quais foram abordados nesta investigação. As principais diferenças encontradas entre as diversas abordagens de algoritmos evolutivos são os operadores genéticos adotados em cada um deles. O uso de algoritmos evolutivos, aplicados na resolução de problemas de otimização, tem aumentado expressivamente nos últimos anos.

A grande vantagem dos algoritmos evolutivos encontra-se na possibilidade de resolver problemas complexos por meio da simples descrição matemática da solução desejada. O algoritmo evolutivo é genérico, desta forma, para obter a solução de diferentes problemas, os passos serão os mesmos.

Devido aos algoritmos evolutivos pertencerem a uma classe de algoritmos genéricos, sua estrutura pode ser descrita pelo seguinte algoritmo apresentado na Figura 3.1. 


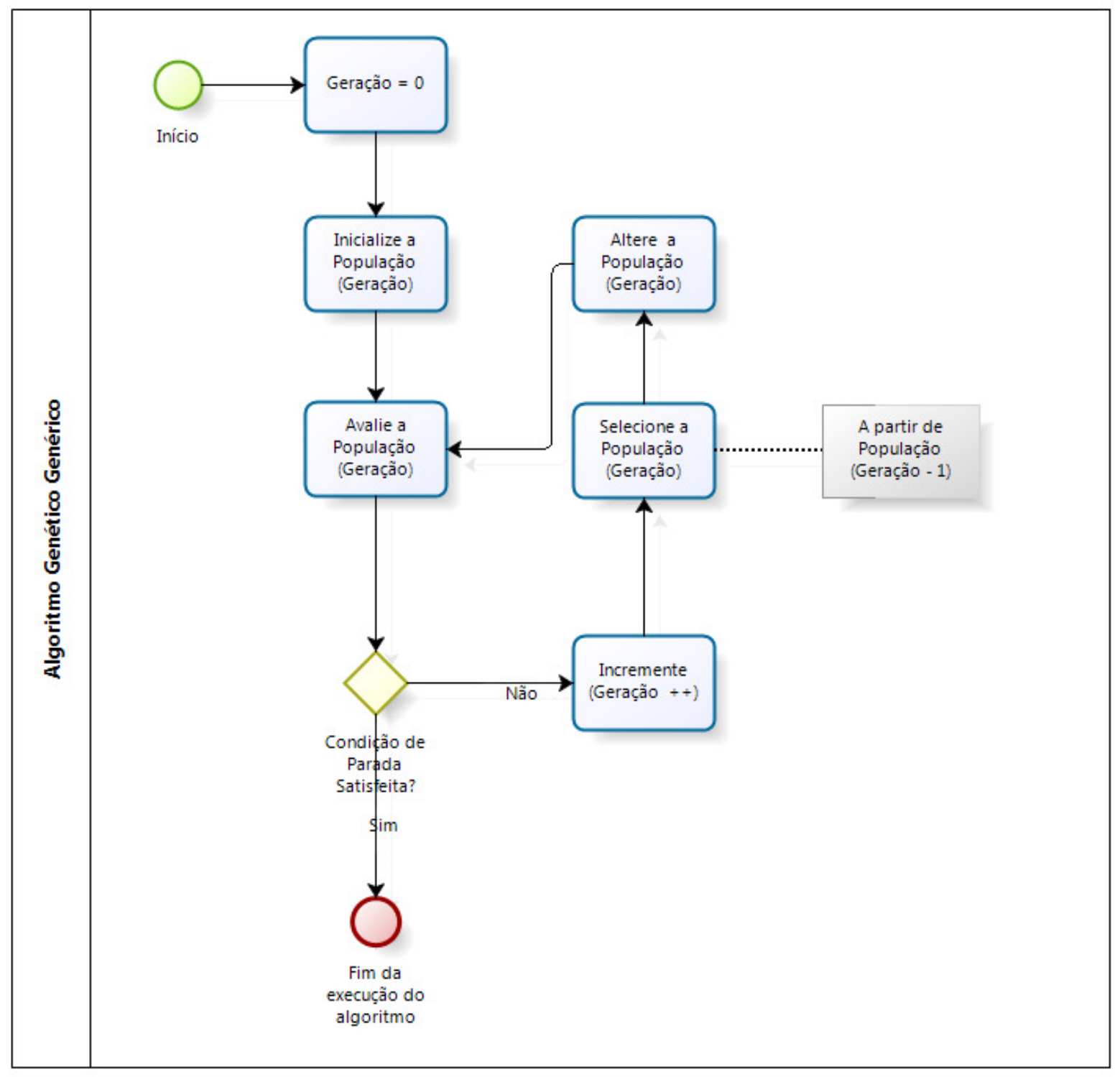

Figura 3.1 - Algoritmo genético genérico.

Algoritmos evolutivos pertencem ao conjunto de técnicas e procedimentos adaptáveis, os quais são aplicados com sucesso em problemas complexos, em que técnicas tradicionais seriam ineficazes ou não aplicáveis. Utilizando-se algoritmos evolutivos, não existe a garantia de obtenção da solução ótima; porém, uma solução viável para o problema em questão será obtida, sem que seja necessário adotar o uso de informações extras, mediante a aplicação de um algoritmo genérico. 


\subsection{Base Biológica}

A seguir serão apresentados importantes conceitos básicos da Biologia, sendo necessários para compreensão do surgimento dos Algoritmos Evolutivos.

\subsubsection{Darwinismo}

Darwin (1859) apresentou o seu trabalho sobre a evolução das espécies, no qual explanou sobre a diversidade entre os seres vivos existentes e o como se dá o surgimento de novas espécies na natureza. A teoria explanada buscava esclarecer o funcionamento do mecanismo de manutenção das variações favoráveis à sobrevivência e reprodução de um organismo no ambiente.

Darwin (1859) justifica o surgimento de novas espécies a partir de espécies já existentes. O surgimento de uma nova espécie ocorria devido ao acúmulo de variações favoráveis, por meio da seleção natural no decorrer de longo espaço de tempo.

Em seu trabalho, Darwin (1859) investigou a forma com que os criadores domésticos eram capazes de criar variedades de espécies, mediante seleção e cruzamento de animais e plantas. Foi observada a capacidade do homem em produzir indivíduos melhorados, por meio de seleção e cruzamento entre os indivíduos apropriados e questionou-se então como a natureza seria capaz de atuar nos órgãos internos e externos dos indivíduos. Além de mostrar como novas espécies surgem, esta teoria apresentava também que espécies poderiam desaparecer.

A seleção natural é um resultado da luta pela sobrevivência, envolvendo a vida do indivíduo e sua capacidade de reproduzir. Quando são produzidos mais indivíduos que podem sobreviver, ocorre a luta pela sobrevivência entre os indivíduos da mesma espécie, espécies distintas ou entre o meio ambiente. 
Segundo Darwin (1859), o processo de evolução exigia que uma população de indivíduos estivesse sujeita à reprodução com herança, variação e seleção natural. Atualmente, estas hipóteses são aceitas apenas para explicar os processos ecológicos. Naquela época, não havia conhecimento de conceitos da genética, o que levou posteriormente às teorias neodarwinistas.

\subsubsection{A Evolução Natural}

A evolução é o resultado da criação de informação genética, sua avaliação e, finalmente, a seleção dos indivíduos melhores adaptados ao ambiente, com objetivo de fornecer material genético para as próximas gerações. Um indivíduo em uma população é afetado pelos demais indivíduos da população e também pelo ambiente em que vive. Desta forma, a evolução natural corresponde ao processo no qual se dá o surgimento de estruturas orgânicas complexas e adaptadas ao ambiente.

Os princípios da seleção natural indicam que indivíduos melhores adaptados ao meio ambiente serão mais promissores à sobrevivência e reprodução. Inicialmente, o indivíduo será afetado; porém, o resultado final ocorrerá na espécie, a qual o indivíduo pertence.

A seleção natural irá preservar as informações que possuírem melhor adaptação ao ambiente. Ao longo do processo evolutivo, ocorre a adição de informação genética oriunda de indivíduos com adaptação acima da média. O caráter não determinístico da reprodução resulta na produção permanente de informação genética nova, ou seja, criação de indivíduos diferenciados.

\subsubsection{Terminologias Básicas dos Sistemas Naturais}

Nos sistemas evolutivos são empregadas terminologias, as quais fazem analogia aos termos biológicos naturais. As estruturas computacionais são compactas, se comparadas às estruturas biológicas naturais; porém, os resultados obtidos a partir de tal simulação, em problemas de 
otimização, são considerados satisfatórios. As terminologias adotadas nos sistemas evolutivos terão seu significado biológico a seguir explanado.

- Cromossomo: nos sistemas naturais, um cromossomo corresponde à uma estrutura nucleoprotéica, formada por uma cadeia de DNA, sendo esta, a base física dos genes nucleares. Cada espécie existente apresenta um número característico de cromossomos. Aqueles cromossomos arranjados em pares são conhecidos como diplóides, assim como aqueles unitários são conhecidos como haplóides. Já nos algoritmos genéticos, um cromossomo representa uma solução completa para o problema tratado.

- Crossover: na natureza, o crossover corresponde à troca de material genético entre dois cromossomos. Assim como na natureza, nos sistemas artificiais, o crossover corresponde ao cruzamento entre duas soluções para o problema tratado, com objetivo de gerar uma solução melhor adaptada.

- Genes: A definição de genes, na Biologia, é de que são blocos funcionais de DNA, responsáveis pela codificação de proteínas específicas, onde cada gene está alocado em um lócus particular, no cromossomo. Em sistemas bio-inspirados, os genes correspondem a cada posição da estrutura de dados ou vetores, na qual será alocado um valor, o chamado Alelo.

\subsection{Conceitos Relacionados aos Algoritmos Genéticos}

Nesta seção serão apresentados importantes conceitos relacionados aos Algoritmos Genéticos. Tais conceitos são necessários para a compreensão do método de busca e otimização aqui adotado e, também, para a relação existente entre os algoritmos genéticos e a biologia natural, conforme descrito por Zuben (2000).

Os algoritmos genéticos foram introduzidos com o objetivo de explicar rigorosamente processos de adaptação em sistemas naturais e desenvolver sistemas artificiais, simulados 
computacionalmente, de forma que retenham os mecanismos originais encontrados em sistemas naturais, afirmou Holland (1975).

Segundo Goldberg et al. (1989), algoritmos genéticos são técnicas de busca estocástica inspiradas na teoria darwinista e nos conceitos da genética natural. Os resultados advindos da imitação dos processos naturais são promissores, como pode ser observado na literatura relacionada.

Em uma determinada população, indivíduos com características genéticas favoráveis, possuem maiores chances de sobreviver e de produzir indivíduos cada vez mais aptos. Indivíduos menos aptos tenderão a desaparecer da população.

Dado um problema de otimização, os algoritmos genéticos buscam a solução a partir de um conjunto aleatório de soluções. Cada uma das possíveis soluções para o problema é chamada de indivíduo ou cromossomo. Um indivíduo representa completamente uma possível solução para o problema tratado. Os algoritmos genéticos têm por objetivo favorecer a combinação de indivíduos mais aptos, de forma que promissores candidatos à solução de um determinado problema evoluam, até que o resultado esperado ou satisfatório seja obtido.

Cada indivíduo da população é avaliado durante todo o processo evolutivo, recebendo uma nota, a qual reflete na sua habilidade de adaptação em um determinado ambiente. São simulados os processos de seleção natural a partir de indivíduos com maior valor de aptidão. $\mathrm{O}$ valor de aptidão, de cada individuo, é calculado a partir de uma função objetivo.

Durante o processo evolutivo, são aplicados os operadores genéticos e métodos de seleção, originando-se assim novas populações. O processo evolutivo é reproduzido até que a condição de parada imposta, para o problema, seja satisfeita. Uma condição de parada pode ser definida pela quantidade de gerações da população ou pela obtenção de uma solução satisfatória para o problema, quando esta é conhecida. 
Os algoritmos genéticos operam sobre uma população de soluções candidatas, trabalhando em paralelo. O espaço de busca é explorado a partir da alocação de um número de membros apropriado, de forma que possibilite a busca em diversas regiões. Desta forma, tais técnicas possuem maior probabilidade de atingir as áreas mais promissoras do espaço de busca, devido a operarem com uma população de soluções e não um único ponto.

Segundo Fogel (1994), a terminologia adotada para representar os atributos dos algoritmos genéticos são os mesmos utilizados pela biologia natural, conforme descrito anteriormente. O genótipo, pertinente a cada cromossomo, representa a codificação de uma possível solução para o problema em questão. Já o fenótipo, representa uma possível solução de problema. Os cromossomos normalmente são representados por intermédio de listas de atributos ou vetores. Cada atributo da lista ou vetor é representado por um gene e os valores de cada gene são chamados de alelos.

Os algoritmos genéticos pertencem à classe de algoritmos probabilísticos, porém não são métodos de busca puramente aleatórios, devido à combinação de métodos aleatórios com métodos de busca diretos e estocásticos.

Os algoritmos genéticos apresentam eficiência na busca por soluções ótimas, ou ainda, satisfatórias, em uma grande variedade de problemas de otimização. Tal resultado é possível, devido a não serem impostas muitas limitações, tal qual encontradas em métodos tradicionais. Embora estas técnicas possam parecer simplistas, quando comparadas às estruturas biológicas naturais, elas são suficientemente complexas a ponto de fornecer mecanismos robustos de busca adaptativa. 


\subsubsection{Representação das Soluções}

A primeira característica importante a ser considerada na configuração dos algoritmos genéticos se encontra no modelo em que serão representadas as possíveis soluções para o problema tratado.

A definição adequada da codificação das soluções é considerada como sendo uma etapa crítica na determinação dos algoritmos genéticos, devido aos problemas que podem ser ocasionados, tais como a convergência prematura do algoritmo, quando as soluções apresentam a representação inadequada de sua codificação.

No algoritmo genético clássico, os cromossomos são codificados em arranjos binários com tamanhos fixos, no qual cada elemento do vetor representa a presença (1) ou ausência (0) de uma determinada característica.

Um exemplo de cromossomo codificado em arranjos binários pode ser visualizado na Figura 3.2, na qual, cada gene possui alelos com valores binários.

\begin{tabular}{lllllllllll|l|l|l|l|} 
Genes & 0 & 1 & 2 & 3 & 4 & 5 & 6 & 7 & 8 & 9 \\
Alelos & 1 & 1 & 0 & 1 & 1 & 0 & 1 & 0 & 0 & 0 \\
\cline { 2 - 8 }
\end{tabular}

Figura 3.2 - Cromossomo codificado em arranjos binários.

O cromossomo representa o conjunto de parâmetros da função-objetivo, cujo retorno esperado é dado frente à maximização ou minimização de tais parâmetros. Os conjuntos de configurações pertencentes aos cromossomos formam o espaço de busca para a solução do problema. Cada cromossomo possui $N$ parâmetros de uma função, sendo que o seu espaço de busca possui então $N$ dimensões.

Em algumas aplicações nas quais a precisão da solução é requerida, a codificação binária demonstra um desempenho insatisfatório. Para estes casos, são adotados os números reais para representarem a codificação das soluções. 
A representação dos cromossomos utilizando-se números reais demonstra superioridade em relação à representação binária, devido aqui à fácil interpretação da solução obtida e, também, por requerer menos esforço computacional que aquela usando uma cadeia binária.

Um exemplo de cromossomo codificado por meio de números reais pode ser visualizado na Figura 3.3, na qual, cada gene possui alelos com números reais.

\begin{tabular}{ll|l|l|l|l|l|l|l|l|l|} 
Genes & 0 & 1 & 2 & 3 & 4 & 5 & 6 & 7 & 8 & 9 \\
\hline Alelos & 5 & 8 & 5 & 0 & 4 & 6 & 4 & 9 & 1 & 3 \\
\cline { 2 - 8 }
\end{tabular}

Figura 3.3 - Cromossomo codificado em números reais.

Em problemas de otimização restrita, tais como o problema de geração de grades horárias, aqui tratado, a codificação inadequada pode gerar indivíduos recombinados ou mutados inválidos.

\subsubsection{Definição da População e seu Tamanho}

O método mais comumente adotado na geração da população inicial é a inicialização aleatória dos indivíduos. Aconselha-se a combinação de aleatoriedade e métodos heurísticos na inicialização da população, quando houver conhecimento prévio a respeito do problema, sempre tendo cuidados especiais para não gerar indivíduos inválidos nesta fase, em caso de problemas de otimização restrita.

A Figura 3.1 demonstrou o algoritmo genético genérico, o qual pode ser adotado em diversos problemas de otimização combinatória. Os passos iniciais, descritos na Figura 3.4, a seguir, definem a inicialização da população inicial em um algoritmo genético. 


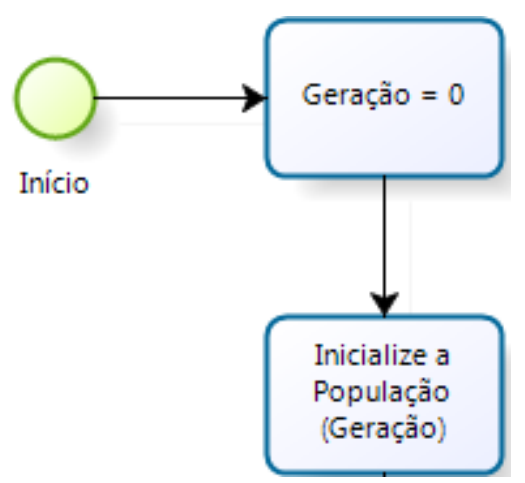

Figura 3.4 - Inicialização da população inicial no AG.

O tamanho da população é um parâmetro importante do algoritmo genético, pois tal parâmetro pode afetar no desempenho do algoritmo. A quantidade insuficiente de indivíduos em uma população irá oferecer pouca cobertura no espaço de busca do problema. Já a quantidade excessiva de indivíduos em uma população fornecerá uma cobertura representativa do domínio do problema e prevenirá a convergência prematura para soluções locais, enquanto que o objetivo é encontrar soluções globais; porém, utilizará recursos computacionais e temporais em alta escala.

\subsubsection{Operadores Genéticos}

Os operadores genéticos são adotados em indivíduos, com objetivo de obter uma população sucessiva na qual o valor de aptidão dos indivíduos seja superior aos dos seus progenitores, resultando-se desta forma, na evolução dos indivíduos. Os novos indivíduos gerados possuem características herdadas dos seus progenitores. Os principais operadores genéticos encontrados na literatura relacionada são os operadores de crossover e de mutação.

A Figura 3.1 demonstrou o algoritmo genético genérico, o qual pode ser adotado em diversos problemas de otimização combinatória. O passo descrito na Figura 3.5, a seguir, define o uso de operadores genéticos em um algoritmo genético. 
Figura 3.5 - Inicialização da População Inicial no AG.

\subsubsection{Crossover}

O operador genético conhecido como crossover, ou cruzamento, possibilita a produção de novos indivíduos a partir do cruzamento de informação genética de indivíduos progenitores, os quais são escolhidos entre os indivíduos da população atual. Os indivíduos gerados serão inseridos na nova população de soluções candidatas, com o propósito de trocar informação entre diferentes soluções candidatas.

Podem ser encontradas, na literatura relacionada, diversas variações do operador de crossover, algumas delas são específicas para determinados tipos de problema. Não é possível afirmar que um determinado tipo de crossover que seja mais eficiente para todos os tipos de problemas, mas sim, que existem tipos de crossover com melhores resultados e indicados para classes de problemas. Sendo assim, cada tipo de crossover é particularmente eficiente para uma determinada classe de problemas, porém ineficiente para outras.

O tipo de crossover empregado no algoritmo genético clássico é o crossover de um ponto. Em diversos experimentos empíricos, encontrados na literatura, tal método apresentou resultados insatisfatórios para alguns tipos de problemas.

Deve ser definida a taxa de crossover, independente do tipo de crossover adotado, pois tal taxa será utilizada durante a execução do algoritmo a fim de determinar qual a quantidade de indivíduos serão expostos à operação de cruzamento.

Ainda nesta seção serão apresentados alguns tipos de crossover mais comumente encontrados na literatura relacionada. 
O crossover de um ponto é o método clássico de cruzamento, no qual são selecionados dois indivíduos da população atual, ambos com comprimento fixo $L$. Será determinado um ponto de corte, o qual indica quais genes serão fornecidos de cada progenitor ao novo indivíduo.

O ponto de corte corresponde a uma posição do vetor, ou lista, de genes de cada indivíduo. O ponto de corte deve, obrigatoriamente, ser um número inteiro, escolhido aleatoriamente, maior que zero e menor que $L$.

Depois de definido o ponto de corte e os dois cromossomos progenitores, pode ser então dado início ao processo de cruzamento, o qual consiste nos passos descritos a seguir:

- Iniciar a varredura do primeiro cromossomo progenitor, copiando cada alelo em uma nova lista ou vetor, de acordo com a estrutura de codificação das soluções, até que seja atingida a posição correspondente ao ponto de corte;

- A partir da posição do ponto de corte, copiar cada alelo do segundo progenitor para o novo indivíduo, aquele que inicialmente recebeu o material genético até o ponto de corte do primeiro progenitor, até atingir o final dos alelos do segundo progenitor.

Um novo indivíduo é então gerado, herdando informação genética de dois outros indivíduos, por meio da troca de um conjunto de atributos.

A Figura 3.6 demonstra graficamente o algoritmo de crossover de um ponto, no qual um novo indivíduo é criado a partir do material genético de dois indivíduos da população atual, considerando o ponto de corte como os limites de alelos recebidos de cada um dos progenitores escolhidos. 


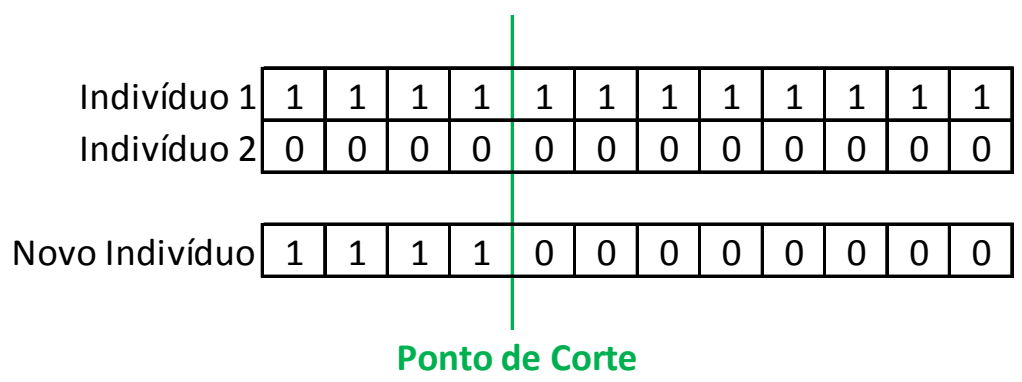

Figura 3.6 - Funcionamento do crossover de um ponto.

Outro tipo conhecido de crossover é o crossover de $N$ pontos, no qual apresenta semelhanças com o método clássico de cruzamento, o crossover de um ponto; porém, permite que seja inserida maior variação na nova população, pois são selecionados dois indivíduos da população atual, ambos com comprimento fixo $L$, e serão determinados mais de um ponto de corte, os quais indicam quais genes serão fornecidos de cada progenitor ao novo indivíduo.

Da mesma forma que ocorre no crossover de um ponto, o ponto de corte corresponde também às posições do vetor, ou lista, que representa a codificação da solução, de genes de cada indivíduo. Os pontos de corte devem, obrigatoriamente, ser números inteiros, determinados aleatoriamente, e maiores que zero e menor que o tamanho $L$ dos cromossomos.

Depois de definidos os pontos de corte e os dois cromossomos progenitores, pode ser então dado início ao processo de cruzamento, o qual consiste nos passos descritos a seguir:

- Iniciar a varredura do primeiro cromossomo progenitor, copiando cada alelo em uma nova lista ou vetor, de acordo com a estrutura de codificação das soluções, até que seja atingida a posição correspondente ao primeiro ponto de corte.

- A partir da posição do ponto de corte, copiar cada alelo do segundo progenitor para o novo indivíduo, aquele que inicialmente recebeu o material genético até o ponto de corte do primeiro progenitor, até atingir o segundo ponto de corte. 
- Tais passos devem ser repetidos até que todos os pontos de corte sejam utilizados como pontos de troca de informação genética e que seja atingido o final dos genes dos progenitores.

Um novo indivíduo é então gerado, herdando informação genética de dois outros indivíduos, mediante à troca de um conjunto de atributos.

A Figura 3.7 demonstra graficamente o algoritmo de crossover $N$ pontos, no qual um novo indivíduo é criado a partir do material genético de dois indivíduos da população atual, considerando cada um dos pontos de corte como os limites de alelos recebidos de cada um dos progenitores escolhidos.

\begin{tabular}{|c|c|c|c|c|c|c|c|c|c|c|c|c|}
\hline Indivíduo 1 & 1 & 1 & 1 & 1 & 1 & 1 & 1 & 1 & 1 & 1 & 1 & 1 \\
\hline Indivíduo 2 & 0 & 0 & 0 & 0 & 0 & 0 & 0 & 0 & 0 & 0 & 0 & 0 \\
\hline Novo Indivíduo & 1 & 1 & 0 & 0 & 0 & 1 & 1 & 1 & 1 & 1 & 0 & 0 \\
\hline
\end{tabular}

Figura 3.7 - Funcionamento do crossover de $N$ pontos.

O crossover com mais de um ponto de corte permite que o novo indivíduo tenha maior variação genética quando comparado àquele gerado a partir do crossover de um ponto. Consequentemente, existirá aqui maior variação na nova população, evitando-se desta forma, que seja atingido um mínimo local no espaço de busca do problema.

\subsubsection{Mutação}

Na subseção anterior, descreveu-se o funcionamento do operador genético de crossover, o qual possibilita a troca de material genético entre indivíduos da população, originando-se um novo indivíduo. Aqui será descrito o funcionamento do operador genético de mutação, muito utilizado também nos algoritmos evolutivos. 
O operador genético de mutação permite a inserção de diversidade na população, pois modifica, aleatoriamente, um ou mais genes de um cromossomo.

Inicialmente deve ser definida a taxa de mutação a ser adotada, para que seja determinada a quantidade de indivíduos que estarão sujeitos à mutação em uma população. A taxa de mutação, usualmente, corresponde a um valor de porcentagem baixo. Tal medida garante que o objetivo da mutação seja atingido, inserindo-se variabilidade extra na população, sem que seja desfeito o progresso já obtido durante o processo evolutivo.

O método adotado para obtenção da mutação é diversificado, de acordo com a codificação adotada na estrutura das soluções.

Os indivíduos codificados binariamente são mutados a partir da troca do valor do alelo por zero ou um, de acordo com o valor atual. Se a codificação dos indivíduos for em ponto flutuante, então os operadores mais comumente adotados, encontrados na literatura relacionada, são a mutação uniforme ou mutação gaussiana, as quais serão detalhadas durante esta subseção.

A mutação aleatória é um método de inserção de diversidade na população, adotado em indivíduos com codificação binária de sua estrutura.

A codificação aleatória consiste na troca do valor dos alelos sorteados. O gene, ou posição do vetor ou lista de atributos, será sorteado de maneira aleatória.

A codificação do novo indivíduo, o qual será inserido na nova população será realizado conforme o algoritmo descrito a seguir.

- Deve-se definir a taxa de mutação do algoritmo genético. A partir a taxa de mutação definida, será então selecionada a quantidade de indivíduos correspondentes na população atual. 
- Os indivíduos selecionados, a partir de um método de seleção qualquer, serão clonados. Os novos indivíduos, idênticos aos indivíduos selecionados, são aqueles que estarão sujeitos à mutação, mantendo os originais conforme foram inicializados.

- Será selecionado aleatoriamente um gene, o qual deve, obrigatoriamente, ser um valor maior que zero e menor que o tamanho do cromossomo.

- O valor sorteado corresponde à posição do vetor, ou lista, de atributos no qual o alelo será trocado.

A Figura 3.8 apresenta graficamente como o algoritmo de mutação aleatória opera sobre um indivíduo em particular. Conforme é possível observar na Figura 3.8, foi sorteado um valor entre zero e onze, sendo este o valor, hipoteticamente, igual a cinco, correspondendo ao gene cinco, de um determinado indivíduo, com alelo de valor "1". O alelo possui valor "1", então deve-se trocar seu valor para " 0 ". Caso o valor original do alelo for igual a "0", então será trocado para " 1 ".

\begin{tabular}{|c|c|c|c|c|c|c|c|c|c|c|c|c|}
\hline Genes & 0 & 1 & 2 & 3 & 4 & 5 & 6 & 7 & 8 & 9 & 10 & 11 \\
\hline Indivíduo original & 1 & 1 & 0 & 1 & 0 & 1 & 0 & 0 & 1 & 1 & 0 & 0 \\
\hline Novo Indivíduo & 1 & 1 & 0 & 1 & 0 & 0 & 0 & 0 & 1 & 1 & 0 & 0 \\
\hline
\end{tabular}

Figura 3.8 - Exemplo de mutação aleatória em um indivíduo de codificação binária.

A mutação indutiva é um método de inserção de diversidade na população, adotado em indivíduos com codificação em ponto flutuante de sua estrutura.

A codificação indutiva consiste na soma de um valor, sorteado aleatoriamente, ao valor original dos alelos sorteados. O gene, ou posição do vetor ou lista de atributos, será sorteado de maneira aleatória.

A codificação do novo indivíduo, o qual será inserido na nova população, será realizado conforme o algoritmo descrito a seguir. 
- Deve-se definir a taxa de mutação do algoritmo genético. A partir da taxa de mutação definida, será então selecionada a quantidade de indivíduos correspondentes na população atual.

- Os indivíduos selecionados, a partir de um método de seleção qualquer, serão clonados. Os novos indivíduos, idênticos aos indivíduos selecionados, são aqueles que estarão sujeitos à mutação, mantendo os originais conforme foram inicializados.

- Será selecionado aleatoriamente um gene, o qual deve, obrigatoriamente, ser um valor maior que zero e menor que o tamanho do cromossomo.

- O valor sorteado corresponde à posição do vetor, ou lista, de atributos no qual o alelo será trocado.

- Sortear um valor, o qual será somado ao valor original do alelo.

- A Figura 3.9 apresenta graficamente como o algoritmo de mutação indutiva opera sobre um indivíduo em particular. Conforme é possível observar na Figura 3.9, foi sorteado um valor entre zero e onze, sendo este o valor, hipoteticamente, igual a dez, correspondendo ao gene dez do vetor de atributos, de um determinado indivíduo, com alelo de valor " 100 ”. Um novo valor foi sorteado, porém agora sem restrição de semente, em sua geração. O valor sorteado foi, também hipoteticamente, igual a " 56 ", e somado ao alelo original, resultando em um novo valor para o alelo.

\begin{tabular}{|c|c|c|c|c|c|c|c|c|c|c|c|c|}
\hline Genes & 0 & 1 & 2 & 3 & 4 & 5 & 6 & 7 & 8 & 9 & 10 & 11 \\
\hline Indivíduo original & 5 & 50 & 8 & 9 & 56654 & 46 & 65 & 49 & 56 & 58 & 100 & 23 \\
\hline Novo Indivíduc & 5 & 50 & 8 & 9 & 56654 & 46 & 65 & 49 & 56 & 58 & 156 & 23 \\
\hline
\end{tabular}

Valor sorteado para soma: 56

Figura 3.9 - Exemplo de mutação indutiva em um indivíduo de codificação em ponto flutuante.

A mutação gaussiana consiste em um método de inserção de diversidade na população, adotado em indivíduos com codificação em ponto flutuante de sua estrutura. 
A codificação gaussiana é definida a partir da aplicação da expressão (3.1) em todos os alelos, correspondentes aos valores dos genes, de indivíduos selecionados.

$$
x^{\prime}=x+N(0, \delta)
$$

onde $N(0, \delta)$ represente o vetor de variáveis gaussianas independentes, sorteadas aleatoriamente, com média zero e desvio padrão $d$.

\subsubsection{Métodos de Seleção}

A seleção de indivíduos que serão adicionados na próxima geração e em quais indivíduos serão aplicados os operadores genéticos será determinado pelo método de seleção escolhido. Na literatura, podem ser encontrados diversos métodos de seleção. Alguns dos métodos, mais habitualmente adotados, serão explanados nesta seção.

O método de seleção Roulette Wheel, ou também conhecido como método de seleção da roleta, possui um algoritmo similar ao funcionamento de uma roleta, onde a roleta completa representa todos os indivíduos e sua representatividade na população.

À cada indivíduo da população será atribuído um valor, o qual determina a sua representatividade na população, determinada por meio de uma função objetivo, a qual determina o seu fitness (a ser detalhado posteriormente).

Quanto melhor adaptada for a solução para o problema tratado, maior será a sua representatividade na população e, desta forma, maior será a sua "fatia" na roleta. Podemos concluir que, se o objetivo da roleta é proporcionar aos indivíduos melhores adaptados ao meio ambiente a maior probabilidade de serem sorteados na roleta, neste caso, quanto maior o valor obtido por intermédio da função objetivo, maior será a representatividade do indivíduo na roleta e maiores serão as suas probabilidades de serem sorteados. 
A probabilidade de ser sorteado, atribuída a cada indivíduo da população, é proporcional ao fitness obtido por meio da função objetivo, em relação à somatória do fitness de todos os indivíduos da população.

O algoritmo que determina o método de seleção aqui descrito pode ser obtido por intermédio dos seguintes passos:

- Cada indivíduo deve ser avaliado, por meio da função objetivo determinada;

- Todos os valores de fitness, obtidos por todos os indivíduos da população devem ser somados;

- O valor total obtido mediante a somatória, realizada no passo anterior, deve ser atribuído como $100 \%$, e então calculado o valor representativo da porcentagem de cada um dos indivíduos da população, em relação à população em sua totalidade;

- Depois de calculado os valores percentuais, referente à representatividade de cada indivíduo na população, então serão distribuídos na roleta uma fatia para cada indivíduo, a qual corresponde ao percentual do indivíduo na população;

- O processo de organização da roleta foi então finalizado, bastando-se apenas sortear os números, os quais representarão quais os indivíduos serão selecionados.

Dada uma população hipotética, contendo dez indivíduos, cada um previamente avaliado, conforme relacionados na Tabela 3.1, será possível aplicar o método de seleção da roleta, conforme apresentado na Figura 3.10. 
Tabela 3.1 - Exemplo de população de indivíduos previamente avaliados e nos quais a porcentagem correspondente à sua representatividade na população é também calculada.

\begin{tabular}{|c|c|c|}
\hline Indivíduo & Fitness & Porcentagem \\
\hline 1 & 10 & $9 \%$ \\
\hline 2 & 15 & $14 \%$ \\
\hline 3 & 2 & $2 \%$ \\
\hline 4 & 8 & $7 \%$ \\
\hline 5 & 9 & $8 \%$ \\
\hline 6 & 18 & $17 \%$ \\
\hline 7 & 6 & $6 \%$ \\
\hline 8 & 20 & $19 \%$ \\
\hline 9 & 17 & $16 \%$ \\
\hline 10 & 2 & $2 \%$ \\
\hline Total & 107 & $100 \%$ \\
\hline
\end{tabular}

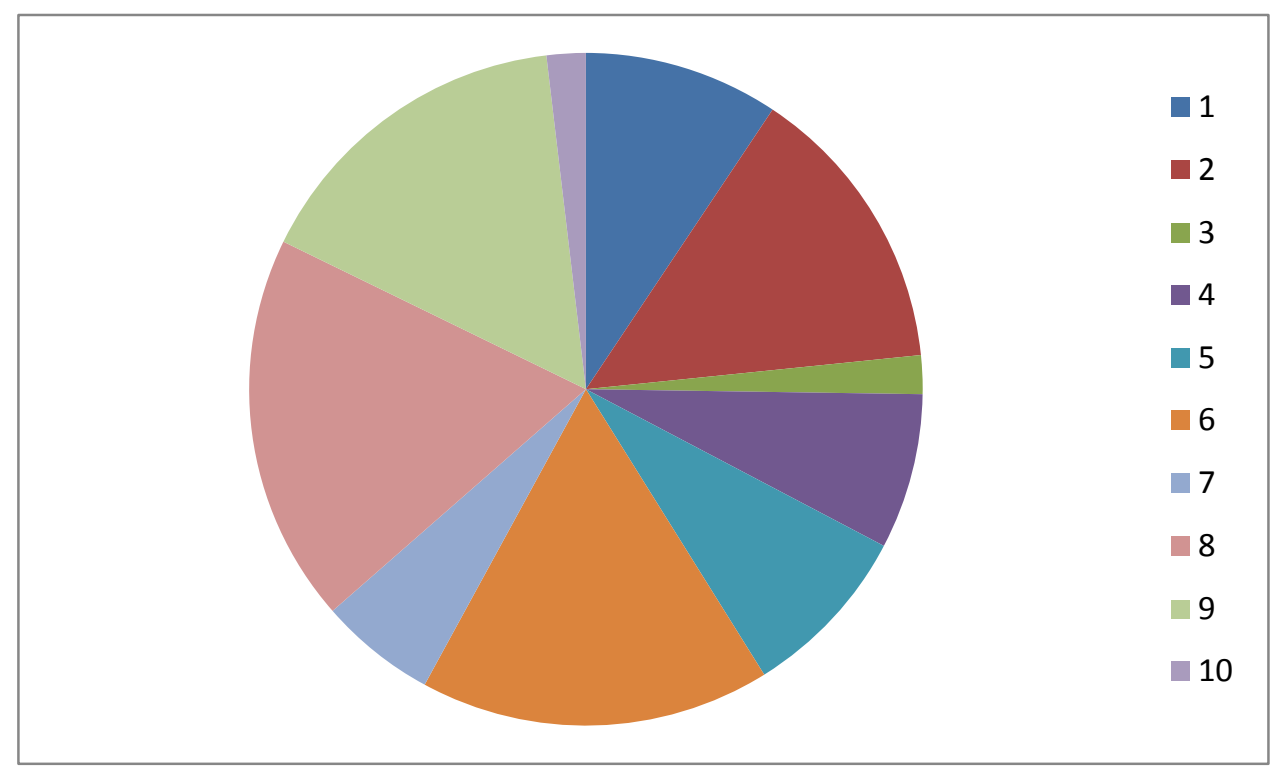

Figura 3.10 - Roleta representando a população apresentada na Tabela 3.1.

O exemplo, apresentado nas Tabelas 3.1 e Figura 3.10, demonstra a representatividade de cada indivíduo de uma população. Para finalizar o algoritmo de seleção, são então sorteados valores maiores que zero e menores que cem, correspondendo às fatias da roleta, e consequentemente ao individuo a ser selecionado.

Tal algoritmo apresenta a desvantagem de não garantir que o melhor indivíduo da população seja selecionado, ainda que a sua probabilidade de ser selecionado seja superior em relação dos demais indivíduos. 
O método de seleção por Rank é também amplamente adotado, devido à garantia de que os melhores indivíduos sempre sejam selecionados.

Neste método, todos os indivíduos são ordenados de acordo com valores obtidos por intermédio da função objetivo. Após a ordenação da população, serão selecionados os $N$ indivíduos, e os demais serão descartados.

O algoritmo de seleção por rank garante que os melhores indivíduos obtidos estarão presentes na próxima geração, ou ainda, que neles sejam aplicados os operadores genéticos.

A técnica de seleção de indivíduos puramente aleatória é uma metodologia na qual consiste em atribuir um identificador numérico a cada indivíduo e, posteriormente, sortear valores que podem variar até a quantidade de indivíduos da população.

O método de seleção aleatória pode ser dividido entre Seleção Aleatória Salvacionista, ou ainda, Seleção Aleatória Não-Salvacionista. A seleção aleatória salvacionista corresponde ao método que, inicialmente, seleciona o melhor indivíduo da população e, posteriormente, aplica o sorteio dos demais indivíduos. Já a seleção aleatória não-salvacionista é puramente aleatória, não garantindo que o melhor indivíduo seja escolhido, o que implica, em grande parte das vezes, se perder o melhor indivíduo obtido durante o processo evolutivo.

\subsubsection{Função Objetivo}

A função objetivo é um importante parâmetro do algoritmo genético, pois determina o quanto cada indivíduo de uma população está adaptado ao meio ambiente. Em outras palavras, a função objetivo retorna um valor determinante, correspondente à representatividade do indivíduo na população. O valor obtido a partir da função objetivo é chamado de fitness.

Cada possível solução para o problema é avaliada durante o processo evolutivo, e como resultado da avaliação, o fitness de cada indivíduo é atualizado com objetivo de atingir um valor de fitness ótimo, concluindo-se que a solução esperada foi obtida. 
A Figura 3.1 demonstrou o algoritmo genético genérico, o qual pode ser adotado em diversos problemas de otimização combinatória. O passo descrito na Figura 3.11, a seguir, define a avaliação da população, em um algoritmo genético.

Avalie a

População

(Geração)

Figura 3.11 - Avaliação da população no AG.

\subsubsection{Condição de Parada do Algoritmo Genético}

A condição de parada do algoritmo genético corresponde ao parâmetro no qual é determinada a finalização da execução do algoritmo desenvolvido.

Existem duas abordagens de condição de parada encontradas na literatura relacionada, as quais são comumente adotadas, diferenciando-se de acordo com o conhecimento prévio da solução esperada.

Um tipo de condição de parada amplamente utilizado, quando não é possível obter conhecimento prévio da solução desejada, é definido a partir da quantidade de execuções do algoritmo desenvolvido. Ao adotar esta metodologia, a quantidade de gerações é pré-definida e ao atingir este valor, o algoritmo é finalizado. A solução obtida na última execução do sistema passa a ser a solução final para o problema tratado.

Quando é conhecida a solução desejada para o problema tratado, então é definida como condição de parada do algoritmo, somente quando for obtida a solução esperada.

A Figura 3.1 demonstrou o algoritmo genético genérico, o qual pode ser adotado em diversos problemas de otimização combinatória. Os passos descritos na Figura 3.12, a seguir, definem a condição de parada em um algoritmo genético. 


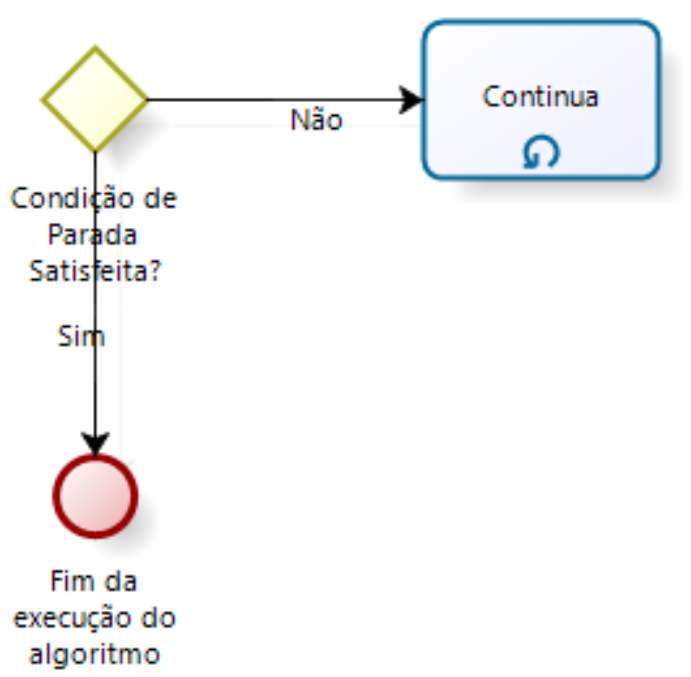

Figura 3.12 - Condição de parada no AG.

\subsection{Considerações Parciais}

No presente capítulo foram explanados consideráveis conceitos relacionados à Computação Evolutiva, enfatizando-se os Algoritmos Genéticos, adotados nesta investigação, com o objeto de otimização para o problema de geração automática de grades horárias e, também adotados na análise comparativa dos resultados obtidos a partir da abordagem de otimização das grades horárias mediante aos Sistemas Imunológicos Artificiais.

Também no presente capítulo, foram aqui introduzidos os conceitos relacionados à Biologia natural e sua relação com a Computação Evolutiva, de forma que seja possível obter o entendimento das estruturas básicas de um algoritmo evolutivo e a sua analogia aos sistemas naturais.

Finalmente, foram expostos os principais parâmetros de um algoritmo genético, tais como operadores genéticos, métodos de seleção, entre outros, e as possíveis variações. 


\section{Sistemas Imunológicos Artificiais}

\subsection{Introdução}

Os sistemas imunológicos artificiais pertencem também à área de pesquisa inspirada nos sistemas naturais, denominada sistemas biologicamente inspirados. Os sistemas bio-inspirados possuem o propósito de modelar computacionalmente os mecanismos encontrados na natureza. Os sistemas imunológicos artificiais pertencem à classe de algoritmos bio-inspirados a partir do sistema imunológico natural.

Os sistemas imunológicos artificiais são responsáveis pela manipulação de dados, classificação e representação, que seguem um paradigma biológico plausível: o sistema imunológico humano.

Os sistemas imunológicos artificiais pertencem a um conjunto de metodologias inspiradas no sistema imunológico natural e aplicados na solução de problemas de otimização, devido a serem sistemas adaptativos, inspirados por imunologia teórica, dadas as funções imunológicas, princípios e modelos.

O sistema imunológico natural é responsável por proteger os organismos animais de agentes patogênicos. Durante todo o período de vida de um indivíduo, o seu sistema imunológico será constantemente adaptado, tendo-se a finalidade de reconhecer os agentes nocivos e apresentar uma eficiente resposta ao ser atacado pelo mesmo agente patogênico. Como resultado do processo de adaptação será então desenvolvida a memória imune do indivíduo, a qual forma o sistema de defesa imune. A capacidade do sistema imunológico adquirido de se adaptar, quando exposto pela primeira vez a um antígeno, e de criar anticorpos específicos para gerar uma resposta imune, fornece a base para a teoria da seleção clonal. 
O algoritmo de seleção CLONALG (Clonal Selection Algorithm), proposto por He et al. (2005), se fundamentou a partir do princípio da seleção clonal. O CLONALG possui as etapas de inicialização da população, processo de expansão clonal, variação da população, as quais serão detalhadas na próxima seção.

\subsection{Base Biológica}

O sistema imunológico natural possui um importante papel na sobrevivência de organismos animais. O sistema imunológico possui diversos mecanismos, os quais devem atuar em conjunto, fornecendo uma resposta eficiente.

A existência de mecanismos de aprendizagem é fundamental em sistemas imunológicos, tanto nos naturais quanto nos artificiais, devido à necessidade de se extrair informações dos agentes patogênicos e armazenar, com objetivo de agir eficientemente em novos ataques pelos mesmos agentes, ou ainda, por agentes similares.

O sistema imune adaptativo é composto por células, os linfócitos, as quais possuem meios de defesa com maior nível de proteção, quando comparado ao sistema imune inato. As células que compõem o sistema imune inato desempenham um importante papel no tratamento das respostas imunes adaptativas.

Cada linfócito é portador de receptores de antígeno com uma única especificidade. Cada organismo possui milhões de linfócitos, os quais apresentam milhões de especificidades distintas. Os linfócitos sofrem um processo similar ao processo de seleção natural durante a vida do indivíduo, pois somente aqueles linfócitos que encontrarem um antígeno com o qual seu receptor pode interagir serão ativados para proliferar e se diferenciar em células efetoras (Castro, 2001). 


\subsubsection{O Princípio da Seleção Clonal}

O princípio da seleção clonal estabelece que apenas uma célula será capaz de reconhecer um determinado estímulo antigênico, e esta irá se proliferar. Desta forma, é possível afirmar que tal célula será selecionada em detrimento das demais.

As principais características do princípio da seleção clonal, conforme encontrado em Castro (2001), podem ser resumidas conforme descrito a seguir:

- Novos linfócitos devem ser eliminados, caso sejam capazes de reagir aos padrões antigênicos expressos por elementos do próprio organismo;

- Devem ser ativados os linfócitos quando ocorrer a interação de uma molécula estranha com um receptor de linfócito, caso este seja capaz de se ligar a tal molécula;

- Ocorre a retenção de um determinado padrão por cada célula do organismo e retenção deste padrão pelos descendentes clonais;

- São geradas variações genéticas aleatórias, por meio do mecanismo de hipermutação somática.

\subsubsection{Aprendizagem por Reforço}

O conjunto de recursos possibilita a resposta imune e efetiva contra os agentes patogênicos (Castro, 2001).

O tamanho da subpopulação de linfócitos é um dos recursos revelantes do sistema imune, pois ele representa o tamanho do clone específico para o antígeno, em relação ao tamanho da população de antígenos.

O processo de aprendizagem envolve a alteração no tamanho da população, devido ao aumento de linfócitos e da sua afinidade quando ocorre o reconhecimento de determinados antígenos. O aumento no tamanho de alguns clones específicos resulta na redução do tamanho de outros clones, porém, conforme descrito anteriormente, o número total de linfócitos não permanece constante. 
Durante o processo de evolução do sistema imune, um organismo é exposto a determinados antígenos por diversas vezes. A função do sistema imune adaptativo, quando exposto pela primeira vez a um determinado antígeno, está em gerar-se um conjunto de clones de células, cada um produzindo anticorpos de diferentes afinidades.

O sistema imune é aperfeiçoado durante toda a vida do organismo, devido às células de memória, sendo aquelas responsáveis pela produção de anticorpos com alta afinidade aos antígenos, aos quais foram expostos anteriormente. Tal estratégia assegura eficácia e aperfeiçoamento da resposta imune de organismos após cada exposição a agentes patogênicos (Perelson et al., 1978; Farmer et al., 1986).

Os mecanismos necessários para a aprendizagem são os seguintes, conforme descritos em (Ahmed e Sprent, 1999; Janeway et al., 2000):

- Expor repetitivamente ao estímulo antigênico;

- Aumentar o tamanho da subpopulação, contendo clones específicos;

- Expor ao processo de maturação de afinidade.

Os autores descrevem também os mecanismos necessários para se obter a memória imune, ou seja:

- Os linfócitos devem possuir períodos prolongados de vida, persistindo em estado de repouso até que sejam expostos novamente por um mesmo antígeno;

- Exposição repetida ao antígeno;

- Reatividade cruzada, ou seja, capacidade de generalização em populações evoluídas.

\subsection{Conceitos Relacionados aos Sistemas Imunológicos Artificiais}

Aplicar um conjunto de princípios que simulam o comportamento de sistemas biológicos naturais leva ao desenvolvimento de novas formas de simulação computacional (Wolfram, 1986). A natureza fornece diversos exemplos de sistemas compostos por elementos simples, nos quais uma interação cooperativa e competitiva de elementos resulta num comportamento 
global complexo, i.e., colônias de insetos, o sistema imunológico natural, o sistema nervoso central, entre outros.

Uma importante característica dos sistemas bio-inspirados se encontra na robustez, a qual é expressa sob a forma de uma tolerância às pequenas perturbações encontradas individualmente. Tal robustez engloba o princípio da distributividade, em que componentes individuais contribuem para o desempenho global do sistema.

O princípio extraído dos sistemas naturais vem sendo utilizado com sucesso no desenvolvimento de ferramentas computacionais, as quais são capazes de resolver problemas de alta complexidade, cujas soluções eram, até então, desconhecidas ou intratáveis.

A seguir, serão apresentados alguns dos conceitos relacionados aos sistemas imunes artificiais, mais comumente encontrados na literatura:

- Os sistemas imunológicos artificiais são metodologias de manipulação de dados, classificação, representação e raciocínio que seguem um paradigma biológico plausível: o sistema imunológico humano (WWW Starlab);

- Um sistema imunológico artificial é um sistema computacional baseado em metáforas do sistema imunológico natural (Timmis, 2000);

- Os sistemas imunológicos artificiais são compostos por metodologias inteligentes, inspiradas no sistema imunológico biológico, para a solução de problemas de mundo real (Dasgupta, 1998);

- A engenharia imunológica é um processo de meta-síntese, o qual vai definir a ferramenta de solução de um determinado problema baseado nas características do próprio problema, e depois aplicá-la na obtenção da solução. Ao invés de buscar a reconstrução parcial ou total do sistema imunológico tão fielmente quanto possível, a engenharia imunológica deve procurar desenvolver e implementar modelos pragmáticos inspirados no sistema imunológico que preservem algumas de suas propriedades essenciais e que se mostrem 
passíveis de implementação computacional e eficazes no desenvolvimento de ferramentas de engenharia (Castro, 2001).

\subsubsection{Analogia entre os Sistemas Imunológicos Biológicos e os Sistemas Computacionais}

Na presente subseção será realizada uma analogia entre os sistemas imunológicos naturais e os sistemas computacionais, conforme encontrado na literatura relacionada (Castro et al., 2007):

- Na biologia e nas instituições, os sistemas trabalham, normalmente, em conformidade e, de maneira integrada e colaborativa;

- Respostas imunológicas naturais são únicas para cada indivíduo, tais como as decisões que os indivíduos tomam em instituições. Alguns fatores são decisivos, tais como o ambiente em que os indivíduos vivem e o mercado em que as instituições pertencem;

- Agentes patogênicos (fungos, vírus, bactérias e parasitas) inicializam ações imunológicas, assim como as informações iniciam o processo de tomada de decisão a ser tomada sistemicamente;

- Os linfócitos, responsáveis pela produção e diluição de anticorpos dos organismos naturais; os macrófagos, os quais intervêm na defesa de organismos em sistemas naturais, através da destruição de microrganismos maléficos e apresentação dos antígenos; e os leucócitos, que realizam a fabricação de anticorpos, na biologia, atuam como possíveis ações a serem tomadas através dos sistemas de apoio à decisão;

- A fagocitose, processo natural responsável pela absorção de microrganismos, correspondente aos processos de conhecimento, análise e decomposição de informações existentes nos sistemas computacionais; 
- O sistema imunológico natural atua eficientemente no combate de agentes patogênicos, evitando possíveis danos aos organismos afetados, da mesma forma em que as soluções apropriadas, resultantes dos sistemas computacionais, são benéficas às instituições;

- As ações desempenhadas pelo sistema imunológico inato sobre a fagocitose possuem correlação com resultados específicos para problemas computacionais estruturados;

- As detecções de agentes nocivos, em organismos, podem ocorrer paralelamente, sem que exista um mecanismo de controle central, da mesma forma em que simples decisões podem ser detectadas, analisadas e realizadas em instituições;

- As detecções baseadas em afinidade são realizadas pelo sistema imunológico natural, baseando-se em certo número de padrões, quando este número é maior que um limiar já determinado. Em sistemas computacionais, a correspondência com as detecções baseadas em afinidade estão relacionadas à tomada de decisão através do aprendizado adquirido durante as iterações anteriores de tal software;

- A geração de diversidade de receptores de linfócitos pode ser equivalente aos diversos pontos existentes no espaço de busca do problema tratado nos sistemas artificiais;

- O sistema imunológico natural possui a capacidade de reconhecer agentes patogênicos que já atacaram determinado organismo e responder eficientemente. Da mesma forma atuam os sistemas artificiais, que possuem capacidade de aprender durante a execução do software e também de utilizarem algum conhecimento prévio, relevante para a determinação da solução para o problema em questão;

- O desempenho da resposta imune em sistemas naturais está ligado ao conjunto de processos integrados, da mesma forma em que ocorrem em sistemas artificiais. 


\subsubsection{Escopo de Aplicação dos Sistemas Imunológicos Artificiais}

Os sistemas imunológicos artificiais são aplicados com sucesso em diversos tipos de problemas. Podem ser encontrados, na literatura relacionada, sistemas imunológicos artificiais aplicados em problemas dos seguintes tipos:

- Reconhecimento e classificação de padrões;

- Detecção de anomalias e falhas;

- Análise de dados, sejam eles agrupamento, quantização ou compactação de informações;

- Sistemas baseados em agentes;

- Busca e otimização, em ambientes contínuos e discretos;

- Aprendizado de máquina;

- Controle autônomo;

- Vida artificial e sistemas complexos;

- Segurança computacional;

- Fluxo de dados;

- Homeostase, que são sistemas compostos pelo sistema nervoso combinado ao sistema endócrino e sistema imunológico.

\subsubsection{Vantagens Encontradas nos Sistemas Imunológicos Artificiais}

A primeira vantagem encontrada nos Sistemas Imunológicos Artificiais está na inerente capacidade do algoritmo em se manter a diversidade da população. Isto ocorre devido ao passo de que em todas as gerações os piores indivíduos são excluídos e novos indivíduos são adicionados, garantindo, desta forma, realizar uma busca global pelo espaço de solução do problema tratado.

Através do uso dos SIA, é possível atribuir o parâmetro de tamanho de população não fixo a cada geração, conforme encontrado em outros algoritmos evolutivos. Tal algoritmo possui a 
possibilidade de definir automaticamente o tamanho da população a cada geração, de acordo com a demanda da aplicação em questão.

A grande vantagem encontrada nos SIA está na garantia de se preservar soluções ótimas locais, localizadas durante a execução do algoritmo.

\subsubsection{Descrição do Algoritmo dos Sistemas Imunológicos Artificiais}

Na presente seção, explanar-se-ão os passos necessários para se obter a síntese dos algoritmos imuno-inspirados, segundo a base teórica encontrada na literatura relacionada.

Segundo Dasgupta (2006), os passos necessários para obtenção da síntese de um algoritmo imuno-inspirado devem basear-se em:

- Definição do problema a ser tratado;

- Mapeamento do problema e conversão de um problema do mundo real para o domínio dos sistemas imunológicos artificiais.

Com o objetivo de obtenção da transformação do problema do mundo real para o domínio dos SIA, é então necessário realizar alguns procedimentos, conforme explanado a seguir:

- Devem ser definidos os tipos de células e moléculas imunes a serem adotadas no algoritmo;

- Deve ser definido o princípio imune, o qual será adotado na solução do problema em questão;

- Deve ser definida a representação matemática dos elementos adotados no sistema imunológico a ser desenvolvido;

- Devem ser avaliadas as iterações existentes entre os elementos dinâmicos adotados no SIA.

Após se obter a solução esperada no sistema imunológico artificial desenvolvido, a finalização do algoritmo é alcançada a partir do mapeamento reverso, o qual permite que a solução do SIA seja convertida em uma solução para o problema do mundo real. 
A Figura 4.1 possui a representação gráfica e sugestiva do algoritmo descrito nesta seção, o qual descreve os passos para se obter a síntese de um algoritmo imuno-inspirado.

O algoritmo imune definido na Figura 4.1 possui no primeiro passo a definição no domínio da aplicação do problema tratado, no qual um problema do mundo real é transformado para o domínio dos SIA; a definição das entidades imunes, tais como a representação dos anticorpos, a função objetivo, a condição de parada do sistema, entre outros. O próximo passo se encontra na definição matemática do problema tratado, de forma que os elementos definidos no SIA são representados matematicamente e podem ser manipulados durante a execução do algoritmo. O passo final do algoritmo apresentado na Figura 4.1 é mensurar a afinidade de cada anticorpo gerado, ou seja, verificar qual a solução mais adaptada ao problema tratado.

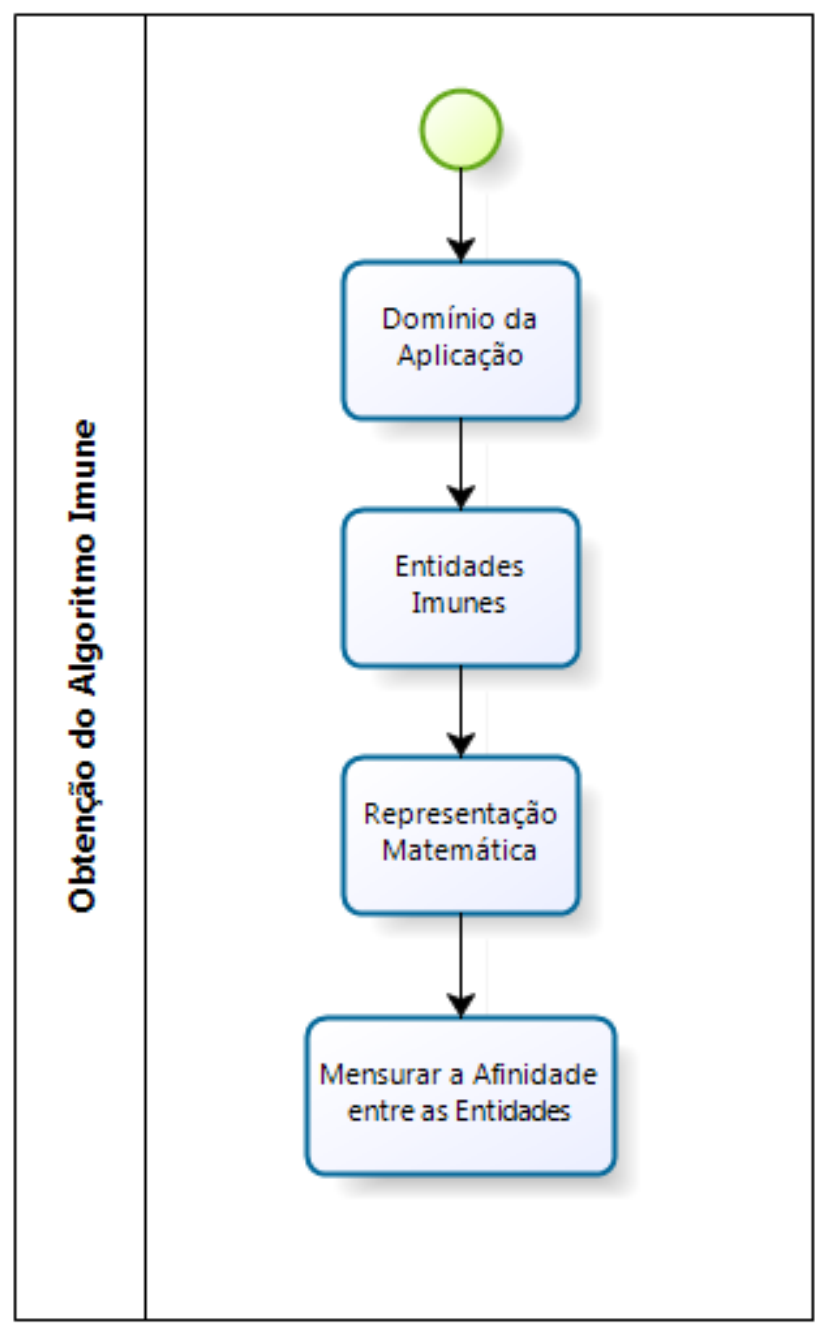

Figura 4.1 - Fluxograma do algoritmo imuno-inspirado. 
A taxonomia encontrada na literatura relacionada aos algoritmos imuno-inspirados pode ser descrita a partir das subdivisões apresentadas na Figura 4.2. Modelos imuno-inspirados são algoritmos genéricos, baseados em princípios específicos e modelos teóricos, podendo ser encontrados como os seguintes tipos principais:

- Algoritmo da Medula Óssea;

- Algoritmo de Timo;

- Algoritmo de Seleção Clonal - CLONALG;

- Algoritmo da Teoria da Rede;

- Algoritmo da Teoria do Perigo.

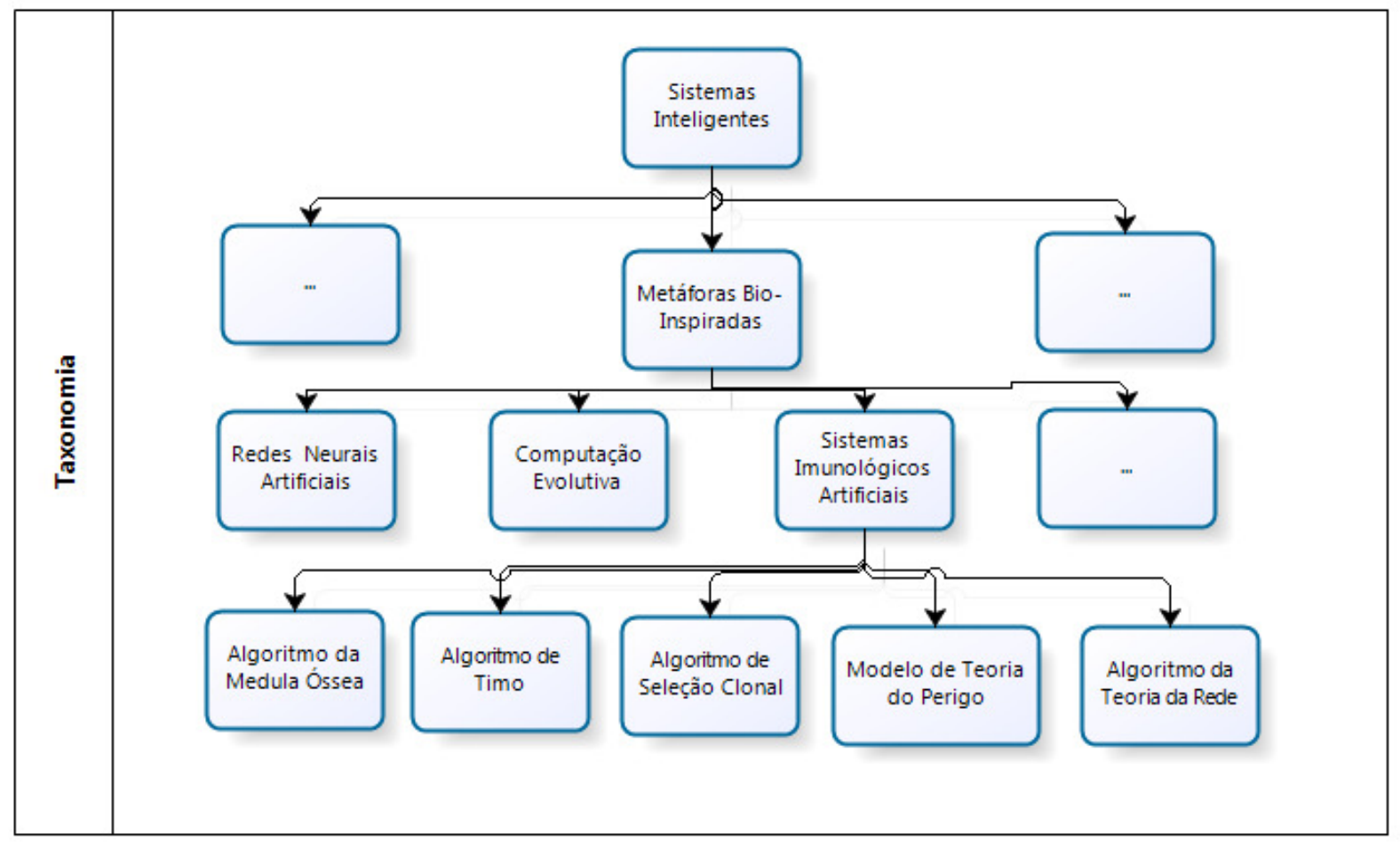

Figura 4.2 - Taxonomia dos algoritmos imune-inspirados.

A Figura 4.2 demonstra a hierarquia existente entre os diversos algoritmos baseados em sistemas inteligentes encontrados na literatura relacionada, alguns exemplos de tais algoritmos, quando aplicados em problemas de otimização foram apresentados em Ozcan et al. (2012); Naseem e Yang (2011); Nothegger et al. (2012); Burke et al. (2012); Turabieh e Abdullah 
(2011); Sabar et al. (2012); Pais e Amaral (2012); Tassopoulos e Beligiannis (2012) e Sabar et al. (2012).

Nesta investigação, foi adotado o Algoritmo de Seleção Clonal, com objetivo de se obter a otimização de grades horárias. Desta forma será detalhada a seguir a teoria de tal algoritmo, para que seja possível obter o entendimento do algoritmo desenvolvido neste estudo, o qual será apresentado no próximo capítulo.

\subsubsection{Algoritmo de Seleção Clonal - CLONALG}

O algoritmo de seleção clonal tem sido adotado com sucesso em problemas de aprendizagem de máquina, reconhecimento de padrões, além da otimização multimodal e combinatória, sendo esta a principal motivação para adoção de tal algoritmo nesta investigação.

O CLONALG pode ser definido pelo desenvolvimento computacional do algoritmo de seleção clonal e também da maturação por afinidade. Podem ser destacadas as características de geração de variações genéticas deste algoritmo, por meio do processo de hipermutação e de proliferação e diferenciação celular, após o reconhecimento antigênico, seguindo o princípio da seleção clonal encontrado nos sistemas naturais.

O algoritmo de seleção clonal pode ser implementado computacionalmente, seguindo um algoritmo genérico, conforme explanado a seguir:

- Geração aleatória da população inicial de anticorpos. Cada anticorpo da população representa uma solução que atende completamente o problema tratado;

- Avaliação da população por meio da função objetivo, a qual determina a afinidade de cada anticorpo;

- Por meio do processo de seleção por afinidade, os $N$ melhores anticorpos da população serão escolhidos e submetidos à expansão clonal. O processo de expansão clonal consiste na clonagem dos anticorpos escolhidos e maturação dos clones, tendo-se aqui o propósito de aperfeiçoar tais soluções; 
- Cada novo anticorpo gerado (a partir da expansão clonal) será avaliado e sua afinidade será confrontada com a afinidade do anticorpo original. Aquele com maior representatividade será inserido na nova população;

- Por fim, será inserida a diversidade na população, com o objetivo de evitar a convergência prematura do algoritmo: os $W$ piores anticorpos serão substituídos por $W$ novos anticorpos;

- Os processos de avaliação, seleção clonal, expansão clonal e inserção de diversidade genética serão repetidos até que seja satisfeito o critério de parada previamente definido.

O algoritmo descrito torna possível realizar a busca local mediante a maturação dos clones, assim como a busca global, por meio da inserção de diversidade na população.

Segundo Castro e Zuben (2000), a solução para o problema tratado é obtida a partir de soluções adaptadas durante todo o processo evolutivo do CLONALG, inerente à memória imune natural, a qual é aperfeiçoada durante toda a vida de um indivíduo.

\subsubsection{Hipermutação Somática}

A hipermutação somática consiste em um recurso utilizado pelo sistema imunológico, no qual é inserida a diversidade dos linfócitos e a melhoria da afinidade dos anticorpos, quando aplicados estímulos aos mesmos (Castro, 2001).

\subsection{Considerações Parciais}

No presente capítulo foram explanados consideráveis conceitos relacionados à Computação Imuno-Inspirada, enfatizando-se o Algoritmo de Seleção Clonal, adotado nesta investigação, com o objeto de otimização para o problema de geração automática de grades horárias e, também, adotados na análise comparativa dos resultados obtidos a partir da abordagem de otimização das grades horárias por meio dos Algoritmos Genéticos. 
Também no presente capítulo, foram introduzidos os conceitos relacionados à imunologia natural e aos sistemas imunológicos artificiais, de forma que seja possível obter o entendimento das estruturas básicas de um algoritmo imuno-inspirado e a sua analogia aos sistemas naturais.

Finalmente, foram expostos os passos para se obter um algoritmo genérico, descrito a partir dos conceitos inspirados na teoria da seleção clonal. 


\section{Otimização de Grades Horárias Baseada em Sistemas Inteligentes}

\subsection{Introdução}

Segundo Yue et al. (2009), o problema de otimização de grades horárias é considerado um problema do tipo NP-Completo, devido à complexidade matemática encontrada. Desta forma, devem ser aplicados métodos de busca estocástica e não determinísticos.

O propósito desta investigação é solucionar o problema de geração de grades horárias em instituições de ensino superior, utilizando-se métodos de busca baseados nos algoritmos genéticos e algoritmo de seleção clonal, devido aos resultados satisfatórios já encontrados na literatura relacionada, conforme encontrado em Ozcan et al. (2012); Naseem e Yang (2011); Nothegger et al. (2012); Burke et al. (2012); Turabieh e Abdullah (2011); Sabar et al. (2012); Pais e Amaral (2012); Tassopoulos e Beligiannis (2012) e Sabar et al. (2012), quando aplicados em problemas de otimização.

Tal problema possui características e restrições que podem variar de acordo com a instituição de ensino, cuja implementação é destinada. Foram também adotadas aqui as restrições de alto grau, ou seja, se alguma destas restrições for violada, o resultado gerado será inválido.

Os algoritmos desenvolvidos, Algoritmos Genéticos (AG) e Sistemas Imunológicos Artificiais (SIA), possuem estruturas de dados e algumas funções computacionais similares, as quais serão apresentadas a seguir.

\subsection{Representação das Soluções Candidatas do Algoritmo Genético}

Na presente investigação, a codificação de cada cromossomo, ou indivíduo, representa uma grade de horários completa, contendo todas as disciplinas do curso com suas informações, organizadas de acordo com o semestre que pertencem. A codificação dos genes é composta por 
uma cadeia finita de elementos, os quais são representados por uma estrutura de dados contendo as seguintes informações:

- Código da disciplina;

- Semestre em que pertence a disciplina;

- Nome da disciplina;

- Professor que ministra a disciplina;

- Carga horária da disciplina;

- Um horário na grade, o qual representa o dia da semana e a hora que será alocada a disciplina.

As grades horárias aqui desenvolvidas se baseiam em um curso real de Engenharia Elétrica, no qual possui nove semestres, contendo oitenta disciplinas.

O problema de geração de grades horárias possui regras de negócios, as quais foram armazenadas e manipuladas por meio de functions, stored procedures e triggers desenvolvidas em um banco de dados SQL Server 2008. A arquitetura do banco de dados do AG, responsável pela otimização de grades horárias, está representada na Figura 5.1. 


\begin{tabular}{|l|l|}
\hline tb_Disponibilidade & \\
\hline PKNI_IdDisponibilidade: INTEGER \\
tb_Professores_tb_DisciplinasCargaHoraria_P... (FK) \\
tb_Professores_PKNI_IdProfessor: INTEGER (FK) \\
\hline FKNI_IdProfessor: INTEGER \\
$\diamond$ FKNI_IdHorarioGrade: INTTEGER \\
\hline tb_Disponibilidade_FKIndex1 \\
tb_Professores_PKNI_IdProfessor \\
tb_Professores_tb_DisciplinasCargatHoraria_PKNI_I:
\end{tabular}

tb_IdHorarioGrade

PKNI_IdHorarioGrade: INTEGER

i tb_Disponibilidade_PKNI_IdDisponibilidade: ... (FK)

tb_DisciplinasCargaHoraria_PKNI_IdDisciplin... (FK)

tb_Disciplinas_tb_Professores_PKNI_IdProfes... (FK)

tb_Disciplinas_tb_Professores_tb_Disciplina... (FK)

tb_Disciplinas_PKNI_IdDisciplina: INTEGER (FK)

tb_Disponibilidade_tb_Professores_PKNI_IdPr... (FK)

tb_Disponibilidade_tb_Professores_tb_Discip... (FK)

$\diamond$ ATDT_DataInicio: DATETIME

$\checkmark$ ATDT_DataFim: DATETIME

$\checkmark$ ATVS_DiaSemana: VARCHAR

tb_IdHorarioGrade_FKIndex1

i tb_Disponibilidade_PKNI_IdDisponibilidade

tb_Disponibilidade_tb_Professores_tb_DisciplinasCa

tb_Disponibilidade tb_Professores_PKNI_IdProfess

a tb_IdHorarioGrade_FKIndex2

tb_DisciplinasCargaHoraria_PKNI_IdDisciplinasCargat

atb_IdHorariograde_FKIndex3

tb_Disciplinas_PKNI_IdDisciplina

tb_Disciplinas_tb_Professores_tb_DisciplinasCarga H

tb_Disciplinas_tb_Professores_PKNI_IdProfessor

b__Fitness
PKNI_IdFitness: INTEGER
$\triangle$ ATNI_IdIndividuo: INTEGER
$\triangle$ ATNI_IdFitnessValue: INTEGER

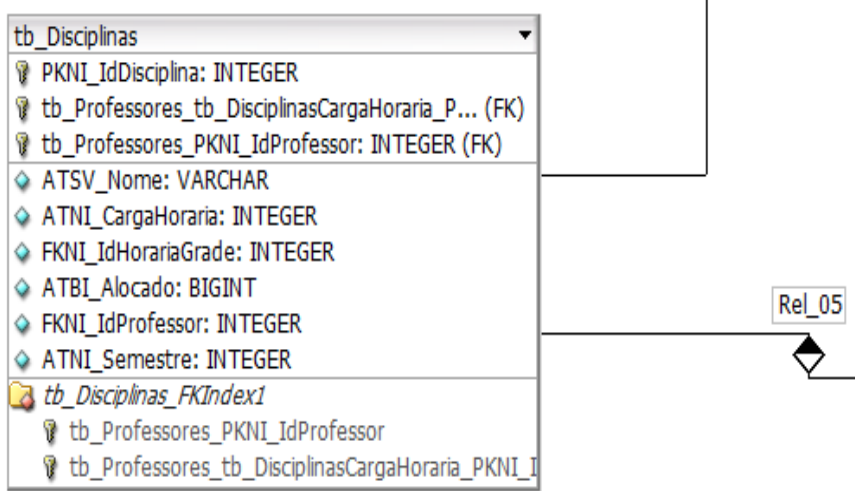

Rel_02

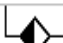

tb_DisciplinasCargaHoraria

PKNI_IdDisciplinasCargaHoraria: INTEGER

$\checkmark$ ATSV_None: VARCHAR

$\triangle$ FKN_IdHorarioGrade: INTEGER

$\checkmark$ ATBI_Alocado: BIGINT

$\triangle$ FKNI_Id_Professor: INTEGER

$\checkmark$ ATNI_Semestre: INTEGER

$\checkmark$ ATNI_Populacao: INTEGER

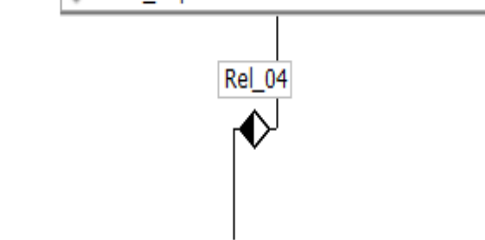

tb_Professores

PKNI_IdProfessor: INTEGER

tb_DisciplinasCargaHoraria_PKNI_IdDisciplin... (FK) $\checkmark$ ATSV_Nome: VARCHAR

tb_Professores_FKIndex1

i tb_DisciplinasCargaHoraria_PKNI_IdDisciplinasCar

Figura 5.1 - Modelo relacional do banco de dados do algoritmo desenvolvido utilizando-se algoritmo genético. 
O sistema desenvolvido é genérico e, desta forma, pode ser aplicado na geração de grades horárias de qualquer curso. O usuário deve, primeiramente, cadastrar as informações necessárias, conforme descrito a seguir:

- Cursos da universidade;

- Horários de aula de cada dia da semana e período (diurno, vespertino ou noturno);

- Disciplinas do curso;

- Professores;

- Disponibilidade de cada professor em cada horário de aula.

\subsection{Inicialização da População no Algoritmo Genético}

A geração da população inicial, no algoritmo genético desenvolvido, é realizada por meio de uma função computacional que determina aleatoriamente a codificação das soluções, sempre combinada às técnicas heurísticas, pois a sua inicialização totalmente aleatória resultaria em soluções cujos valores de fitness obtidos seriam elevados, assim como o custo computacional para alcançar a convergência do algoritmo. O custo computacional aqui tratado está relacionado aos recursos de hardware disponíveis, visto que os recursos de tempo não são relevantes, devido a não ser uma aplicação que atua em tempo real.

As técnicas heurísticas aqui adotadas tendem a gerar uma população melhor adaptada, na qual são verificados os horários em que o professor não está disponível na universidade e, consequentemente, não deve ser alocado. Desta forma, uma das restrições do problema é satisfeita na inicialização da população.

As grades horárias resultantes possuem a estrutura representada na Tabela 5.1. 
Tabela 5.1 - Representação tabular de uma grade horária.

\begin{tabular}{|c|c|c|c|c|c|c|}
\hline Horários & $\begin{array}{c}\text { Segunda- } \\
\text { feira }\end{array}$ & $\begin{array}{l}\text { Terça- } \\
\text { feira }\end{array}$ & $\begin{array}{l}\text { Quarta- } \\
\text { feira }\end{array}$ & $\begin{array}{l}\text { Quinta- } \\
\text { feira }\end{array}$ & $\begin{array}{l}\text { Sexta- } \\
\text { feira }\end{array}$ & Sábado \\
\hline $7: 00$ & 1 & 7 & 13 & 19 & 25 & 31 \\
\hline $7: 50$ & 2 & 8 & 14 & 20 & 26 & 32 \\
\hline 08:50 & 3 & 9 & 15 & 21 & 27 & 33 \\
\hline 09:40 & 4 & 10 & 16 & 22 & 28 & 34 \\
\hline $10: 10$ & 5 & 11 & 17 & 23 & 29 & 35 \\
\hline 11:30 & 6 & 12 & 18 & 24 & 30 & 36 \\
\hline $12: 30$ & 37 & 43 & 49 & 55 & 61 & - \\
\hline $14: 20$ & 38 & 44 & 50 & 56 & 62 & - \\
\hline $15: 20$ & 39 & 45 & 51 & 57 & 63 & - \\
\hline $16: 10$ & 40 & 46 & 52 & 58 & 64 & - \\
\hline 17:10 & 41 & 47 & 53 & 59 & 65 & - \\
\hline $18: 00$ & 42 & 48 & 54 & 60 & 66 & - \\
\hline 19:00 & 67 & 71 & 75 & 79 & 83 & - \\
\hline $19: 50$ & 68 & 72 & 76 & 80 & 84 & - \\
\hline $20: 50$ & 69 & 73 & 77 & 81 & 85 & - \\
\hline 21:40 & 70 & 74 & 78 & 82 & 86 & - \\
\hline
\end{tabular}

Desta forma, grades horárias para todos os semestres são geradas e estarão de acordo com a quantidade de aulas existentes no curso.

\subsection{Função de Avaliação e Condição de Parada do Algoritmo Genético}

A função objetivo, na qual determina o fitness do algoritmo genético, aplicada na avaliação de cada indivíduo visa encontrar uma solução viável, na qual todas as restrições são 
satisfeitas e, desta forma, o resultado obtido possui valor igual a zero. Neste estudo, o fitness foi definido como um contador que é incrementado cada vez que uma solução possui uma característica que viola alguma das restrições impostas.

A disponibilidade dos professores em cada horário da grade horária é armazenada em uma tabela, devidamente relacionada à tabela de professores e de horários da grade, a qual possui o código do professor e o horário em que o mesmo não estará disponível na universidade. O sistema realiza uma verificação nesta tabela e caso o professor não possua disponibilidade no horário em que foi alocado, o fitness deve ser então incrementado.

Na inicialização da população, a restrição de disponibilidade do professor é verificada; porém, durante o processo de crossover, que será descrito a seguir, pode ocorrer a violação desta restrição.

Sempre que alguma das restrições de recursos impostas for violada, o fitness deve ser, obrigatoriamente, incrementado. A condição de parada imposta neste estudo é de se obter como resultado da função objetivo o valor igual a zero, ou seja, quando for obtida uma solução que, ao ser avaliada, será considerada viável, pois nenhuma das restrições foi violada e uma grade horária factível foi gerada.

\subsection{Método de Seleção Aplicado no Algoritmo Genético Desenvolvido}

O método de seleção utilizado nesta investigação, a fim de escolher as soluções para a próxima geração e para aplicação de operadores genéticos, foi o método no qual se busca as melhores soluções para o problema tratado: método de seleção por Rank. Neste tipo de método de seleção, as $N$ soluções com os melhores valores obtidos com a aplicação da função objetivo serão escolhidas. 


\subsection{Operadores Genéticos Aplicados no AG: Mutação e Crossover}

Os operadores genéticos são utilizados no AG com a finalidade de inserir diversidade na população e alcançar o objetivo desta pesquisa, i.e, encontrar uma grade horária factível. Os operadores genéticos aqui adotados foram a mutação e o crossover.

A mutação tem por objetivo inserir uma pequena diversidade na população. Assim, recomenda-se utilizar uma baixa taxa de mutação, a fim de que não sejam perdidos os avanços alcançados por meio da adoção dos métodos heurísticos usados na inicialização da população e também do processo evolutivo. Os passos utilizados para realizar a mutação foram os seguintes:

- Definir a taxa de mutação;

- Escolher aleatoriamente os indivíduos a serem mutados;

- Sortear dois pontos diferentes na grade horária, a fim de que os indivíduos selecionados tenham estes horários trocados na grade horária;

- Trocar todos os pontos selecionados nos indivíduos sorteados, em todos os semestres;

- Avaliar os indivíduos gerados.

A mutação adotada não viola as restrições respeitadas, pois a troca é feita em todos os semestres da solução. Um exemplo de mutação pode ser examinado nas Tabelas 5.2 e 5.3, no qual as posições 4 e 32 foram trocadas em todos os semestres da grade. 
Tabela 5.2 - Representação tabular de uma grade horária na qual será aplicada a mutação.

\begin{tabular}{|c|c|c|c|c|c|c|}
\hline Horários & $\begin{array}{c}\text { Segunda- } \\
\text { feira }\end{array}$ & $\begin{array}{l}\text { Terça- } \\
\text { feira }\end{array}$ & $\begin{array}{l}\text { Quarta- } \\
\text { feira }\end{array}$ & $\begin{array}{l}\text { Quinta- } \\
\text { feira }\end{array}$ & $\begin{array}{l}\text { Sexta- } \\
\text { feira }\end{array}$ & Sábado \\
\hline $7: 00$ & 1 & 7 & 13 & 19 & 25 & 31 \\
\hline $7: 50$ & 2 & 8 & 14 & 20 & 26 & 32 \\
\hline 08:50 & 3 & 9 & 15 & 21 & 27 & 33 \\
\hline 09:40 & 4 & 10 & 16 & 22 & 28 & 34 \\
\hline 10:10 & 5 & 11 & 17 & 23 & 29 & 35 \\
\hline $11: 30$ & 6 & 12 & 18 & 24 & 30 & 36 \\
\hline $12: 30$ & 37 & 43 & 49 & 55 & 61 & - \\
\hline $14: 20$ & 38 & 44 & 50 & 56 & 62 & - \\
\hline $15: 20$ & 39 & 45 & 51 & 57 & 63 & - \\
\hline $16: 10$ & 40 & 46 & 52 & 58 & 64 & - \\
\hline $17: 10$ & 41 & 47 & 53 & 59 & 65 & - \\
\hline 18:00 & 42 & 48 & 54 & 60 & 66 & - \\
\hline 19:00 & 67 & 71 & 75 & 79 & 83 & - \\
\hline $19: 50$ & 68 & 72 & 76 & 80 & 84 & - \\
\hline $20: 50$ & 69 & 73 & 77 & 81 & 85 & - \\
\hline 21:40 & 70 & 74 & 78 & 82 & 86 & - \\
\hline
\end{tabular}


Tabela 5.3 - Representação tabular de uma grade horária após a realização da mutação.

\begin{tabular}{|c|c|c|c|c|c|c|}
\hline Horários & $\begin{array}{c}\text { Segunda- } \\
\text { feira }\end{array}$ & $\begin{array}{c}\text { Terça- } \\
\text { feira }\end{array}$ & $\begin{array}{c}\text { Quarta- } \\
\text { feira }\end{array}$ & $\begin{array}{c}\text { Quinta- } \\
\text { feira }\end{array}$ & $\begin{array}{c}\text { Sexta- } \\
\text { feira }\end{array}$ & Sábado \\
\hline $\mathbf{7 : 0 0}$ & 1 & 7 & 13 & 19 & 25 & 31 \\
\hline $\mathbf{7 : 5 0}$ & 2 & 8 & 14 & 20 & 26 & 4 \\
\hline $\mathbf{0 8 : 5 0}$ & 3 & 9 & 15 & 21 & 27 & 33 \\
\hline $\mathbf{0 9 : 4 0}$ & 32 & 10 & 16 & 22 & 28 & 34 \\
\hline $\mathbf{1 0 : 1 0}$ & 5 & 11 & 17 & 23 & 29 & 35 \\
\hline $\mathbf{1 1 : 3 0}$ & 6 & 12 & 18 & 24 & 30 & 36 \\
\hline $\mathbf{1 2 : 3 0}$ & 37 & 43 & 49 & 55 & 61 & - \\
\hline $\mathbf{1 4 : 2 0}$ & 38 & 44 & 50 & 56 & 62 & - \\
\hline $\mathbf{1 5 : 2 0}$ & 39 & 45 & 51 & 57 & 63 & - \\
\hline $\mathbf{1 6 : 1 0}$ & 40 & 46 & 52 & 58 & 64 & - \\
\hline $\mathbf{1 7 : 1 0}$ & 41 & 47 & 53 & 59 & 65 & - \\
\hline $\mathbf{1 8 : 0 0}$ & 42 & 48 & 54 & 60 & 66 & - \\
\hline $\mathbf{1 9 : 0 0}$ & 67 & 71 & 75 & 79 & 83 & - \\
\hline $\mathbf{1 9 : 5 0}$ & 68 & 72 & 76 & 80 & 84 & - \\
\hline $\mathbf{2 0 : 5 0}$ & 69 & 73 & 77 & 81 & & \\
\hline $\mathbf{2 1 : 4 0}$ & 70 & 74 & 78 & & & \\
\hline
\end{tabular}

Já o crossover realiza o cruzamento entre dois cromossomos selecionados aleatoriamente, gerando-se assim um novo cromossomo, que possui as características dos dois cromossomos originais. O novo cromossomo deve ser verificado e, se necessário, deve ser também reestruturado, pois poderá violar todas as restrições impostas pelo problema tratado. Os passos utilizados para realizar o crossover foram os seguintes: 
- Selecionar a taxa de crossover;

- Selecionar aleatoriamente os indivíduos nos quais será aplicado o crossover;

- Selecionar um ponto de corte, que corresponderá a um horário da grade horária;

- Para a geração do novo indivíduo, utilizar-se-ão os genes de um cromossomo até o ponto de corte, sendo que o restante dos genes será extraído do próximo cromossomo, a partir do ponto de corte até o final da grade horária;

- Verificar no novo cromossomo gerado se todas as disciplinas foram alocadas;

- Corrigir (se necessário) o novo cromossomo a fim de que todas as disciplinas constem no seu devido semestre, com a carga horária correta;

- Avaliar os novos indivíduos gerados.

\subsection{Representação das Soluções Candidatas no CLONALG}

$\mathrm{Na}$ presente investigação, a codificação de cada anticorpo representa uma grade de horários completa, contendo todas as disciplinas do curso com suas informações, organizadas de acordo com o semestre que pertencem. A codificação dos anticorpos é composta por uma cadeia finita de elementos, os quais são representados por uma estrutura de dados contendo as seguintes informações:

- Código da disciplina;

- Semestre em que pertence a disciplina;

- Nome da disciplina;

- Professor que ministra a disciplina;

- Carga horária da disciplina;

- Um horário na grade, o qual representa o dia da semana e a hora que será alocada a disciplina. 
Com objetivo de se obter as informações necessárias para a manipulação do CLONALG, foi então desenvolvido um banco de dados em SQL Server 2008, o qual possui a arquitetura apresentada na Figura 5.2.

\begin{tabular}{|l}
\hline tb_Disponibilidade \\
\hline PKNI_IdDisponibilidade: INTEGER \\
tb_Professores_tb_DisciplinasCargaHoraria_P... (FK) \\
tb_Professores_PKNI_IdProfessor: INTEGER (FK) \\
\hline FKNI_IdProfessor: INTEGER \\
$\checkmark$ FKNI_IdHorarioGrade: INTEGER \\
tb_Disponibilidade_FKIndex1 \\
tb_Professores_PKNI_IdProfessor \\
tb_Professores_tb_DisciplinasCargaHoraria_PKN \\
\hline
\end{tabular}

tb_Disponibilidade_PKNI_IdDisponibilidade: .... (FK)

tb_DisciplinasCargäHoraria_PKNI_IdDisciplin... (FK)

tb Disciplinas tb Professores_PKNI_IdProfes... (FK)

tb_Disciplinas_tb_Professores_tb_Disciplina... (FK)

tb_Disciplinas_PKNI_IdDisciplina: INTEGER (FK)

tb_Disponibilidade_tb_Professores_PKNI_IdPr... (FK)

Q tb_Professores_tb_DisciplinasCargaHoraria_PKNI

(FK)

$\triangle$ ATDT_DataInicio: DATETIME

$\checkmark$ ATDT_DataFim: DATETIME

$\triangle$ ATVS DiaSemana: VARCHAR

tb_IdHorarioGrade FKIndex1

tb_Disponibilidade_PKNI_IdDisponibilidade

tb_Disponibilidade_tb_Professores_tb_DisciplinasCa

tb_Disponibilidade_tb_Professores_PKNI_IdProfess otb_IdHorarioGrade_FKIndex2

tb_DisciplinasCargaHoraria_PKNI_IdDisciplinasCargal It tb_IdHorarioGrade_FKIndex3

tb_Disciplinas_PKNI_IdDisciplina

tb_Disciplinas_tb_Professores_tb_DisciplinasCargaH

tb_Disciplinas_tb_Professores_PKNI_IdProfessor

PKNI_IdAdinidade: INTEGER

ATNI_IdAnticorpo: INTEGER

$\triangle$ ATNI_ValorAfinidade: INTEGER

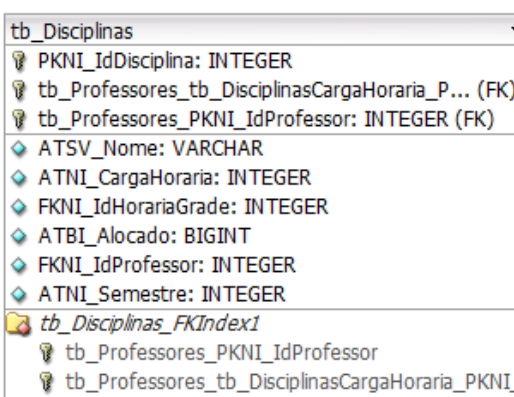

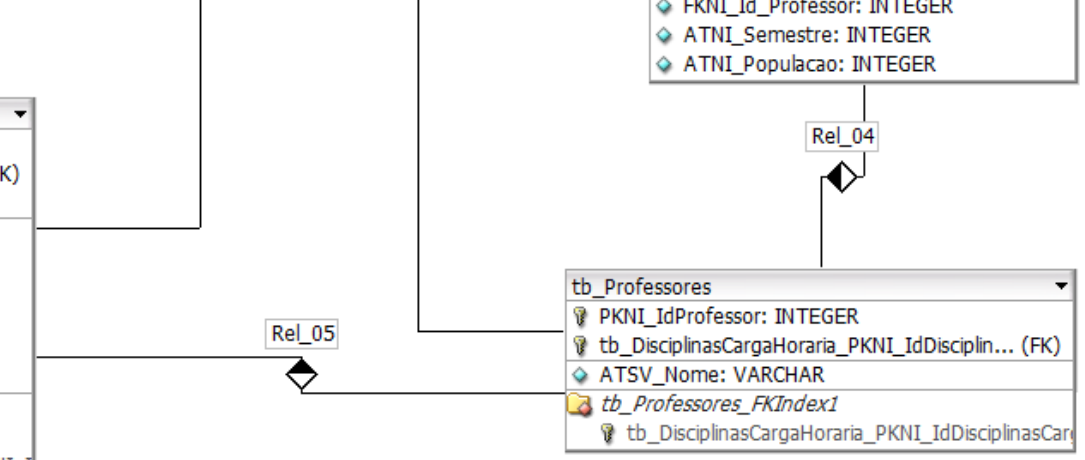

Figura 5.2 - Modelo relacional do banco de dados do algoritmo desenvolvido utilizando-se o algoritmo de seleção clonal.

Os sistemas desenvolvidos são genéricos e, desta forma, podem também ser aplicados na geração de grades horárias de qualquer curso. O usuário deve, primeiramente, cadastrar as informações necessárias, conforme descrito a seguir: 
- Cursos da universidade;

- Horários de aula de cada dia da semana e período (diurno, vespertino ou noturno);

- Disciplinas do curso;

- Professores;

- Disponibilidade de cada professor em cada horário de aula.

\subsection{Inicialização da População no CLONALG}

A geração da população inicial no algoritmo desenvolvido é realizada por meio de uma função computacional que determina aleatoriamente a codificação das soluções, sempre combinada às técnicas heurísticas, pois a sua inicialização totalmente aleatória resultaria em soluções cujos valores de afinidade obtidos seriam elevados, assim como o custo computacional para alcançar a convergência dos algoritmos. Lembrando-se que o custo computacional aqui tratado tem relação aos recursos de hardware disponíveis, e não aos recursos computacionais de tempo, devido à aplicação não atuar em tempo real.

As técnicas heurísticas adotadas tendem a gerar uma população melhor adaptada, na qual são verificados os horários em que o professor não está disponível na universidade e, conseqüentemente, não deve ser alocado. Desta forma, uma das restrições do problema é satisfeita na inicialização da população.

As grades horárias resultantes possuem a estrutura representada na Tabela 5.4. 
Tabela 5.4 - Representação tabular de uma grade horária.

\begin{tabular}{|c|c|c|c|c|c|c|}
\hline Horários & $\begin{array}{c}\text { Segunda- } \\
\text { feira }\end{array}$ & $\begin{array}{c}\text { Terça- } \\
\text { feira }\end{array}$ & $\begin{array}{c}\text { Quarta- } \\
\text { feira }\end{array}$ & $\begin{array}{c}\text { Quinta- } \\
\text { feira }\end{array}$ & $\begin{array}{c}\text { Sexta- } \\
\text { feira }\end{array}$ & Sábado \\
\hline $\mathbf{7 : 0 0}$ & 1 & 7 & 13 & 19 & 25 & 31 \\
\hline $\mathbf{7 : 5 0}$ & 2 & 8 & 14 & 20 & 26 & 32 \\
\hline $\mathbf{0 8 : 5 0}$ & 3 & 9 & 15 & 21 & 27 & 33 \\
\hline $\mathbf{0 9 : 4 0}$ & 4 & 10 & 16 & 22 & 28 & 34 \\
\hline $\mathbf{1 0 : 1 0}$ & 5 & 11 & 17 & 23 & 29 & 35 \\
\hline $\mathbf{1 1 : 3 0}$ & 6 & 12 & 18 & 24 & 30 & 36 \\
\hline $\mathbf{1 2 : 3 0}$ & 37 & 43 & 49 & 55 & 61 & - \\
\hline $\mathbf{1 4 : 2 0}$ & 38 & 44 & 50 & 56 & 62 & - \\
\hline $\mathbf{1 5 : 2 0}$ & 39 & 45 & 51 & 57 & 63 & - \\
\hline $\mathbf{1 6 : 1 0}$ & 40 & 46 & 52 & 58 & 64 & - \\
\hline $\mathbf{1 7 : 1 0}$ & 41 & 47 & 53 & 59 & 65 & - \\
\hline $\mathbf{1 8 : 0 0}$ & 42 & 48 & 54 & 60 & 66 & - \\
\hline $\mathbf{1 9 : 0 0}$ & 67 & 71 & 75 & 79 & 83 & - \\
\hline $\mathbf{1 9 : 5 0}$ & 68 & 72 & 76 & 80 & 84 & - \\
\hline $\mathbf{2 0 : 5 0}$ & 69 & 73 & 77 & 81 & 85 & - \\
\hline $\mathbf{2 1 : 4 0}$ & 70 & 74 & 78 & 82 & 86 & - \\
\hline
\end{tabular}

Desta forma, grades horárias para todos os semestres são geradas e estarão de acordo com a quantidade de aulas existentes no curso.

\subsection{Função de Avaliação e Condição de Parada do CLONALG}

A função objetivo, na qual determina a afinidade aplicada na avaliação de cada candidato, visa encontrar uma solução viável, na qual todas as restrições são satisfeitas e, desta forma, o 
resultado obtido possui valor igual a zero. Nesta investigação, a afinidade foi definida como um contador que é incrementado cada vez que uma solução possui uma característica que viola alguma das restrições impostas.

A disponibilidade dos professores em cada horário da grade horária é armazenada em uma tabela, devidamente relacionada à tabela de professores e de horários da grade, a qual possui o código do professor e o horário em que o mesmo não estará disponível na universidade.

Na inicialização da população, a restrição de disponibilidade do professor é verificada; porém, durante o processo de expansão clonal, que serão descritos a seguir, pode ocorrer a violação desta restrição.

Sempre que alguma das restrições de recursos impostas for violada, a afinidade deve ser, obrigatoriamente, incrementada. A condição de parada imposta na presente investigação é de se obter como resultado da função objetivo um valor igual a zero, ou seja, quando for obtida uma solução que, ao ser avaliada, será considerada viável, pois nenhuma das restrições foi violada e uma grade horária factível foi gerada.

\subsection{Métodos de Seleção do CLONALG}

O método de seleção utilizado aqui, a fim de escolher as soluções para a próxima geração e para se aplicar o processo de expansão clonal, foi o método no qual se busca as melhores soluções para o problema tratado: método de seleção por afinidade. Neste tipo de método de seleção, as $N$ soluções com os melhores valores obtidos mediante à função objetivo serão escolhidas.

\subsection{Expansão Clonal do CLONALG}

O processo de expansão clonal existente no CLONALG possui as seguintes etapas: clonagem dos $n$ melhores anticorpos, maturação dos clones e sua avaliação.

A quantidade de clones selecionados foi obtida a partir da seguinte equação: 


$$
N_{c}=\sum_{i=1}^{n} \operatorname{round}\left(\frac{\beta . N}{i}\right)
$$

onde $N_{c}$ representa o total de clones gerados; $\beta$ representa o fator de multiplicação; $N$ representa a quantidade de anticorpos da população; e round é o operador responsável por transformar o resultado numérico em um valor inteiro (Castro e Zuben, 2000).

A maturação corresponde à mutação aplicada nos clones, cuja taxa é calculada inversamente proporcional à sua afinidade. A maturação aqui adotada consiste nos seguintes passos:

- Sortear pontos diferentes na grade horária selecionada e clonada, a fim de que estes horários sejam trocados;

- Trocar todos os pontos selecionados em cada clone, em todos os semestres;

- Avaliar os novos anticorpos gerados;

- Verificar, por intermédio da análise comparativa entre os valores de afinidade, se o novo anticorpo possui maior representatividade na população que aquele anticorpo no qual o originou.

Após o processo de maturação, as grades horárias são avaliadas, sendo inseridos na subpopulação aqueles anticorpos com melhor afinidade.

\subsection{Inserção de Diversidade na População do CLONALG}

O processo de introdução de diversidade na população consiste na substituição de grades horárias com piores valores de afinidade por novas soluções, geradas por meio da função computacional que determina aleatoriamente a codificação das soluções, sempre combinada às técnicas heurísticas, conforme realizado na geração da população inicial deste algoritmo. 


\subsection{Representação dos Algoritmos Desenvolvidos}

Os algoritmos desenvolvidos podem ser representados mediante os fluxogramas apresentados nas Figuras 5.7 e 5.8.

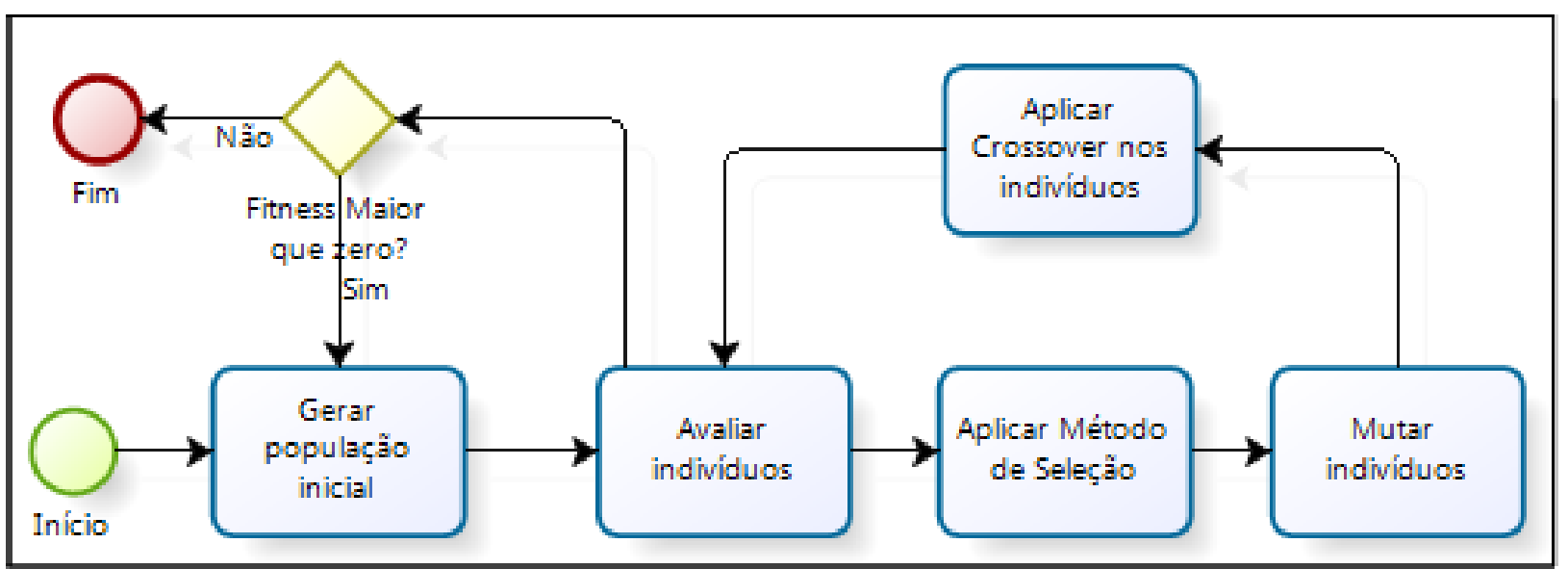

Figura 5.7 - Representação gráfica do algoritmo genético adotado na otimização de grades horárias.

A Figura 5.7 apresentou os passos para se obter o algoritmo genético desenvolvido na presente investigação, sendo eles:

- Início da execução do algoritmo genético;

- Inicialização da população inicial: algoritmo aleatório combinado à técnica heurística;

- Avaliação de cada indivíduo e obtenção de seu fitness;

- Condição de parada encontrada?

- Se a resposta for não para a satisfação da condição de parada, então:

- Aplica-se o método de seleção por rank;

- Aplicam-se os operadores genéticos de mutação e crossover;

○ Gerar nova população;

○ Repete-se o looping, até que a condição de parada seja encontrada.

- Se a resposta for sim para a satisfação da condição de parada, então: 
○ Finaliza-se a execução do algoritmo, pois uma grade horária factível foi obtida.

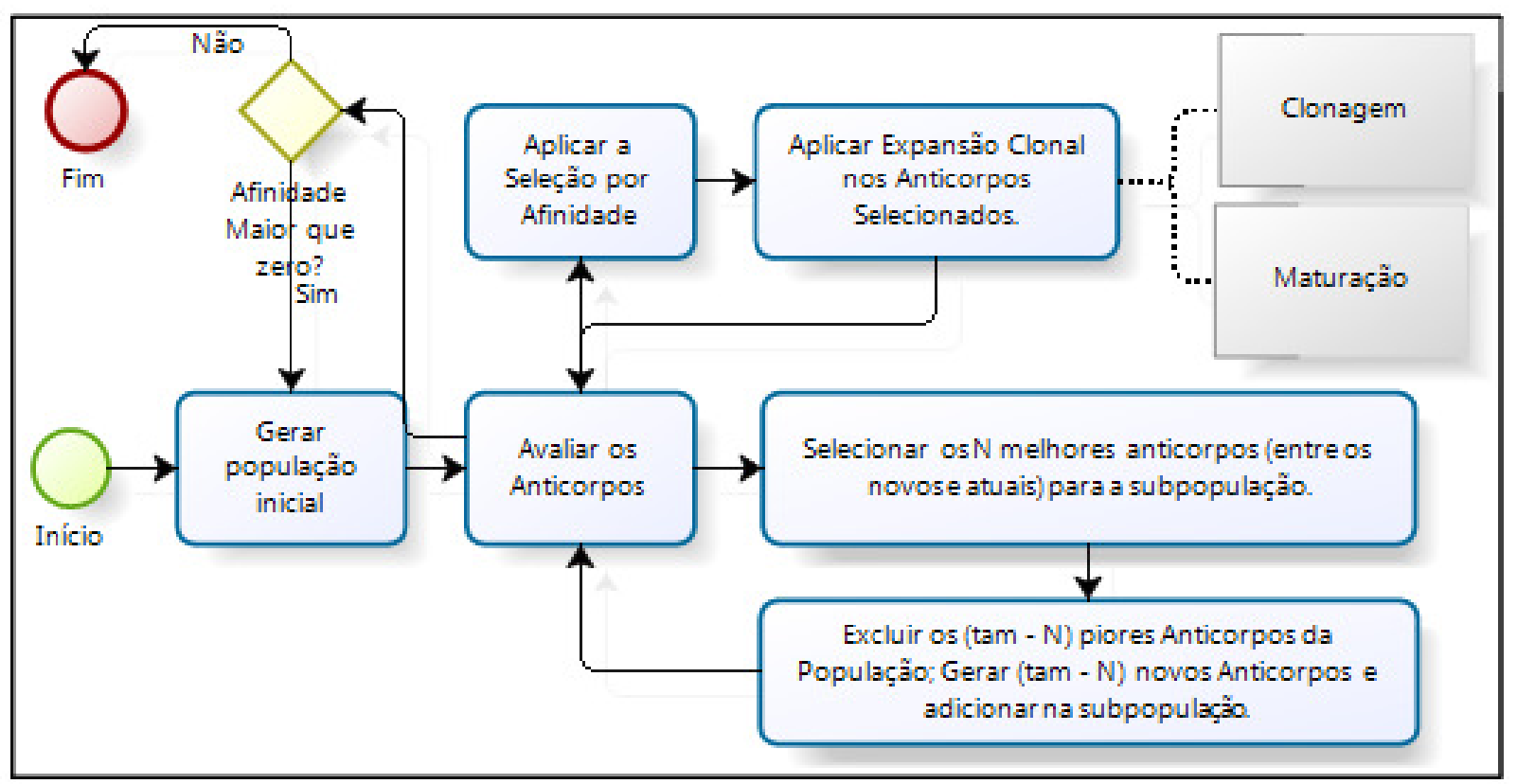

Figura 5.8 - Representação gráfica do algoritmo de seleção clonal adotado na otimização de grades horárias.

A Figura 5.8 apresentou os passos para se obter o algoritmo de seleção clonal desenvolvido na presente investigação, sendo eles os seguintes:

- Início da execução do algoritmo de seleção clonal;

- Inicialização da população inicial: algoritmo aleatório combinado à técnica heurística;

- Avaliação de cada anticorpo e obtenção de sua afinidade;

- Condição de parada encontrada?

- Se a resposta for não para a satisfação da condição de parada, então:

○ Aplica-se o método de seleção por afinidade;

- Aplica-se a expansão clonal nos anticorpos selecionados: clonagem e maturação;

- Gerar a subpopulação;

○ Repete-se o looping até que a condição de parada seja encontrada. 
- Se a resposta for sim para a satisfação da condição de parada, então:

○ Finaliza-se a execução do algoritmo, pois uma grade horária factível foi obtida.

Por intermédio dos algoritmos apresentados, grades horárias factíveis foram obtidas, conforme os resultados apresentados no próximo capítulo.

\subsection{Considerações Parciais}

No presente capítulo foram explanados ambos os algoritmos desenvolvidos neste estudo, os quais se basearam nos conceitos relacionados à Computação Evolutiva, com o objetivo de se obter a otimização automática de grades horárias em instituições de ensino superior.

Finalmente, foram expostos os principais parâmetros e metodologias adotadas tanto no AG quanto no CLONALG, tais como operadores genéticos, métodos de seleção, entre outros, e as possíveis variações e similaridades entre os algoritmos. 


\section{Resultados de Simulações}

A seguir serão apresentados resultados das execuções dos sistemas de apoio à decisão desenvolvidos no presente estudo. O objetivo é obter grades horárias válidas com o menor custo computacional. Desta forma, foram realizadas diversas simulações computacionais, visando evidenciar a habilidade de cada um dos algoritmos desenvolvidos, em explorar adequadamente o espaço de busca do problema.

As Tabelas 6.1 e 6.2 possuem os resultados obtidos a partir de 30, 60, 90 e 120 grades horárias factíveis e as quantidades de gerações que são necessárias pelos algoritmos desenvolvidos, para cada uma das configurações adotadas para os operadores genéticos de mutação e de crossover. Foram realizados diversos testes, com a finalidade de se encontrar a taxa de crossover e mutação mais adequadas para esta aplicação.

O tamanho da população aqui adotado, em ambos os algoritmos, foi igual a cem, correspondendo a cem cromossomos no AG e, cem anticorpos no CLONALG.

Conforme apresentando em capítulos anteriores, o processo de expansão clonal possui as etapas de clonagem dos $n$ melhores anticorpos e a maturação dos clones, para posterior avaliação. A quantidade de clones selecionados é obtida a partir da seguinte equação:

$$
N_{c}=\sum_{i=1}^{n} \operatorname{round}\left(\frac{\beta . N}{i}\right)
$$

onde $N_{c}$ representa a quantidade de clones gerados; $\beta$ representa o fator de multiplicação, aqui definido como 0,$7 ; N$ representa a quantidade total de anticorpos da população (100 anticorpos); e round é o operador responsável por transformar o resultado numérico em um valor inteiro.

A taxa de maturação é calculada inversamente proporcional à sua afinidade, multiplicando-se pelo operador round, o qual transforma o resultado obtido em um valor inteiro. 
A taxa de mutação obtida a partir do cálculo inversamente proporcional à taxa de afinidade arredondado para um valor inteiro sempre é igual à 1 , devido à afinidade ser sempre um valor maior que zero (enquanto a condição de parada não for encontrada). Ao submeter ao arredondamento, não se pode adotar zero, sendo que, desta forma, sempre se arredonda para cima.

Tabela 6.1 - Resultados de simulações do CLONALG desenvolvido.

\begin{tabular}{|c|c|}
\hline $\begin{array}{c}\text { Quantidade de Grades Horárias } \\
\text { Factíveis Obtidas com o } \\
\text { CLONALG }\end{array}$ & $\begin{array}{c}\text { Quantidade de Iterações do } \\
\text { CLONALG }\end{array}$ \\
\hline 30 & 13953 \\
\hline 60 & 29568 \\
\hline 90 & 35456 \\
\hline 120 & 53658 \\
\hline
\end{tabular}

No AG, foi adotada a mutação de um ponto, ou seja, foi selecionado um ponto na grade horária, em cada um dos semestres da solução, para ser mutado.

Tabela 6.2 - Resultados de simulações do AG desenvolvido.

\begin{tabular}{|c|c|c|c|}
\hline $\begin{array}{c}\text { Quantidade de Grades } \\
\text { Horárias Factíveis } \\
\text { Obtidas com AG }\end{array}$ & $\begin{array}{c}\text { Quantidade } \\
\text { de Iterações } \\
\text { do AG }\end{array}$ & $\begin{array}{c}\text { Taxa de } \\
\text { Mutação }\end{array}$ & $\begin{array}{c}\text { Taxa de } \\
\text { Crossover }\end{array}$ \\
\hline 30 & 17865 & $10 \%$ & $80 \%$ \\
\hline 30 & 24630 & $3 \%$ & $30 \%$ \\
\hline 30 & 19562 & $5 \%$ & $60 \%$ \\
\hline 60 & 37898 & $10 \%$ & $80 \%$ \\
\hline 60 & 52654 & $3 \%$ & $30 \%$ \\
\hline 60 & 38956 & $5 \%$ & $60 \%$ \\
\hline 90 & 45865 & $10 \%$ & $80 \%$ \\
\hline 90 & 61578 & $3 \%$ & $30 \%$ \\
\hline 90 & 62457 & $10 \%$ & $60 \%$ \\
\hline 120 & 105212 & $3 \%$ & $30 \%$ \\
\hline 120 & 89215 & $5 \%$ & $60 \%$ \\
\hline 120 & & & $5 \%$ \\
\hline
\end{tabular}


Como pode ser verificado na Tabela 6.1, o CLONALG foi executado 30, 60, 90 e 120 vezes, o que significa que foram encontradas 30, 60, 90 e 120 grades horárias factíveis, pois a condição de parada adotada para este problema tem objetivo de encontrar grades horárias nas quais não são violadas as restrições definidas.

Na Tabela 6.1, na segunda coluna, são apresentadas as quantidades de iterações necessárias para se encontrar 30, 60, 90 e 120 grades horárias factíveis.

A mesma condição de parada foi adotada para o AG, desta forma, pode-se ser observado na Tabela 6.2 que, para cada uma das configurações adotadas, foram também geradas 30, 60, 90 e 120 grades horárias válidas.

As configurações mais adequadas para o AG são encontradas através da taxa de mutação de $10 \%$ e de crossover de $80 \%$, como pode ser observado ao se analisar os resultados da Tabela 6.2, em todos os casos. Porém, pode ser observado que em 90 execuções, a convergência do algoritmo foi mais eficiente.

Comparando-se o AG e o CLONALG, foi possível então verificar a superioridade do CLONALG para esta aplicação, pois foram necessárias menos iterações para se obter a mesma quantidade de grades horárias factíveis, mesmo na melhor configuração encontrada para o AG.

Comparando-se os resultados obtidos na Tabela 6.1, foi observado, assim como no AG, que ao executar o algoritmo 90 vezes, os resultados foram mais eficientes que em 30, 60 ou 120 execuções, frente aos parâmetros adotados nesta investigação. 


\section{Conclusões Finais e Perspectivas Futuras}

A investigação proposta objetivou realizar uma análise comparativa entre os resultados obtidos a partir dos algoritmos genéticos e sistemas imunológicos artificiais, quando aplicados na solução do problema de geração de grades horárias em instituições de ensino. Como principal contribuição deste trabalho, sistemas de apoio à decisão, responsáveis pela geração automática de grades horárias factíveis, foram desenvolvidos, os quais foram baseados nos parâmetros mais comuns adotados por universidades.

Os resultados obtidos empiricamente nos levam a concluir que o algoritmo de seleção clonal apresentou resultados superiores aos algoritmos genéticos, considerando-se aqui os parâmetros adotados, pois foram necessárias menos iterações do software para se obter grades horárias válidas. A adoção de técnicas heurísticas adequadas na geração da população inicial foi um fator de sucesso nesta pesquisa, pois possibilitou obter convergência eficiente em ambos os algoritmos desenvolvidos.

A partir dos resultados obtidos concluiu-se que o CLONALG apresentou melhores respostas que o AG, possivelmente devido à pequena quantidade de restrições do problema aqui adotada. A principal vantagem do CLONALG sobre o AG, para o problema assumido, se encontra na inserção de diversidade em todas as iterações do algoritmo, mantendo-se sempre o melhor anticorpo e possibilitando-se, ainda, a melhoria dos melhores anticorpos por meio da expansão clonal.

Como propostas para trabalhos futuros, outros algoritmos bio-inspirados encontrados na literatura relacionada podem ser abordados, tais como Sistemas Endócrinos Artificiais e Otimização por Enxame de Partícula, e também o seu desenvolvimento baseado em programação paralela, com objetivo de realizar a distribuição da carga de trabalho dos 
algoritmos em vários processadores, e encontrar a solução para o problema em menor período de tempo.

Além da adoção de outros algoritmos bio-inspirados na otimização do problema de geração de grades horárias, como proposta para trabalhos futuros, poderão ser também adotadas restrições de baixo grau, nas quais a qualidade da grade horária obtida será maior que as grades horárias obtidas na presente investigação.

Os trabalhos apresentados adiante estão relacionados à presente investigação e foram publicados em anais de congressos científicos.

- Francisco, D. O., Silva, I. N. (2012). On the Application of Bio-inspired Algorithms in Timetabling Problem, ICONIP 2012, Part III, LNCS, vol. 7665, pp. 637-644.

- Francisco, D. O., Silva, I. N. (2011). Uma Visão Geral da Aplicação de Algoritmos BioInspirados ao Problema de Geração Automática de Grades Horárias, X Congresso Brasileiro de Inteligência Computacional, 2011, Fortaleza, CE.

- Francisco, D. O., Silva, I. N. (2011). Estratégia de Otimização Baseada em Sistemas Inteligentes Aplicada ao Problema de Geração de Grades Horárias, X Conferência Brasileira de Dinâmica, Controle e Aplicações, 2011, Águas de Lindóia, SP.

- Francisco, D. O., Silva, I. N. (2009). Estratégia de Otimização Baseada em Algoritmos Genéticos Aplicada ao Problema de Geração de Grades Horárias, Conferência Brasileira de Dinâmica e Controle, 2009, Bauru, SP. 


\section{Referências Bibliográficas}

Ahmed, R. \& Sprent, J. (1999). Immunological Memory, The Immunologist, vol. 7, pp.23-26.

Bai, R., Blazewicz, J., Burke, E.K.,Kendall, G., McCollum, B. (2012). A simulated annealing hyper-heuristic methodology for flexible decision support, 4OR, vol. 10, pp. 43-66.

Beligiannis, G.N., Moschopoulos, C., Likothanassis, S.D. (2009). A Genetic Algorithm Approach to School Timetabling, Journal of the Operational Research Society, vol. 60, pp. 23-42.

Burke, E. K., Qu, R., Soghier, A. (2012). Adaptive selection of heuristics for improving exam Timetables by ant colony optimization, Annals of Operations Research, pp. 1-17.

Castro, L.N. e Zuben, F.J.V. (2000). Artificial immune systems: Part II - a survey of applications, Technical report, FEEC/UNICAMP.

Castro, L.N., Zuben, F.J.V. e Knidel, H. (2007). How to Obtain Appropriate Executive Decisions Using Artificial Immunologic Systems, LNCS, vol. 4628, pp. 207-219.

Castro, L.N. (2001). Engenharia imunológica: desenvolvimento e aplicação de ferramentas computacionais inspiradas em sistema imunológicos artificiais. Tese de Doutorado, Faculdade de Engenharia Elétrica e de Computação, UNICAMP.

Conant-Pablos, S.E., Magaña-Lozano, D.J., Terashima-Marín, H. (2009). Pipelining memetic algorithms, constraint satisfaction, and local search for course timetabling, Lecture Notes in Computer Science (including subseries Lecture Notes in Artificial Intelligence and Lecture Notes in Bioinformatics), LNAI, vol. 5845, pp. 408-419.

Darwin, C. (1859). The Origin of Species. Ed. John Murray.

Dasgupta, D. (2006). Computational intelligence in cyber security, Proceedings of the 2006 IEEE International Conference on Computational Intelligence for Homeland Security and Personal Safety, CIHSPS 2006, pp. 2-3. 
Dasgupta, D. (Ed.) (1998). Artificial Immune Systems and Their Applications, Springer-Verlag. Dowsland, K.A., Thompson, J.M. (2005). Ant colony optimization for the examination scheduling problem, Journal of the Operational Research Society, vol. 56, pp. 426-438.

Farmer, J. D., Packard, N. H. \& Perelson, A. S. (1986). The Immune System, Adaptation, and Machine Learning, Physica 22D, pp. 187-204.

Fogel, D. B. (1994). An Introduction to Simulated Evolutionary Computation, IEEE Trans.

Neural Networks, vol. 5, pp. 3-14.

Goldberg, D. E., Korb, B. e Deb, K. (1989). Messy Genetic Algorithms: Motivation, Analysis and First Results, Complex Systems, vol. 3, pp. 493-530.

Holland, J. H. (1975). Adaptation in Natural and Artificial Systems, The University of Michigan Press, 1st. ed. 1975.

Janeway, C. A., P. Travers, Walport, M. \& Capra, J. D. (2000). Imunobiologia: O Sistema Imunológico na Saúde e na Doença, Artes Médicas, 4a Ed., Editora Artes Médicas Sul.

Jat, S. N., Yang, S. (2011). A Hybrid Genetic Algorithm and Tabu Search Approach for Post Enrolment Course Timetabling, Journal of Scheduling, vol. 14, pp. 617-637.

Nothegger, C., Mayer, A., Chwatal, A., Raidl, G. R. (2012). Solving the post enrolment course timetabling problem, Annals of Operations Research, vol. 194, pp. 325-339.

Ozcan, E., Parkes, A. J, Alkan, A. (2012). The Interleaved Constructive Memetic Algorithm and its application to timetabling, Computers and Operations Research. vol. 39, pp. 23102322.

Paechter, B., Cumming, A., Luchian, H., Petriuc, M. (1994). Two Solutions to the General Timetable Problem using Evolutionary Methods, Proc. IEEE. Conference on Evolutinary Computation. vol. 1, pp. 300-305. 
Pais, T.C., Amaral, P. (2012). Managing the Tabu List Length Using a Fuzzy Inference System: An Application to Examination Timetabling, Annals of Operations Research, vol. 194, pp. 341-363.

Perelson, A. S., Mirmirani, M. \& Oster, G. F. (1978). Optimal Strategies in Immunology II. B Memory Cell Production, J. Math. Biol., vol. 5, pp. 213-256.

Pillay, N., Banzhaf, W. (2010). An Informed Genetic Algorithm for the Examination Timetabling Problem, Applied Soft Computing Journal, vol. 10, pp. 457-467.

Raghavjee, R., Pillay, N. (2008). An Application of Genetic Algorithms to the School Timetabling Problem, ACM International Conference Proceeding Series 338, pp. 193-199.

Sabar, N.R., Ayob, M., Kendall, G., Qu, R. (2012). A honey-bee mating optimization algorithm for educational timetabling problems, European Journal of Operational Research, vol. 216, pp. 533-543.

Sabar, N.R., Ayob, M., Qu, R., Kendall, G. (2012). A graph coloring constructive hyperheuristic for examination timetabling problems, Applied Intelligence, vol. 37, pp. 1-11.

Starlab, URL: http://www.starlab.org/genes/ais/

Suyanto (2010). An Informed Genetic Algorithm for University Course and Student Timetabling Problems, LNAI, vol. 6114, pp. 229-236.

Tassopoulos, I.X., Beligiannis, G.N. (2012). Using particle swarm optimization to solve effectively the school timetabling problem, Soft Computing, vol. 16, pp. 1229-1252.

Timmis, J. (2000). Artificial Immune Systems: A Novel Data Analysis Technique Inspired by the Immune Network Theory, Tese de Doutorado, Department of Computer Science, University of Whales.

Turabieh, H., Abdullah, S. (2011). An Integrated Hybrid Approach to the Examination Timetabling Problem, Omega, vol. 39, pp. 598-607.

Wang, Z., Liu, J.L., Yu, X. (2009). Self-Fertilization Based Genetic Algorithm for University 
Timetabling Problem, 2009 World Summit on Genetic and Evolutionary Computation, 2009 GEC Summit - Proceedings of the 1st ACM/SIGEVO Summit on Genetic and Evolutionary Computation, GEC'09, pp. 1001-1004.

Wolfram, S. (1986). Approaches to Complexity Engineering, Phisyca 22D, pp. 385-399.

Yue, Z., Li, S., Xiao, L. (2009). Solving university course timetabling problems by a novel genetic algorithm based on flow, LNCS, vol. 5854, pp. 214-223.

Zadeh, L. A., (1965). Fuzzy sets, Information and Control, vol.8, p.29-44.

Zuben, F.J. V. (2000). Computação Evolutiva: Uma Abordagem Pragmática, DCA/FEEC/Unicamp. 
Apêndice

Como resultado de ambos os sistemas desenvolvidos na presente investigação, foram geradas grades horárias factíveis, respeitando as restrições impostas para o problema. As grades horárias resultantes são baseadas em um curso de uma instituição acadêmica real, no qual as disciplinas e professores são apresentados na Tabela A.1.

Tabela A.1 - Principais parâmetros de entrada para os sistemas desenvolvidos.

\begin{tabular}{|c|c|c|c|c|}
\hline Item & $\begin{array}{c}\text { Siglas das } \\
\text { Disciplinas }\end{array}$ & Semestre & $\begin{array}{c}\text { Nome do } \\
\text { Professor }\end{array}$ & $\begin{array}{c}\text { Carga } \\
\text { horária }\end{array}$ \\
\hline 1 & Filosofia_I & 1 & Davidson & 4 \\
\hline 2 & FisicaEB_G1 & 1 & Artur & 2 \\
\hline 3 & Fisica___ I & 1 & Marcolino & 4 \\
\hline 4 & Introducao_ & 1 & Lideir & 2 \\
\hline 5 & Matematic_I & 1 & Marcolino & 4 \\
\hline 6 & Matemati_II & 1 & Marcia & 4 \\
\hline 7 & Program_C_I & 1 & João & 2 \\
\hline 8 & ProgC_II_G1 & 1 & Luciana & 2 \\
\hline 9 & Qu_Aplicada & 1 & Ana_Paula & 2 \\
\hline 10 & Quim_Exp_G1 & 1 & Ana_Paula & 2 \\
\hline 11 & Circuitos_I & 2 & Marcos & 4 \\
\hline 12 & Desenho_G1 & 2 & Ladislau & 2 \\
\hline 13 & Filosof_II & 2 & Mourtada & 4 \\
\hline 14 & Fisica__II & 2 & Artur & 2 \\
\hline 15 & EletricB_G1 & 2 & Assumpcao & 2 \\
\hline 16 & Matemat_III & 2 & Marcia & 4 \\
\hline 17 & Matemati_IV & 2 & Maggi & 4 \\
\hline 18 & MateriaisEE & 2 & Delboni & 2 \\
\hline 19 & Sist_Logi_I & 2 & Udo & 4 \\
\hline 20 & CircuitE_II & 3 & Marcos & 4 \\
\hline 21 & Eletronic_I & 3 & Lideir & 4 \\
\hline 22 & Fisica_III & 3 & Artur & 4 \\
\hline 23 & Eletr_II_G1 & 3 & Rony & 2 \\
\hline 24 & SistL_II_G1 & 3 & Udo & 2 \\
\hline 25 & Matematic_V & 3 & Marcia & 4 \\
\hline 26 & ProC_III_G1 & 3 & Artur & 2 \\
\hline 27 & Arquitetura & 4 & Ramiro & 4 \\
\hline 28 & Eletromag_I & 4 & Marcelo & 4 \\
\hline 29 & Eletroni_II & 4 & Lideir & 4 \\
\hline 30 & Matemati_VI & 4 & Artur & 2 \\
\hline
\end{tabular}




\begin{tabular}{|c|c|c|c|c|}
\hline 31 & Matem_VI_G1 & 4 & Marcia & 2 \\
\hline 32 & Matemat_VII & 4 & Marcelo & 4 \\
\hline 33 & Mecânica__ & 4 & Assumpcao & 4 \\
\hline 34 & Meio_Ambien & 4 & Maria Tereza & 2 \\
\hline 35 & SegurancaTr & 4 & Caponi & 2 \\
\hline 36 & ConversaoEE & 5 & Rafael & 4 \\
\hline 37 & Mag__ II & 5 & Henrique & 2 \\
\hline 38 & Mag__II_G1 & 5 & Delboni & 2 \\
\hline 39 & Eletr_Ap_G1 & 5 & Lideir & 2 \\
\hline 40 & Legislacao__ & 5 & Marco Antonio & 2 \\
\hline 41 & Matemati_IX & 5 & Assumpcao & 2 \\
\hline 42 & Matem__VIII & 5 & Sônia & 4 \\
\hline 43 & RedesComput & 5 & Fabiano & 4 \\
\hline 44 & RedesC__ G1 & 5 & Fabiano & 2 \\
\hline 45 & Resistencia & 5 & Elizabeth & 2 \\
\hline 46 & AnaliseSist & 6 & Marcos & 4 \\
\hline 47 & Analise_G1 & 6 & Lideir & 2 \\
\hline 48 & AntenasProp & 6 & Henrique & 4 \\
\hline 49 & AntenasP_G1 & 6 & Henrique & 2 \\
\hline 50 & Economia__ & 6 & José Antonio & 4 \\
\hline 52 & FenomenosTr & 6 & Marcia & 2 \\
\hline 51 & MaquinasEle & 6 & Rafael & 2 \\
\hline 52 & Maquinas_G1 & 6 & Rafael & 2 \\
\hline 53 & OrientPI_G1 & 6 & Marcia & 2 \\
\hline 54 & PrincipiosC & 6 & Marcos & 4 \\
\hline 55 & Comunic_Dig & 7 & Ramiro & 4 \\
\hline 56 & Comu_Dig_G1 & 7 & Henrique & 2 \\
\hline 57 & Controle_I & 7 & Rafael & 4 \\
\hline 58 & CulturaRe_I & 7 & Mourtada & 4 \\
\hline 59 & DispositOpt & 7 & Assumpção & 4 \\
\hline 60 & Microondas_ & 7 & Henrique & 2 \\
\hline 61 & Microond_G1 & 7 & Henrique & 2 \\
\hline 62 & Estagio__G1 & 7 & Marcolino & 2 \\
\hline 63 & Controle_II & 8 & Rony & 2 \\
\hline 64 & Contr_II_G1 & 8 & Rony & 2 \\
\hline 65 & Gestao & 8 & Fabio & 4 \\
\hline 66 & Redes_Telec & 8 & Rony & 2 \\
\hline 67 & Redes_Te_G1 & 8 & Rony & 2 \\
\hline 68 & ServicosTel & 8 & Rony & 4 \\
\hline 69 & Siste_Radio & 8 & Sindi & 4 \\
\hline 70 & Sistema_Opt & 8 & Ramiro & 4 \\
\hline 71 & Sist_Opt_G1 & 8 & Ramiro & 2 \\
\hline 72 & Comun_S_Fio & 9 & Sindi & 2 \\
\hline 73 & Comu_S_F_G1 & 9 & Sindi & 2 \\
\hline 74 & CulturaR_II & 9 & Mourtada & 2 \\
\hline
\end{tabular}




\begin{tabular}{|l|l|l|l|l|}
75 & GerenciaRed & 9 & Correa & 4 \\
\hline 76 & Negocios__ & 9 & Fabio & 4 \\
\hline 77 & OrienPFC_G1 & 9 & Lideir & 2 \\
\hline 78 & SisSatelite & 9 & Henrique & 4 \\
\hline 79 & TopicosET_I & 9 & Marcelo & 2 \\
\hline 80 & Topicos_II & 9 & Sindi & 2 \\
\hline
\end{tabular}

A Tabela A.1 possui oitenta disciplinas, sendo que a segunda coluna possui as siglas para identificação da disciplina na grade horária; já na terceira coluna, são apresentados os semestres ao qual a disciplina pertence; na quarta coluna, o nome dos professores e na quinta e última coluna, a carga horária semanal da disciplina.

A seguir, serão apresentados exemplos de grades horárias geradas pelos algoritmos aqui desenvolvidos, nas quais se utilizaram os parâmetros de entrada apresentados na Tabela A.1 e tabelas contendo a disponibilidade de cada um dos professores.

As grades horárias a seguir apresentadas estão divididas entre nove semestres; com seis aulas diárias, de segunda-feira a sábado.

Serão então apresentados exemplos de grades horárias geradas automaticamente através do algoritmo genético e do CLONALG, desenvolvidos na presente pesquisa, as quais estão divididas entre os nove semestres do curso, com seis aulas diárias, de segunda-feira à sábado.

\section{A.1 Algoritmo Genético: Grade horária 1}

Fisica | | ProgC_IIG1 | JANELA | JANELA | Fisica | Filosofia_I |

Fisica I | ProgC_IIG1 | JANELA | JANELA | Fisica | Filosofia_I |

FisicaEB_G1 | JANELA | Matemati_II | Qu_Aplicada | Filosofia_I| Fisica__ |

FisicaEB_G1 | JANELA | Matemati_II|Qu_Aplicada | Filosofia_I| Fisica__ I |

Fisica_I | Program_C_I| Qu_Aplicada | Matemati_II | JANELA | Introducao_ |

Fisica_I | Program_C_I| Qu_Aplicada | Matemati_II | JANELA | Introducao_ |

\begin{tabular}{|c|c|c|}
\hline Desenho_G1 | MateriaisEE | Circuitos_I | & JANELA & I FlotricR G1 I Circu \\
\hline Desenho_G1 | MateriaisEE | Circuitos_I | & JANELA & | EletricB_G1 | Circuitos_I| \\
\hline Matemati_II | Sist_Logi_I| Matemati_IV | & JANELA & | FisicaEB_G1 | JANELA | \\
\hline Matemati_II | Sist_Logi_I| Matemati_IV | & JANELA & | FisicaEB_G1 | JANELA \\
\hline Sist_Logi_I| Matemati_IV | Matemati_II | & JANELA & | Filosof_II | Filosof_II | \\
\hline Sist_Logi_I| Matemati_IV | Matemati_II | & JANELA & | Filosof_II | Filosof_II | \\
\hline
\end{tabular}


Circuitos_I | FisicaEB_G1 | FisicaEB_G1 | FisicaEB_G1 | JANELA | Introducao_ | Circuitos_I| FisicaEB_G1 | FisicaEB_G1 | FisicaEB_G1 | JANELA | Introducao_ | Sist_Logi_I|Matemati_II| JANELA | Eletr_II_G1 | Matemati_II| JANELA | Sist_Logi_I| Matemati_II JANELA | Eletr_II_G1 | Matemati_II | JANELA | JANELA | Circuitos_I| Introducao_ | JANELA | JANELA | JANELA | JANELA | Circuitos_I| Introducao_| JANELA | JANELA | JANELA |

Introducao_| Matemati_II | Arquitetura | Eletromag_I| JANELA | SegurancaTr | Introducao_| Matemati_II | Arquitetura | Eletromag_I| JANELA | SegurancaTr | EletricB_G1|Meio_Ambien | JANELA | EletricB_G1|Eletromag_I| JANELA | EletricB_G1|Meio_Ambien | JANELA | EletricB_G1 | Eletromag_I| JANELA | Introducao_| FisicaEB_G1 | Arquitetura | Eletromag_I| JANELA | Eletromag_I| Introducao_| FisicaEB_G1 | Arquitetura | Eletromag_I| JANELA | Eletromag_I|

RedesComput | Legislacao_ | ConversaoEE | JANELA | ConversaoEE | Mag II |

RedesComput | Legislacao_ | ConversaoEE | JANELA | ConversaoEE | Mag__II | Resistencia | Introducao_| EletricB_G1 | JANELA | RedesComput | Matem_VIII | Resistencia | Introducao_ | EletricB_G1 | JANELA | RedesComput | Matem_VIII | JANELA | MateriaisEE | JANELA | JANELA | Matem_VIII | RedesComput | JANELA | MateriaisEE | JANELA | JANELA | Matem_VIII | RedesComput |

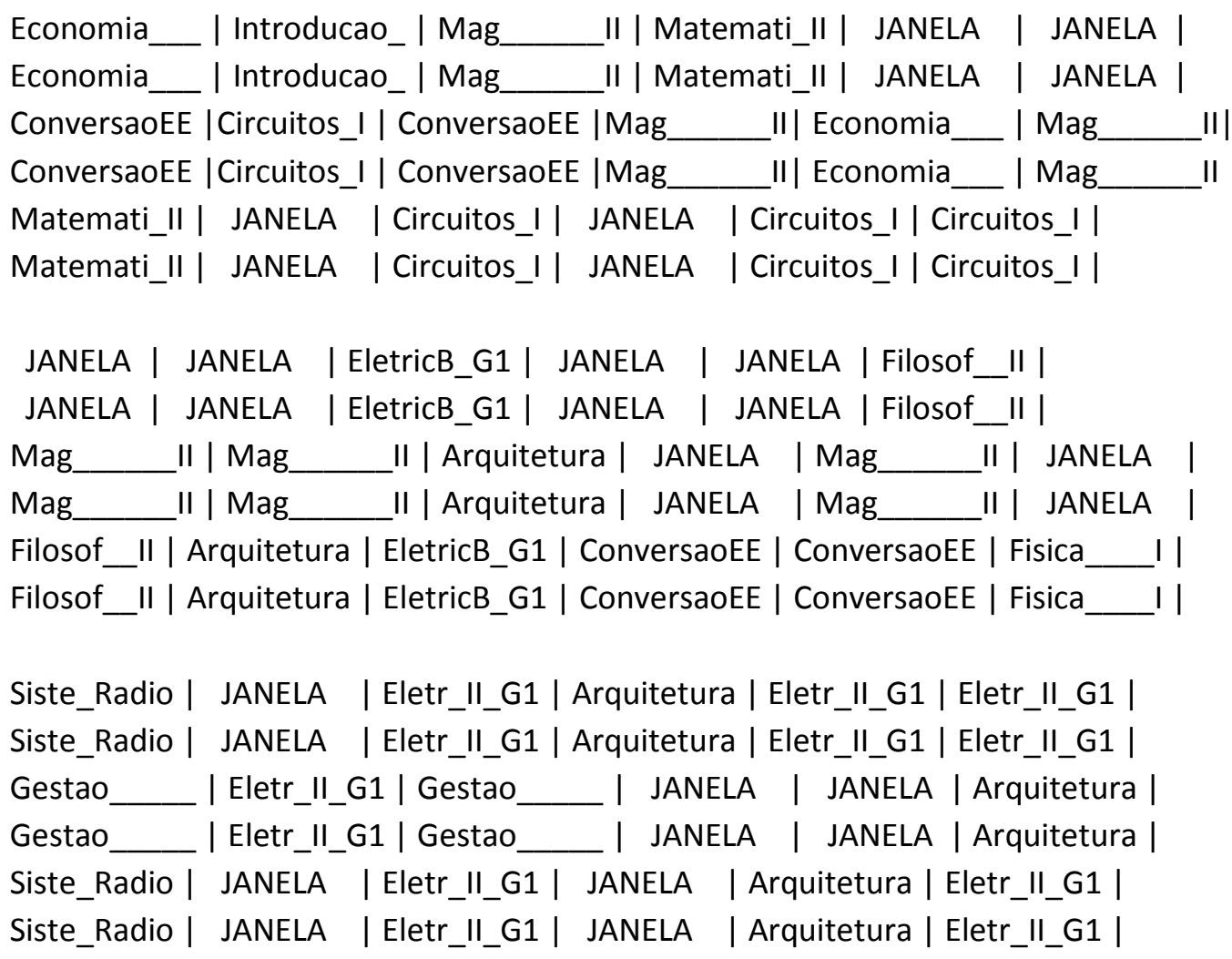


GerenciaRed | Siste_Radio | JANELA | JANELA | Gestao | JANELA |

GerenciaRed | Siste_Radio | JANELA | JANELA | Gestao JANELA | Introducao_| JANELA | JANELA | JANELA | Siste_Radio|Eletromag_I| Introducao_| JANELA | JANELA | JANELA | Siste_Radio | Eletromag_I| GerenciaRed | Mag II | Filosof_II | JANELA | Mag II | Gestao

GerenciaRed | Mag II | Filosof_II | JANELA | Mag II | Gestao

\section{A.2 Algoritmo Genético: Grade horária 2}

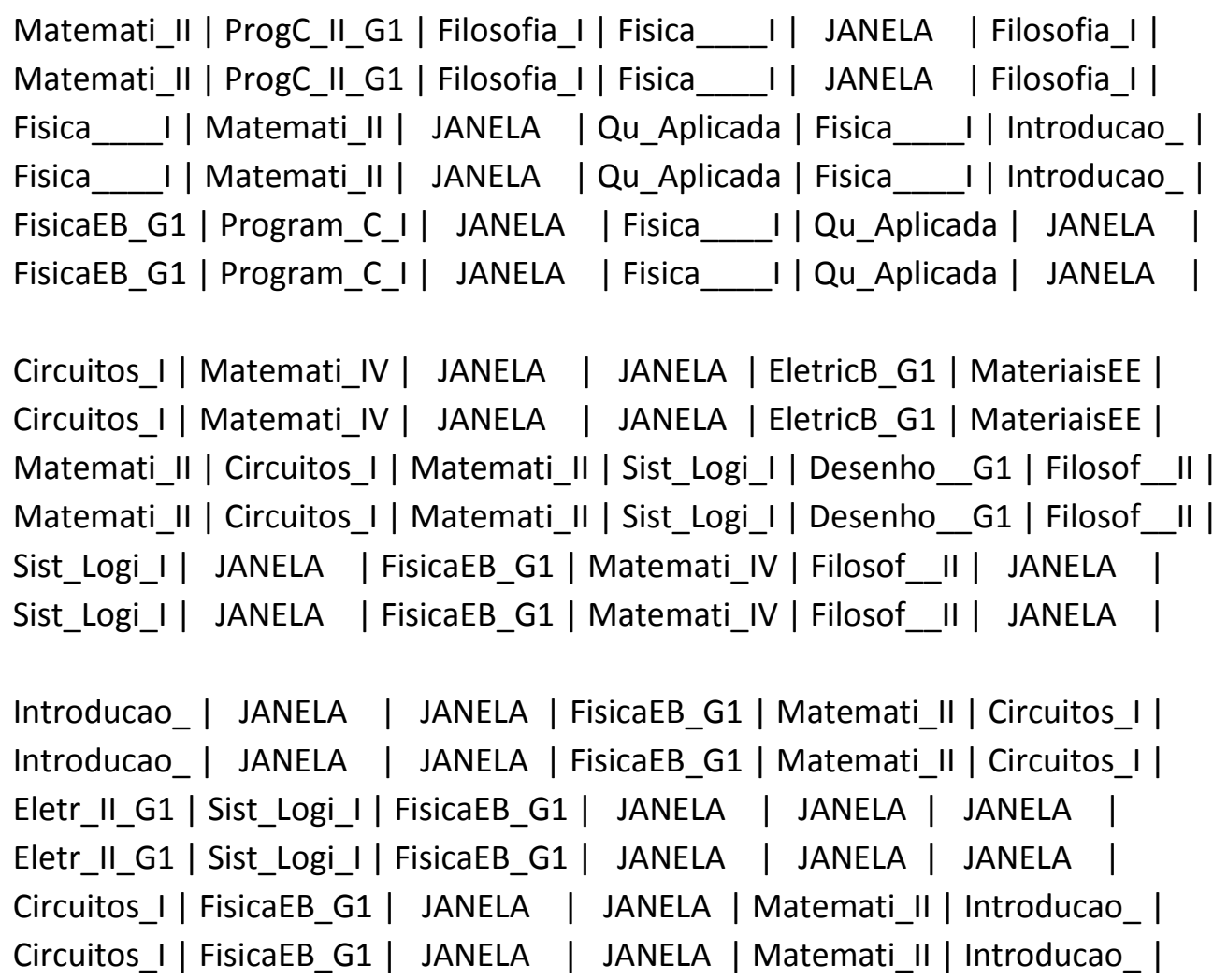

Arquitetura | Matemati_I| SegurancaTr | JANELA | JANELA | Introducao_ | Arquitetura | Matemati_II|SegurancaTr | JANELA | JANELA | Introducao_ | Meio_Ambien | FisicaEB_G1 | EletricB_G1 | Introducao_ | JANELA | Eletromag_I| Meio_Ambien | FisicaEB_G1 | EletricB_G1 | Introducao_| JANELA | Eletromag_I| Arquitetura | EletricB_G1 | Eletromag_I| Eletromag_I| Eletromag_I| JANELA | Arquitetura | EletricB_G1 | Eletromag_I| Eletromag_I| Eletromag_I| JANELA |

RedesComput | JANELA | MateriaisEE | JANELA | ConversaoEE | Matem_VIII | RedesComput | JANELA | MateriaisEE | JANELA | ConversaoEE | Matem_VIII | Resistencia | RedesComput | JANELA | EletricB_G1 | JANELA | Legislacao_ | Resistencia | RedesComput | JANELA | EletricB_G1 | JANELA | Legislacao_ | ConversaoEE | Mag II | Introducao_ I JANELA | RedesComput | Matem_VIII | ConversaoEE | Mag II | Introducao_ I JANELA | RedesComput | Matem_VIII | 


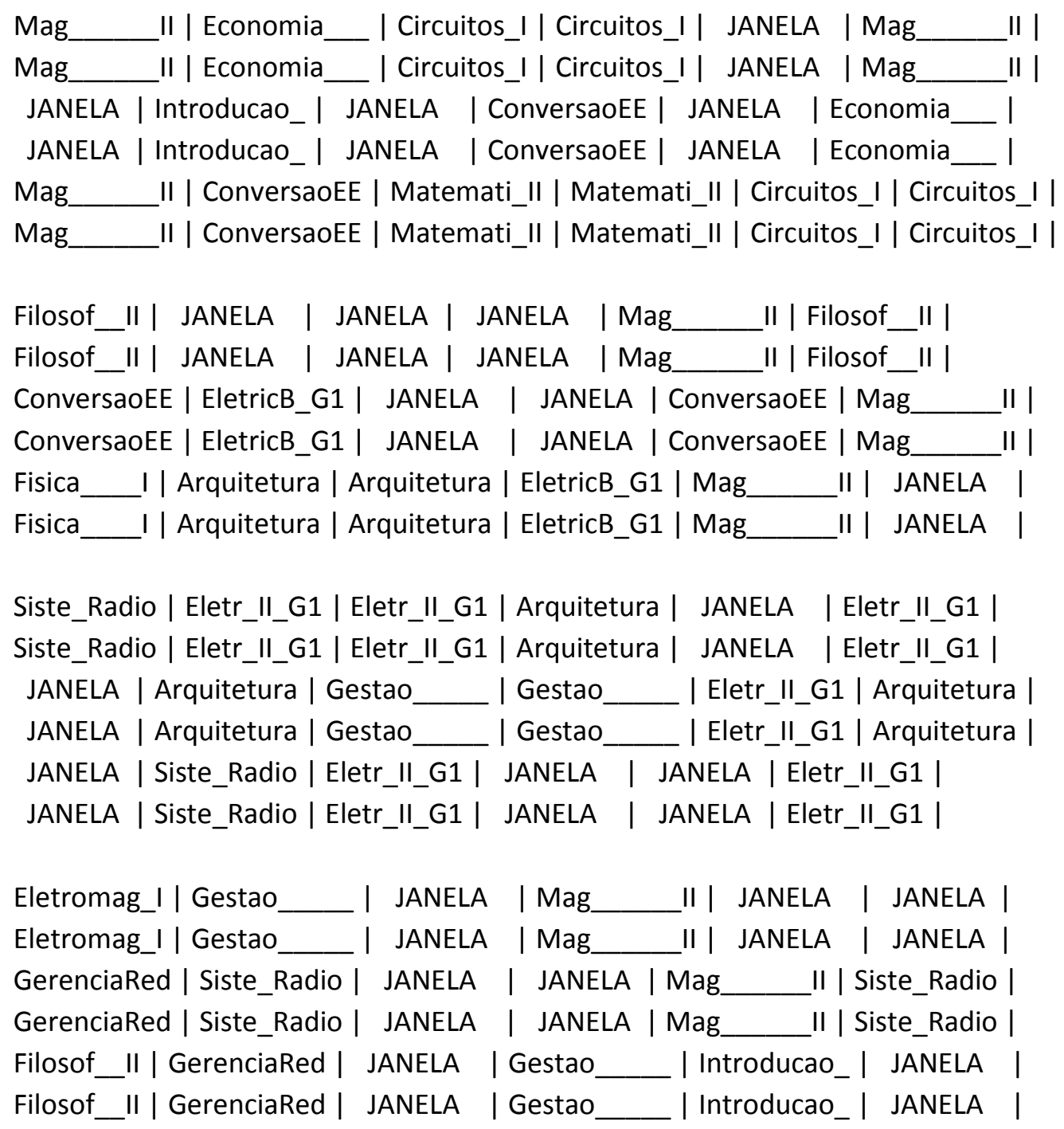

\title{
A.3 Algoritmo Genético: Grade horária 3
}

\author{
JANELA | Fisica__I I JANELA | FisicaEB_G1 | Matemati_II | Filosofia_I | \\ JANELA | Fisica__I I JANELA | FisicaEB_G1 | Matemati_II | Filosofia_I | \\ JANELA | Qu_Aplicada | Matemati_II | Fisica__ I Program_C_I | Fisica_ \\ JANELA | Qu_Aplicada | Matemati_II | Fisica__ I Program_C_I | Fisica__I | \\ ProgC_II_G1 | JANELA | Filosofia_I| Qu_Aplicada | Fisica__ I Introducao_ | \\ ProgC_II_G1 | JANELA | Filosofia_I| Qu_Aplicada | Fisica__I Introducao_ | \\ Desenho_G1 | Matemati_IV | Sist_Logi_I | Circuitos_I | Matemati_IV | Filosof_II | \\ Desenho_G1 | Matemati_IV | Sist_Logi_I | Circuitos_I | Matemati_IV | Filosof_II | \\ Filosof_II | Matemati_II | JANELA | Sist_Logi_I| FisicaEB_G1 | JANELA | \\ Filosof_II | Matemati_II | JANELA | Sist_Logi_I| FisicaEB_G1 | JANELA | \\ MateriaisEE | JANELA | EletricB_G1|Matemati_II|Circuitos_I| JANELA | \\ MateriaisEE | JANELA | EletricB_G1| Matemati_II|Circuitos_I| JANELA |
}




Sist_Logi_I | Matemati_II | Circuitos_I | Matemati_II | JANELA | JANELA |
Sist_Logi_I | Matemati_II | Circuitos_I | Matemati_II | JANELA | JANELA |
Introducao_ | JANELA | Eletr_II_G1 | JANELA | JANELA | Circuitos_I |
Introducao_ | JANELA | Eletr_II_G1 | JANELA | JANELA | Circuitos_I |
FisicaEB_G1 | FisicaEB_G1 | Introducao_ | JANELA | FisicaEB_G1 | JANELA |
FisicaEB_G1 | FisicaEB_G1 | Introducao_ | JANELA | FisicaEB_G1 | JANELA |
Introducao_ | Eletromag_I | Arquitetura | Introducao_ | FisicaEB_G1 | Meio_Ambien |
Introducao_ | Eletromag_I | Arquitetura | Introducao_ | FisicaEB_G1 | Meio_Ambien |
JANELA | EletricB_G1 | EletricB_G1 | JANELA | SegurancaTr | JANELA |
JANELA | EletricB_G1 | EletricB_G1 | JANELA | SegurancaTr | JANELA |
Matemati_II | JANELA | Eletromag_I | Eletromag_I| Eletromag_I| Arquitetura |
Matemati_II | JANELA | Eletromag_I | Eletromag_I| Eletromag_I| Arquitetura |
ConversaoEE | Legislacao_ | JANELA | JANELA | MateriaisEE | Resistencia |
ConversaoEE | Legislacao_ | JANELA | JANELA | MateriaisEE | Resistencia |
RedesComput | JANELA | JANELA | Matem_VIII | RedesComput | Introducao_ |
RedesComput | JANELA | JANELA | Matem_VIII | RedesComput | Introducao_ |
Mag__II | EletricB_G1 | RedesComput | ConversaoEE | JANELA | Matem_VIII |
Mag_II | EletricB_G1 | RedesComput | ConversaoEE | JANELA | Matem_VIII |

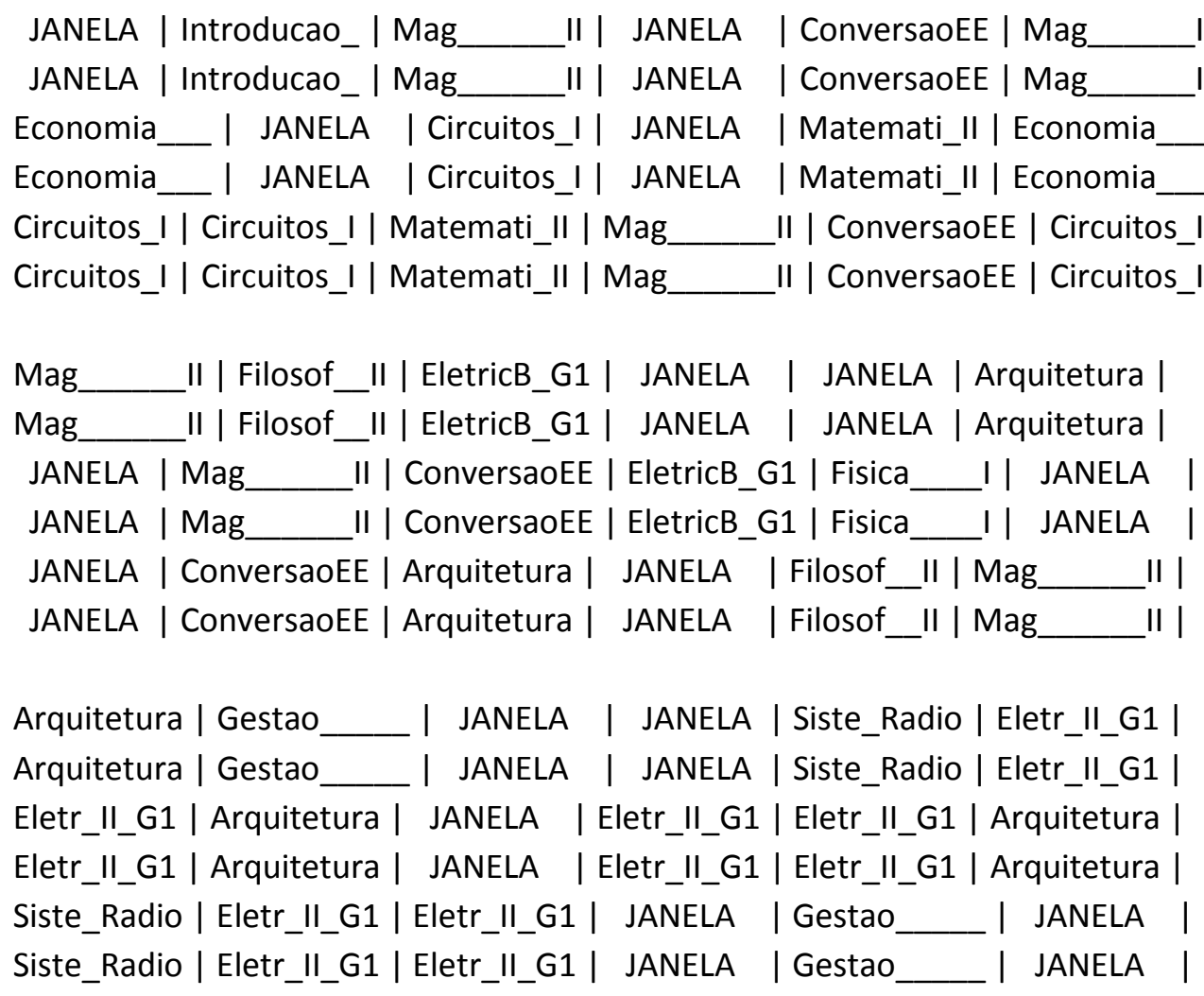




Gestao__ GerenciaRed | JANELA | GerenciaRed | JANELA | JANELA |
Gestao_ | GerenciaRed | JANELA | GerenciaRed | JANELA | JANELA |
Siste_Radio | Introducao_ | Filosof_II | JANELA | Mag_II | Mag__II |
Siste_Radio | Introducao_ | Filosof_II | JANELA | Mag__II | Mag__ I |
Eletromag_I| JANELA | Gestao__ JANELA | Siste_Radio | JANELA |
Eletromag_I| JANELA | Gestao__ JANELA | Siste_Radio | JANELA |

\section{A.4 Algoritmo Genético: Grade horária 4}

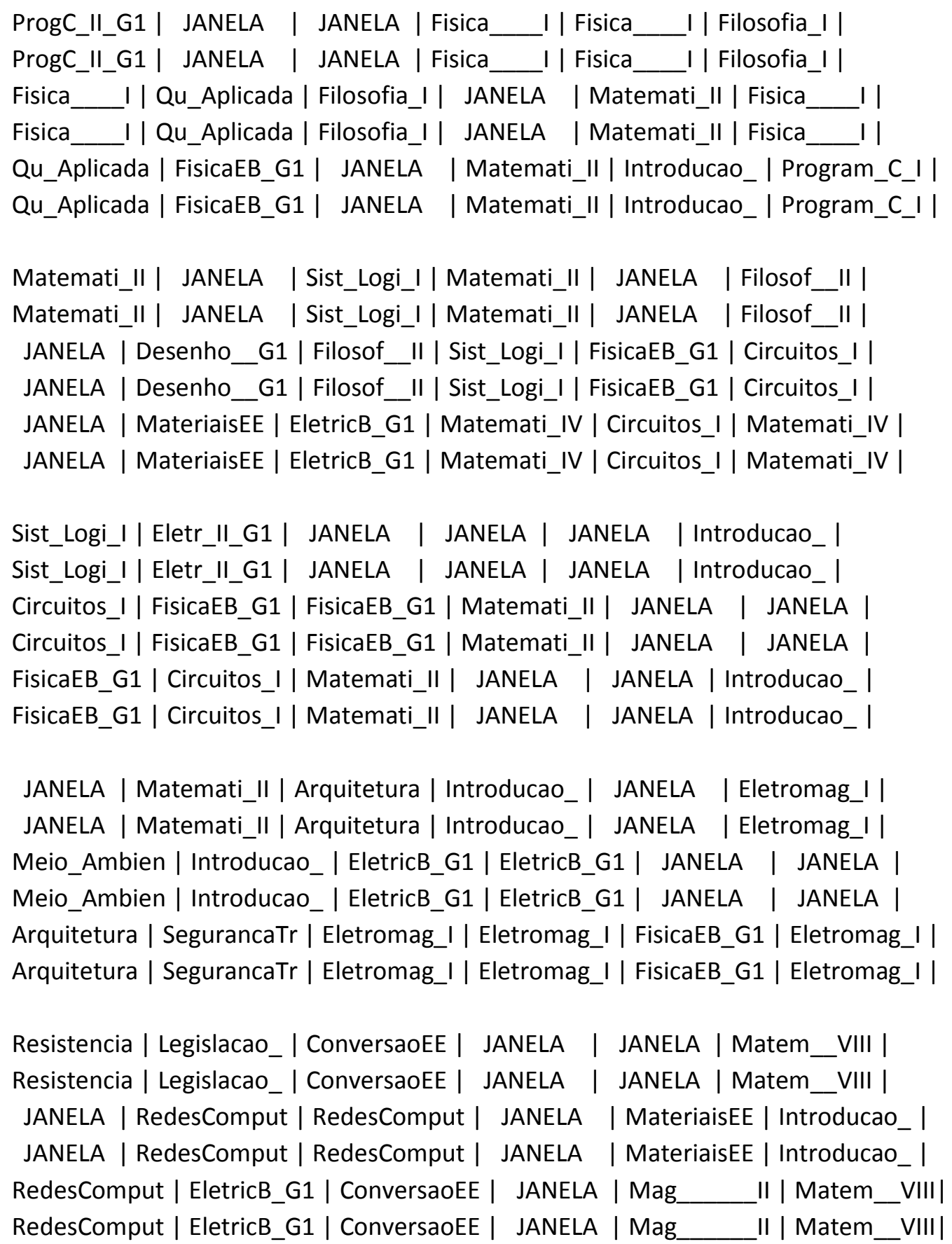


Economia | Introducao_ | JANELA | JANELA | Matemati_II | Circuitos_I | Economia_ I Introducao_ | JANELA | JANELA | Matemati_II | Circuitos_I| JANELA | Circuitos_I| Circuitos_I| JANELA | Mag II | Mag II I JANELA | Circuitos_I|Circuitos_I| JANELA | Mag II | Mag II |

Circuitos_I| ConversaoEE | Mag II |ConversaoEE | Matemati_II |Economia

Circuitos_I| ConversaoEE | Mag II |ConversaoEE | Matemati_I||Economia

Fisica I| Filosof_II | EletricB_G1 | Mag II | JANELA | Mag II |

Fisica I| Filosof_II | EletricB_G1 | Mag II | JANELA | Mag III

JANELA | JANELA | ConversaoEE | ConversaoEE | JANELA | Filosof_II JANELA | JANELA | ConversaoEE | ConversaoEE | JANELA | Filosof_II | Mag II | Arquitetura | JANELA | EletricB_G1 | JANELA | Arquitetura |

Mag II | Arquitetura | JANELA | EletricB_G1 | JANELA | Arquitetura |

Gestao | Arquitetura | Gestao | Eletr_II_G1 | Arquitetura | JANELA |

Gestao | Arquitetura | Gestao | Eletr_II_G1 | Arquitetura | JANELA |

Siste_Radio | JANELA | Eletr_II_G1 | JANELA | Eletr_II_G1 | JANELA | Siste_Radio | JANELA | Eletr_II_G1 | JANELA | Eletr_II_G1 | JANELA | JANELA | Eletr_II_G1 | Arquitetura | Eletr_II_G1 | Siste_Radio | Eletr_II_G1 | JANELA | Eletr_II_G1 | Arquitetura | Eletr_IIG1 | Siste_Radio | Eletr_IIG1 |

Introducao_ | Gestao | JANELA | JANELA | JANELA | Gestao

Introducao_ | Gestao I JANELA | JANELA | JANELA | Gestao

Mag___ II | Mag II | JANELA | JANELA | Eletromag_I| Siste_Radio |

Mag II | Mag II | JANELA | JANELA | Eletromag_I|Siste_Radio | Filosof_II | Siste_Radio | JANELA | JANELA | GerenciaRed | GerenciaRed | Filosof_II| Siste_Radio | JANELA | JANELA | GerenciaRed | GerenciaRed |

\section{A.5 CLONALG: Grade horária 1}

JANELA | ProgC_II_G1 | FisicaEB_G1 | Qu_Aplicada | Fisica I) JANELA | JANELA | ProgC_II_G1 | FisicaEB_G1 | Qu_Aplicada | Fisica | JANELA | JANELA | Matemati_II | Qu_Aplicada | Fisica I| Filosofia_I| Fisica JANELA | Matemati_II | Qu_Aplicada | Fisica 1| Filosofia_I| Fisica II Introducao_| JANELA | Program_C_I| Matemati_II | Fisica I | Filosofia_I | Introducao_| JANELA | Program_C_I| Matemati_II| Fisica I| Filosofia_I|

Matemati_II | Circuitos_I| Matemati_IV | Sist_Logi_I| JANELA | Filosof_II | Matemati_II | Circuitos_I| Matemati_IV | Sist_Logi_I| JANELA | Filosof_II | MateriaisEE | Desenho_G1 | Matemati_II | JANELA | Filosof_II | Matemati_IV | MateriaisEE | Desenho_G1 | Matemati_II JANELA | Filosof_II| Matemati_IV | EletricB_G1 | JANELA | FisicaEB_G1 | Sist_Logi_I|Circuitos_I| JANELA | EletricB_G1| JANELA | FisicaEB_G1|Sist_Logi_I|Circuitos_I| JANELA | 
Eletr_II_G1 | FisicaEB_G1 | Circuitos_I| Matemati_II | JANELA | Circuitos_I |

Eletr_IIG1 | FisicaEB_G1 | Circuitos_I| Matemati_II | JANELA | Circuitos_I| Introducao_| Introducao_| FisicaEB_G1 | JANELA | JANELA | JANELA | Introducao_| Introducao_| FisicaEB_G1 | JANELA | JANELA | JANELA | Matemati_II | FisicaEB_G1 | Sist_Logi_I| JANELA | JANELA | JANELA | Matemati_II| FisicaEB_G1 |Sist_Logi_I| JANELA | JANELA | JANELA |

Eletromag_I|Arquitetura | Arquitetura | JANELA | JANELA | EletricB_G1 | Eletromag_I|Arquitetura | Arquitetura | JANELA | JANELA | EletricB_G1 | Matemati_II Meio_Ambien | SegurancaTr | JANELA | JANELA | Eletromag_I| Matemati_II | Meio_Ambien | SegurancaTr | JANELA | JANELA | Eletromag_I| FisicaEB_G1 | EletricB_G1 | Introducao_ | Eletromag_I| Eletromag_I Introducao_ | FisicaEB_G1 | EletricB_G1 | Introducao_ | Eletromag_I| Eletromag_I| Introducao_ |

JANELA | Legislacao_ | RedesComput | Matem_VIII | JANELA | JANELA |
JANELA | Legislacao__ RedesComput | Matem_VIII | JANELA | JANELA |
RedesComput | Mag__I | ConversaoEE | Introducao_ | RedesComput |JANELA |
RedesComput | Mag__I | ConversaoEE | Introducao_ | RedesComput | JANELA |
Resistencia | MateriaisEE | EletricB_G1 | JANELA | ConversaoEE | Matem_VIII |
Resistencia | MateriaisEE | EletricB_G1 | JANELA | ConversaoEE | Matem_VIII |

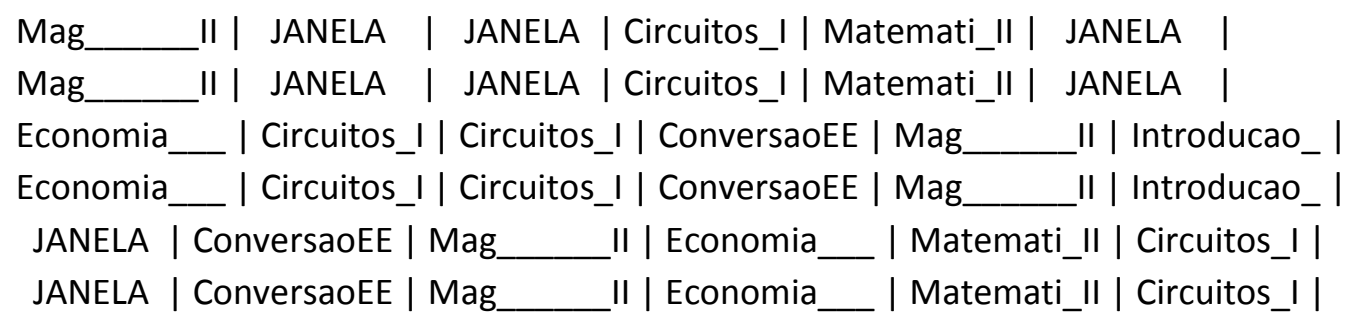

ConversaoEE | Filosof_II | JANELA | Mag__II | JANELA | Mag__II |

ConversaoEE | Filosof_II| JANELA | Mag__II IANELA | Mag__II |

Fisica_II JANELA | JANELA | JANELA | EletricB_G1 | EletricB_G1 |

Fisica_ I JANELA | JANELA | JANELA | EletricB_G1 | EletricB_G1 |

Mag__II | Arquitetura | Arquitetura | ConversaoEE | JANELA | Filosof_II |

Mag__II | Arquitetura | Arquitetura | ConversaoEE | JANELA | Filosof_II |

Siste_Radio | Gestao__ I JANELA | Eletr_II_G1 | Arquitetura | JANELA |

Siste_Radio | Gestao__ I JANELA | Eletr_II_G1 | Arquitetura | JANELA |

Gestão__ Siste_Radio | Eletr_IIG1 | JANELA | Eletr_II_G1 | Eletr_II_G1 |

Gestão__ | Siste_Radio | Eletr_II_G1 | JANELA | Eletr_II_G1 | Eletr_II_G1 |

Eletr_II_G1 | Eletr_IIG1 | JANELA | JANELA | Arquitetura | Arquitetura |

Eletr_II_G1 | Eletr_IIG1 | JANELA | JANELA | Arquitetura | Arquitetura | 


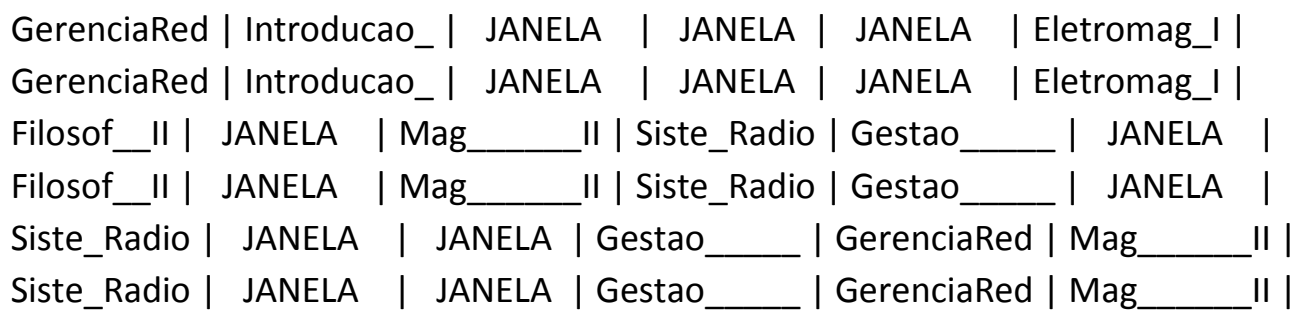

\section{A.6 CLONALG: Grade horária 2}

ProgC_II_G1 | Matemati_II | Filosofia_I| FisicaEB_G1 | JANELA | Introducao_ | ProgC_II_G1 | Matemati_II| Filosofia_I| FisicaEB_G1 | JANELA | Introducao_ | Matemati_II | Qu_Aplicada | JANELA | JANELA | JANELA | Filosofia_I| Matemati_II|Qu_Aplicada | JANELA | JANELA | JANELA | Filosofia_I| Fisica__ | Program_C_I | Qu_Aplicada | Fisica__ | Fisica__ | Fisica__I | Fisica__ I Program_C_I | Qu_Aplicada | Fisica__ I Fisica__ I Fisica__ I |

Filosof_II | FisicaEB_G1 | Circuitos_I| JANELA | Matemati_II | EletricB_G1 | Filosof_II | FisicaEB_G1 | Circuitos_I| JANELA | Matemati_II | EletricB_G1 | Sist_Logi_I| Matemati_IV | Sist_Logi_I| Matemati_II| JANELA | Filosof_II | Sist_Logi_I| Matemati_IV | Sist_Logi_I| Matemati_II JANELA | Filosof_II | Circuitos_I|Desenho_G1 | MateriaisEE | JANELA | JANELA | Matemati_IV | Circuitos_I|Desenho_G1| MateriaisEE | JANELA | JANELA | Matemati_IV |

Matemati_II Circuitos_I| JANELA | JANELA | FisicaEB_G1 | FisicaEB_G1 | Matemati_II | Circuitos_I| JANELA | JANELA | FisicaEB_G1 | FisicaEB_G1 | Circuitos_I|Eletr_II_G1 | JANELA | JANELA | JANELA | JANELA | Circuitos_I|Eletr_II_G1 | JANELA | JANELA | JANELA | JANELA | Sist_Logi_I| FisicaEB_G1 | Matemati_II | JANELA | Introducao_ I Introducao_ | Sist_Logi_I| FisicaEB_G1 | Matemati_II | JANELA | Introducao_| Introducao_|

Eletromag_I | Eletromag_I| FisicaEB_G1 | Arquitetura | EletricB_G1 | Meio_Ambien | Eletromag_I| Eletromag_I| FisicaEB_G1 | Arquitetura | EletricB_G1 | Meio_Ambien | Introducao_| JANELA | Matemati_II| Eletromag_I| Eletromag_I| Arquitetura | Introducao_| JANELA | Matemati_II|Eletromag_I| Eletromag_I| Arquitetura | EletricB_G1 | JANELA | Introducao_|SegurancaTr | JANELA | JANELA | EletricB_G1 | JANELA | Introducao_| SegurancaTr | JANELA | JANELA |

JANELA | RedesComput | RedesComput | Matem_VIII | ConversaoEE | JANELA | JANELA | RedesComput | RedesComput | Matem_VIII | ConversaoEE | JANELA | Mag__II Introducao_| EletricB_G1 | MateriaisEE | JANELA | Legislacao_ | Mag__II Introducao_| EletricB_G1 | MateriaisEE | JANELA | Legislacao_ | Resistencia | ConversaoEE | RedesComput | JANELA | JANELA | Matem_VIII | Resistencia | ConversaoEE | RedesComput | JANELA | JANELA | Matem_VIII | 


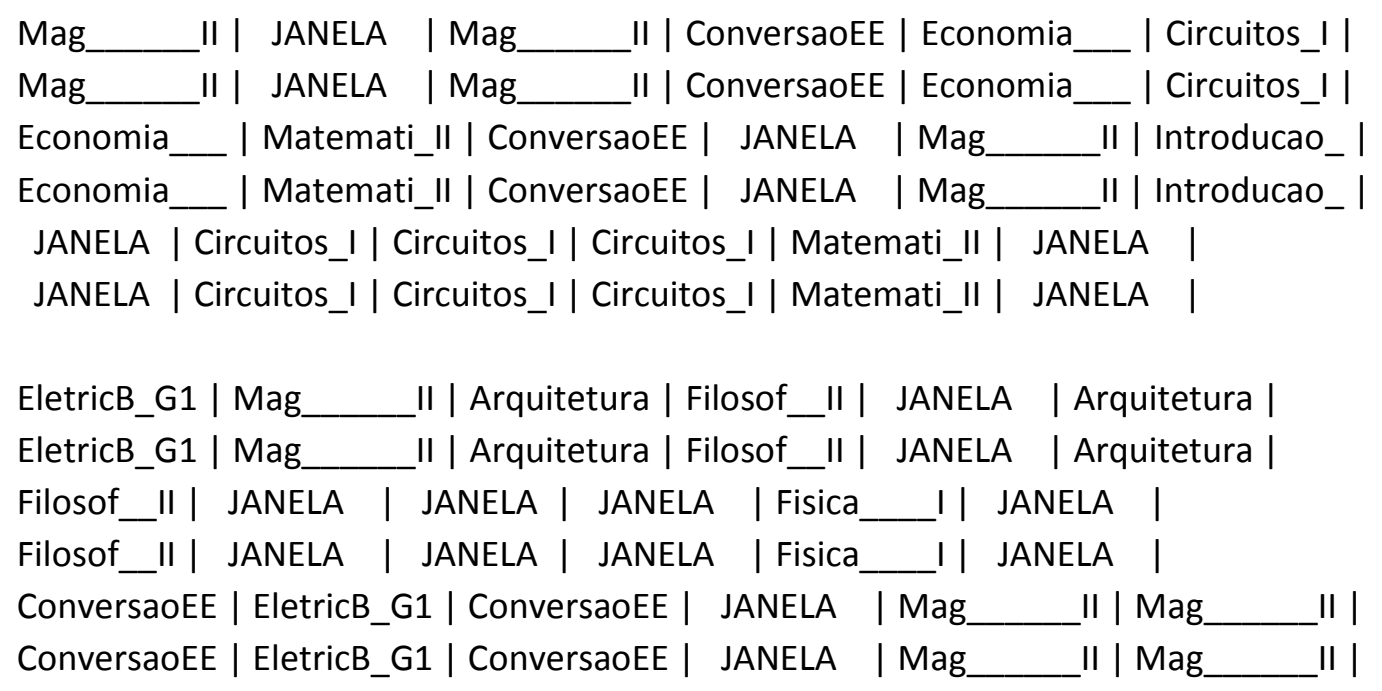

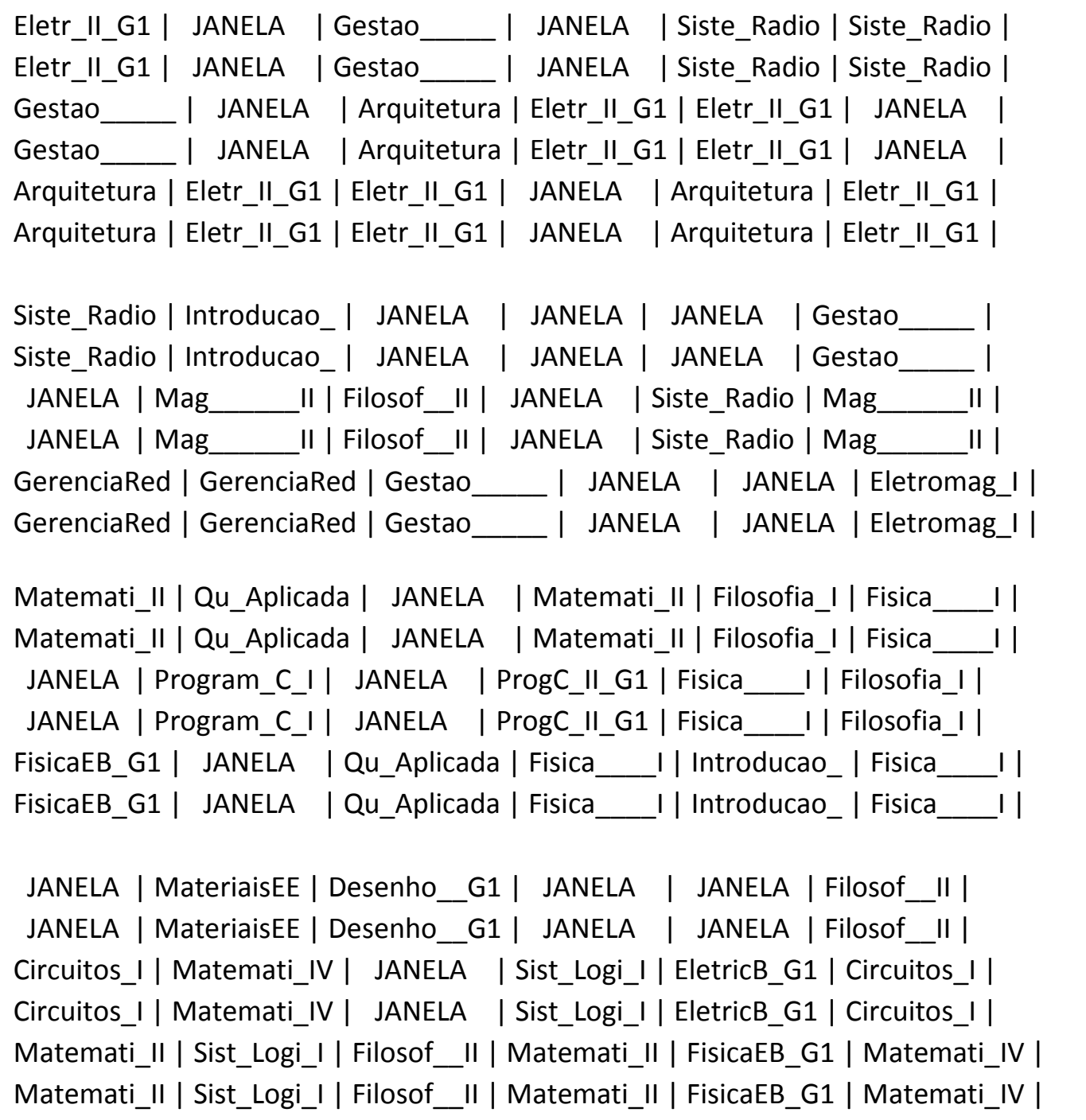


FisicaEB_G1 | Sist_Logi_I| JANELA | JANELA | FisicaEB_G1 | Introducao_ | FisicaEB_G1 | Sist_Logi_I| JANELA | JANELA | FisicaEB_G1 | Introducao_ | Matemati_II | Matemati_II FisicaEB_G1 | Introducao_ | JANELA | JANELA | Matemati_II | Matemati_II | FisicaEB_G1 | Introducao_ | JANELA | JANELA | JANELA | JANELA | JANELA | Eletr_II_G1 | Circuitos_I| Circuitos_I| JANELA | JANELA | JANELA | Eletr_II_G1 | Circuitos_I|Circuitos_I|

JANELA | SegurancaTr | Arquitetura | Arquitetura | Eletromag_I| Meio_Ambien | JANELA | SegurancaTr | Arquitetura | Arquitetura | Eletromag_I| Meio_Ambien | Introducao_| EletricB_G1 | Matemati_II | Eletromag_I | FisicaEB_G1 | EletricB_G1 | Introducao_ | EletricB_G1 | Matemati_II | Eletromag_I | FisicaEB_G1 | EletricB_G1 | JANELA | JANELA | Eletromag_I| Introducao_| JANELA | Eletromag_I| JANELA | JANELA | Eletromag_I| Introducao_| JANELA | Eletromag_I|

Introducao_| Mag__I| ConversaoEE | JANELA | EletricB_G1 | Legislacao_ | Introducao_| Mag__II ConversaoEE | JANELA | EletricB_G1 | Legislacao_ | Resistencia |MateriaisEE | Matem__VIII | RedesComput |RedesComput |RedesComput| Resistencia |MateriaisEE | Matem_VIII | RedesComput |RedesComput |RedesComput| JANELA | JANELA | JANELA | JANELA | ConversaoEE | Matem_VIII | JANELA | JANELA | JANELA | JANELA | ConversaoEE | Matem_VIII |

Circuitos_I | Matemati_II | Circuitos_I | ConversaoEE | ConversaoEE | Circuitos_I | Circuitos_I | Matemati_II | Circuitos_I | ConversaoEE | ConversaoEE | Circuitos_I | JANELA | Mag__II | Mag__III JANELA | Mag___II | Introducao_ I JANELA | Mag__II | Mag__II | JANELA | Mag___II | Introducao_ | Economia__ JANELA | Circuitos_I|Economia_ | Matemati_II | JANELA | Economia__ JANELA | Circuitos_I|Economia__ Matemati_II JANELA |

ConversaoEE | Filosof_II | JANELA | Mag__II | Arquitetura | EletricB_G1 |

ConversaoEE | Filosof_II | JANELA | Mag__II Arquitetura | EletricB_G1 |

Mag__II Arquitetura | JANELA | JANELA | ConversaoEE | Mag___I |

Mag__II Arquitetura | JANELA | JANELA | ConversaoEE | Mag__II |

Fisica_ I| EletricB_G1 | JANELA | JANELA | JANELA | Filosof_II

Fisica_I| EletricB_G1 | JANELA | JANELA | JANELA | Filosof_II

Siste_Radio | Arquitetura | Siste_Radio | Eletr_IIG1 | JANELA | Eletr_II_G1 |

Siste_Radio | Arquitetura | Siste_Radio | Eletr_II_G1 | JANELA | Eletr_IIG1 |

Arquitetura | JANELA | Eletr_IIG1 | JANELA | JANELA | Gestao___ |

Arquitetura | JANELA | Eletr_II_G1 | JANELA | JANELA | Gestao__ I

Eletr_IIG1 | Eletr_II_G1 | Arquitetura | JANELA | Gestao__ | Eletr_IIG1 |

Eletr_II_G1 | Eletr_II_G1 | Arquitetura | JANELA | Gestao__ | Eletr_IIG1 | 


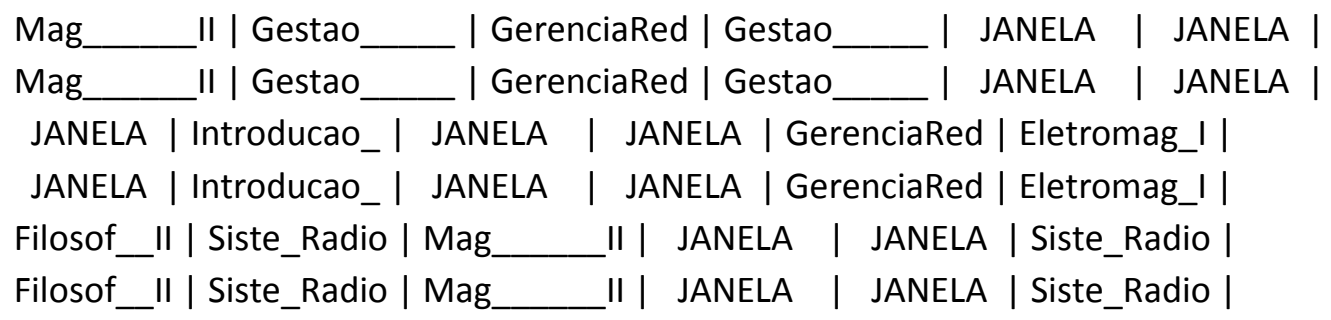

\section{A.7 CLONALG: Grade horária 3}

JANELA | FisicaEB_G1 | JANELA | Fisica__ | JANELA | Fisica__ |
JANELA | FisicaEB_G1 | JANELA | Fisica__ | JANELA | Fisica__ |

Fisica__I JANELA | ProgC_II_G1 | Qu_Aplicada | Matemati_II | Filosofia_I |

Fisica_II JANELA | ProgC_IIGG1 | Qu_Aplicada | Matemati_II | Filosofia_I |

Introducao_| Program_C_I | Matemati_I | Fisica__ I Filosofia_I | Qu_Aplicada |

Introducao_| Program_C_I| Matemati_II | Fisica__I| Filosofia_I| Qu_Aplicada |

MateriaisEE | Matemati_I| JANELA | Sist_Logi_I| JANELA | Circuitos_I| MateriaisEE | Matemati_II | JANELA | Sist_Logi_I| JANELA | Circuitos_I| EletricB_G1 | JANELA | Sist_Logi_I| Matemati_II | Desenho_G1 | Filosof_II | EletricB_G1 | JANELA | Sist_Logi_I| Matemati_II Desenho_G1 | Filosof_II | Circuitos_I| FisicaEB_G1 | JANELA | Matemati_IV | Filosof_II | Matemati_IV | Circuitos_I| FisicaEB_G1 | JANELA | Matemati_IV | Filosof_II | Matemati_IV |

JANELA | JANELA | FisicaEB_G1 | JANELA | JANELA | JANELA | JANELA | JANELA | FisicaEB_G1 | JANELA | JANELA | JANELA | Introducao_| JANELA | Matemati_II JANELA | FisicaEB_G1 | Circuitos_I| Introducao_| JANELA | Matemati_II | JANELA | FisicaEB_G1 | Circuitos_I| FisicaEB_G1 | Circuitos_I | Eletr_II_G1 | Sist_Logi_I | Matemati_II | Introducao_ | FisicaEB_G1 | Circuitos_I | Eletr_IIG1 | Sist_Logi_I| Matemati_II | Introducao_ |

Meio_Ambien | Eletromag_I|SegurancaTr | Arquitetura | JANELA | Eletromag_I| Meio_Ambien | Eletromag_I|SegurancaTr | Arquitetura | JANELA | Eletromag_I| FisicaEB_G1 | Matemati_II | EletricB_G1 | Eletromag_I | Eletromag_I EletricB_G1 | FisicaEB_G1 | Matemati_II | EletricB_G1 | Eletromag_I| Eletromag_I EletricB_G1 | JANELA | JANELA | Introducao_| JANELA | Introducao_| Arquitetura | JANELA | JANELA | Introducao_| JANELA | Introducao_| Arquitetura |

Resistencia | Introducao_| RedesComput | JANELA | JANELA | Legislacao_ | Resistencia | Introducao_| RedesComput | JANELA | JANELA | Legislacao_ | JANELA | RedesComput | MateriaisEE | ConversaoEE | ConversaoEE | JANELA | JANELA | RedesComput | MateriaisEE | ConversaoEE | ConversaoEE | JANELA | JANELA |Matem_VIII | Matem_VIII | EletricB_G1 | Mag_ II | RedesComput | JANELA |Matem_VIII | Matem_VIII | EletricB_G1 | Mag II | RedesComput | 


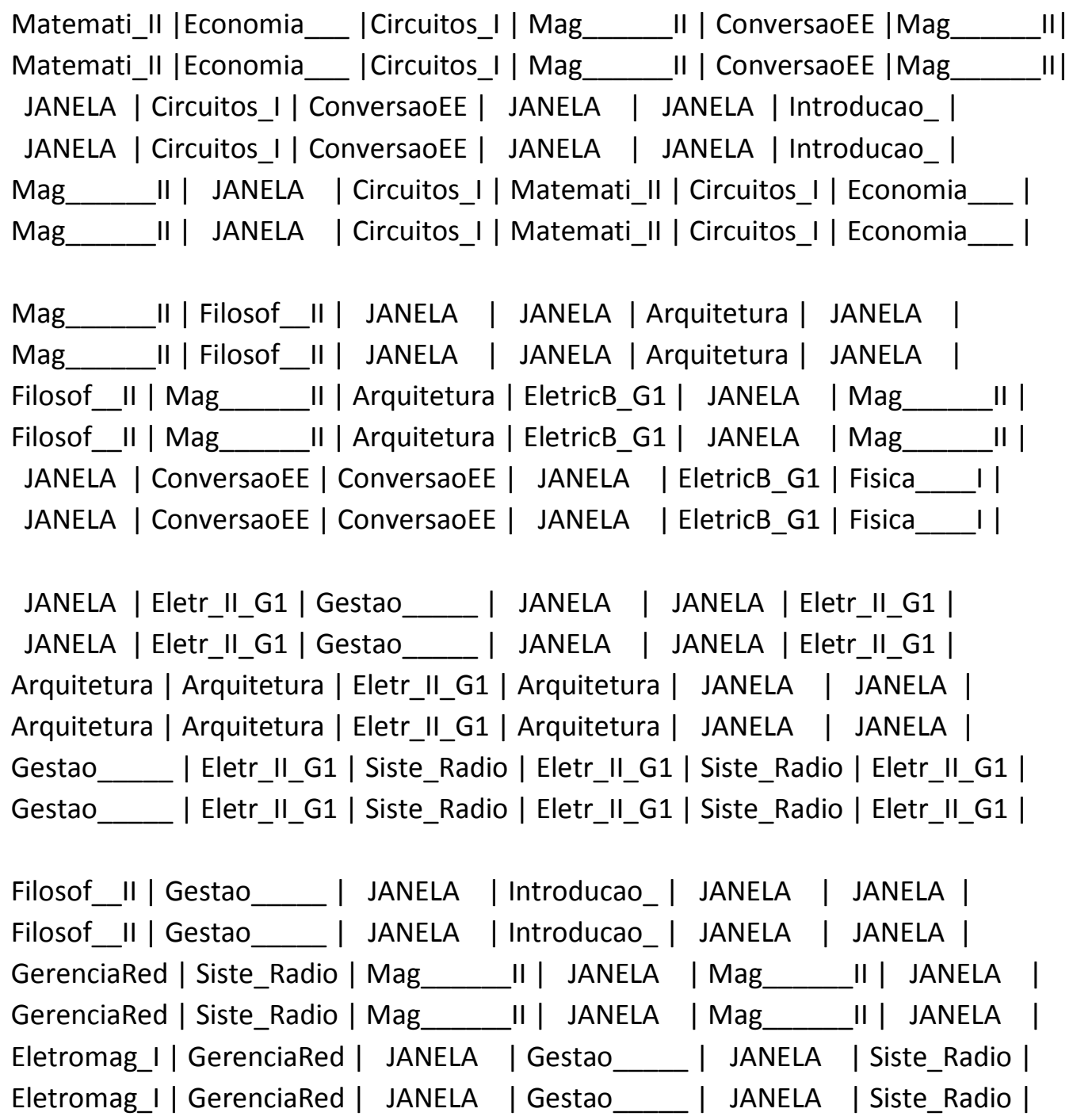

\section{A.8 CLONALG: Grade horária 4}

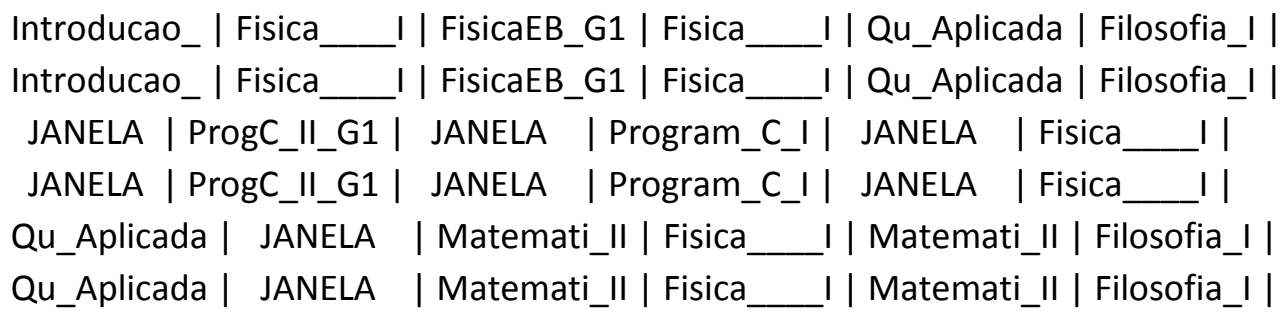

Filosof_II | Matemati_II | Matemati_IV | FisicaEB_G1 | JANELA | JANELA | Filosof_II | Matemati_II | Matemati_IV | FisicaEB_G1 | JANELA | JANELA | Matemati_IV | Desenho_G1 | Circuitos_I| MateriaisEE | JANELA | Circuitos_I| Matemati_IV | Desenho_G1 | Circuitos_I| MateriaisEE | JANELA | Circuitos_I| EletricB_G1 | Sist_Logi_I|Sist_Logi_I| Matemati_II | Filosof_II | JANELA | EletricB_G1 | Sist_Logi_I|Sist_Logi_I| Matemati_II| Filosof_II| JANELA | 
FisicaEB_G1 | Circuitos_I| JANELA | Circuitos_I| Matemati_II | JANELA | FisicaEB_G1|Circuitos_I| JANELA | Circuitos_I| Matemati_II | JANELA | Matemati_II | Introducao_| JANELA | JANELA | FisicaEB_G1 | JANELA | Matemati_II Introducao_| JANELA | JANELA | FisicaEB_G1 | JANELA | Sist_Logi_I| JANELA | FisicaEB_G1 | Eletr_II_G1 | Introducao_ | JANELA | Sist_Logi_I| JANELA | FisicaEB_G1 | Eletr_II_G1 | Introducao_| JANELA |

Matemati_II | Arquitetura | Arquitetura | Introducao_ | JANELA | Introducao_ | Matemati_II | Arquitetura | Arquitetura | Introducao_ I JANELA | Introducao_ | Eletromag_I| FisicaEB_G1 | JANELA | EletricB_G1 | JANELA | JANELA | Eletromag_I| FisicaEB_G1 | JANELA | EletricB_G1 | JANELA | JANELA | Meio_Ambien|SegurancaTr | EletricB_G1 | Eletromag_I| Eletromag_I |Eletromag_I| Meio_Ambien|SegurancaTr | EletricB_G1 | Eletromag_I| Eletromag_I|Eletromag_I|

RedesComput | Introducao_| MateriaisEE | JANELA | JANELA | Matem_VIII | RedesComput | Introducao_| MateriaisEE | JANELA | JANELA | Matem_VIII | JANELA | Mag__II | EletricB_G1 | ConversaoEE | Matem_VIII | Resistencia | JANELA | Mag__II | EletricB_G1 | ConversaoEE | Matem_VIII | Resistencia | RedesComput | RedesComput | ConversaoEE | JANELA | Legislacao_| JANELA | RedesComput | RedesComput | ConversaoEE | JANELA | Legislacao_|JANELA |

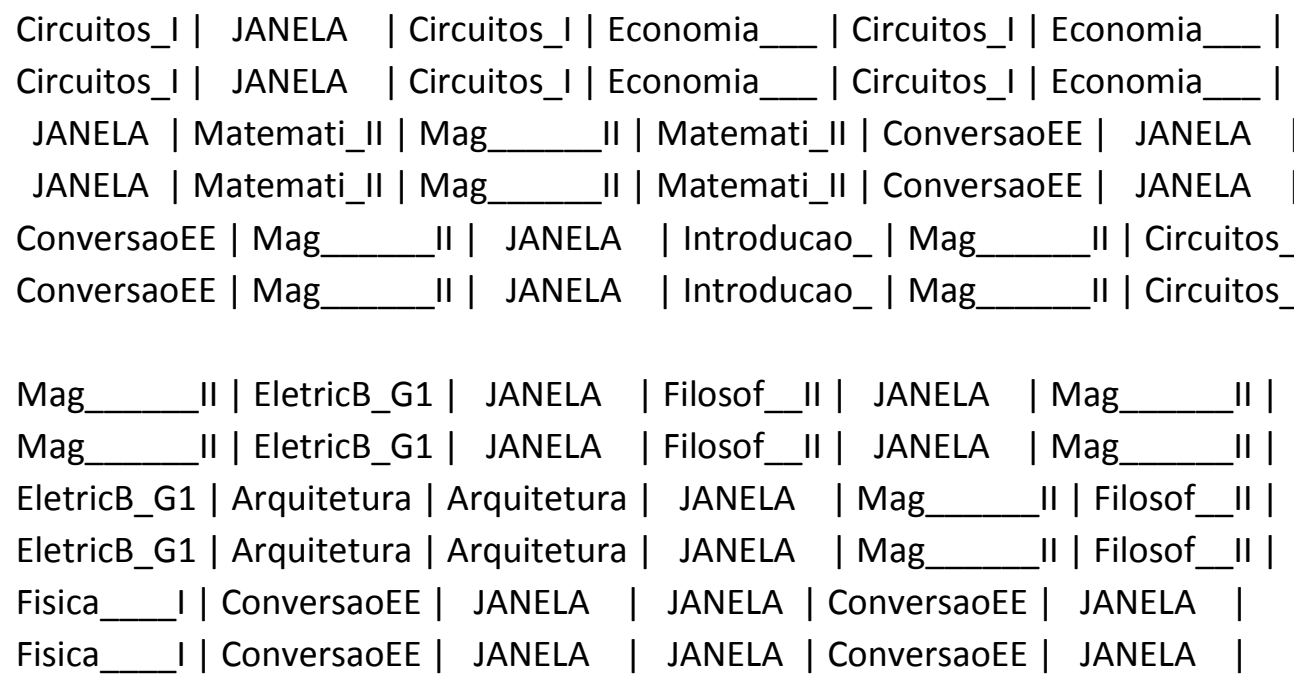

Eletr_I_G1 | Siste_Radio | Eletr_IIG1 | Eletr_II_G1 | JANELA | Siste_Radio | Eletr_IIG1 | Siste_Radio | Eletr_II_G1 | Eletr_IIG1 | JANELA | Siste_Radio | JANELA | Eletr_IIG1 | JANELA | Gestao__ | Eletr_II_G1 | Eletr_IIG1 | JANELA | Eletr_II_G1 | JANELA | Gestao__ | Eletr_IIG1 | Eletr_II_G1 | JANELA | Arquitetura | Arquitetura | JANELA | Arquitetura | Gestao JANELA | Arquitetura | Arquitetura | JANELA | Arquitetura | Gestao 
GerenciaRed | GerenciaRed | Mag II | JANELA | JANELA | Filosof_II |

GerenciaRed | GerenciaRed | Mag II | JANELA | JANELA | Filosof_II |

Gestao | Siste_Radio | JANELA | JANELA | Eletromag_I| JANELA |

Gestao | Siste_Radio | JANELA | JANELA | Eletromag_I| JANELA |

Siste_Radio | JANELA | Mag II | Gestao | JANELA | Introducao_ |

Siste_Radio | JANELA | Mag II | Gestao | JANELA | Introducao_ | 